\author{
UNIVERSIDADE DE SÃO PAULO - USP \\ Escola de Engenharia de São Carlos \\ Programa de Pós-Graduação em Engenharia Elétrica
}

Fernando Henrique Morais da Rocha

\title{
Aprendizado Bayesiano Aplicado ao Controle de Veículos Autônomos de Grande Porte
}

São Carlos 

UNIVERSIDADE DE SÃO PAULO - USP

Escola de Engenharia de São Carlos

Programa de Pós-Graduação em Engenharia Elétrica

Fernando Henrique Morais da Rocha

\title{
Aprendizado Bayesiano Aplicado ao Controle de Veículos Autônomos de Grande Porte
}

\author{
Documento apresentado ao Departamento de \\ Engenharia Elétrica para obtenção do título 1 \\ de Doutor em Ciências, Programa de Enge- \\ nharia Elétrica, Área de Concentração em \\ Sistemas Dinâmicos
}

Orientador: Valdir Grassi Junior

São Carlos

2018

$\overline{1}$ Trata-se da versão corrigida da tese. A versão original se encontra disponível na EESC/USP que aloja o Programa de Pós-Graduação em Engenharia Elétrica. 
AUTORIZO A REPRODUÇÃO TOTAL OU PARCIAL DESTE TRABALHO, POR QUALQUER MEIO CONVENCIONAL OU ELETRÔNICO, PARA FINS DE ESTUDO E PESQUISA, DESDE QUE CITADA A FONTE.

Ficha catalográfica elaborada pela Biblioteca Prof. Dr. Sérgio Rodrigues Fontes da EESC/USP com os dados inseridos pelo(a) autor(a).

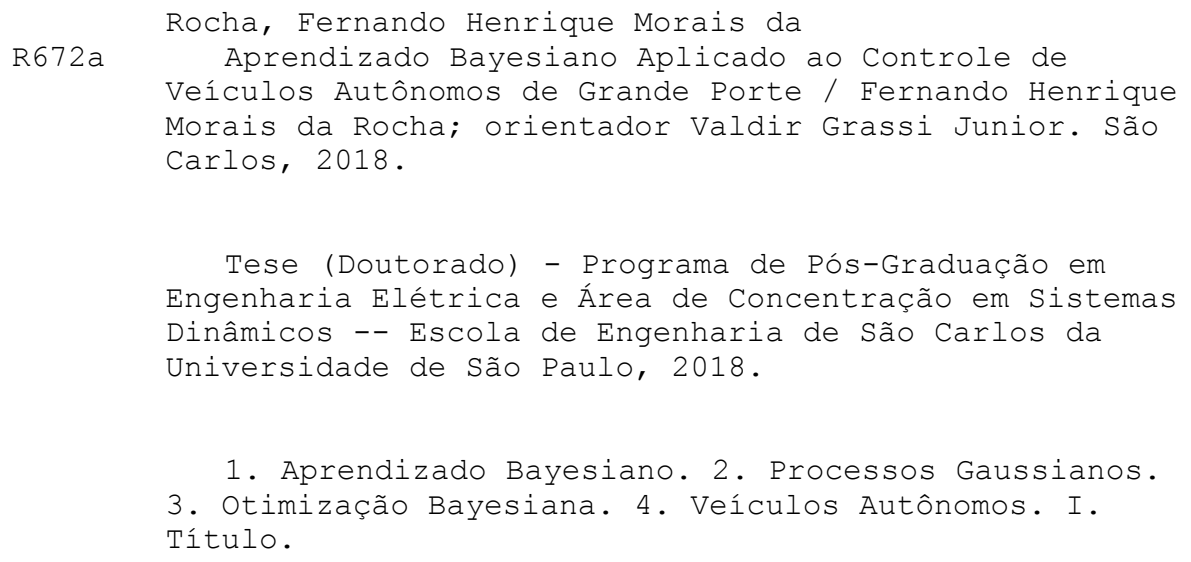

Eduardo Graziosi Silva - CRB - 8/8907 
FOLHA DE JULGAMENTO

Candidato: Engenheiro FERNANDO HENRIQUE MORAIS DA ROCHA.

Título da tese: "Aprendizado bayesiano aplicado ao controle de veículos autônomos de grande porte".

Data da defesa: 21/02/2018.

Comissão Julgadora:

Resultado:

Prof. Dr. Valdir Grassi Junior

(Orientador)

(Escola de Engenharia de São Carlos/EESC)

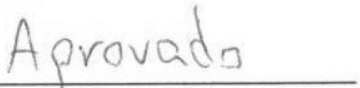

Prof. Associado Adriano Almeida Gonçalves Siqueira APROVADO

(Escola de Engenharia de São Carlos/EESC)

Prof. Associado Denis Fernando Wolf

A PREVADO

(Instituto de Ciências Matemáticas e de Computação/ICMC-USP)

Prof. Titular Glauco Augusto de Paula Caurin

APROUADO

(Escola de Engenharia de São Carlos/EESC)

Prof. Dr. Alberto Ferreira de Souza

Aprovado

(Universidade Federal do Espírito Santo/UFES)

Coordenador do Programa de Pós-Graduação em Engenharia Elétrica:

Prof. Associado Luis Fernando Costa Alberto

Presidente da Comissão de Pós-Graduação:

Prof. Associado Luis Fernando Costa Alberto 



\section{Agradecimentos}

À Universidade de São Paulo (USP), à Escola de Engenharia de São Carlos, ao Departamento de Engenharia Elétrica, ao Instituto Federal de Educação, Ciência e Tecnologia de São Paulo e ao CNPq, pelo apoio e fomento dados durante o período de formação acadêmica e desenvolvimento da pesquisa que gerou esta tese.

A todos meus familiares que sempre me apoiaram ao longo da realização deste trabalho, principalmente a meus pais e meus irmãos, por todo o incentivo, carinho e compreensão nos momentos de ausência. Agradeço por vocês terem formado a pessoa que sou hoje.

Ao meu orientador, Prof Dr. Valdir Grassi Junior pela oportunidade, orientação, paciência, sabedoria e confiança ao longo de meu doutorado. Ao Prof. Dr. Fabio Ramos por ter me recebido na School of IT da Universidade de Sydney, e por toda a orientação e suporte.

Aos amigos do LASI, da USP - São Carlos e aos amigos da School of IT da Universidade de Sydney, por todas as discussões teóricas, auxílio nos experimentos, parceria nos trabalhos, companheirismo e amizade.

A todos, meu sincero agradecimento. 



\section{Resumo}

ROCHA, Fernando Henrique Morais da. Aprendizado Bayesiano Aplicado ao Controle de Veículos Autônomos de Grande Porte. 2018. 54 f. Tese (Doutorado) - Curso de Engenharia Elétrica, Departamento de Engenharia Elétrica, Escola de Engenharia de São Carlos, Universidade de São Paulo, São Carlos, 2018.

O tópico de identificação de sistemas aparece em vários ramos da ciência, com especial importância ao campo de Controle Automático. Entretanto, os problemas encontrados na construção de uma representação precisa de um sistema, como a falta de informações prévias, e as diversas decisões de projeto que devem ser tomadas para a resolução de problemas de identificação de sistemas por meios mais tradicionais, podem ser solucionados através da análise empírica do sistema. Nesse sentido, os processos Gaussianos apresentamse como uma alternativa viável para a modelagem não-paramétrica de sistemas, trazendo a vantagem da estimação da incerteza do modelo. Para verificar o potencial dos processos Gaussianos em problemas de identificação de sistemas, foi realizada a identificação do modelo longitudinal de um veículo de grande porte, tendo alcançado um desempenho satisfatório, mesmo quando se utilizou poucos dados de treinamento. A partir do modelo aprendido, foi projetado um controlador preditivo baseado em modelo para controlar a velocidade do veículo. O controlador levou em consideração a variância da predição do modelo GP (Gaussian Process - Processos Gaussianos) em consideração durante o processo de otimização do sinal de controle. O controlador proposto alcançou um baixo erro no seguimento da referência, mesmo em situações extremas, como estradas íngremes. Entretanto, em alguns tipos de problemas, o resultado só pode ser mensurado a partir da combinação de uma sequência de ações, ou sinais de controle, aplicados ao longo da execução do processo, como é o caso do problema de direção ecológica (eco-driving). Nesses casos, estratégias que otimizem sinais de controle instantâneos podem não ser viáveis, sendo necessária a utilização de estratégias em que toda a política de controle seja otimizada de uma vez. Além disso, a avaliação do custo, ou execução de todo um episódio do processo, pode ser dispendiosa, é desejável que uma solução seja encontrada com a menor quantidade de interações possíveis com o sistema real. Uma técnica apropriada para essa situação é a Otimização Bayesiana, um algoritmo de otimização caixa-preta bastante eficiente. Porém, um dos problemas dessa solução é a incapacidade de lidar com um grande número de dimensões. Sendo assim, nesse trabalho, foi proposto o Coordinate Descent Bayesian Optimisation, um algoritmo baseado na Otimização Bayesiana, que busca o ótimo em espaços de alta dmensionalidade de maneira mais eficiente pois otimiza cada dimensão individualmente, em um esquema de descida coordenada.

Palavras-chave: Processos Gaussianos, Otimização Bayesiana, Veículos Autônomos. 



\section{Abstract}

ROCHA, Fernando Henrique Morais da. Bayesian Learning Applied to the Control of Heavy-duty Autonomous Vehicles. 2018. 54 f. Tese (Doutorado) - Curso de Engenharia Elétrica, Departamento de Engenharia Elétrica, Escola de Engenharia de São Carlos, Universidade de São Paulo, São Carlos, 2018.

The system identification topic appears in various branches of science, with particular emphasis on Automatic Control field. However, problems encountered in building an accurate representation of a system, such as lack of prior information, and the various design decisions which have to be taken to deal with system identification problems by more traditional means, can be solved through the empirical analysis of the system. In this sense, the Gaussian processes are presented as a viable alternative for non-parametric modelling systems, bringing the advantage of estimating the uncertainty of the model. To investigate the potential of Gaussian processes of system identification problems, identifying the longitudinal model of a large vehicle was performed, achieving reasonable performance even when used little training data. From the obtained model, a Model Predictive Controller was designed to control the vehicle speed. The controller took into account the variance of the GP model prediction on the control signal optimization and achieved low reference tracking error, even on hard conditions, like steep roads. However, in some kinds of problems, the observable outcome can often be described as the combined effect of an entire sequence of actions, or controls, applied throughout its execution. In these cases, strategies to optimise control policies for individual stages of the process might not be applicable, and instead the whole policy might have to be optimised at once. Also, the cost to evaluate the policy's performance might also be high, being desirable that a solution can be found with as few interactions with the real system as possible. One appropriate candidate is Bayesian Optimization, a very efficient black-box optimization algorithm. But one of the main problems of this solution is the inability of dealing with a large number of dimensions. For that reason, in this work it was proposed Coordinate Descent Bayesian Optimisation, an algorithm to search more efficiently over high-dimensional policy-parameter spaces with BO, by searching over each dimension individually, in a sequential coordinate descent-like scheme.

Keywords: System identification, active modelling, Gaussian process. 



\section{Lista de ilustrações}

Figura 1 - Etapas e informações necessárias para a modelagem de sistemas. . . . . 26

Figura 2 - Modelo NARX genérico. . . . . . . . . . . . . . . 31

Figura 3 - Validação Cruzada utilizando n-partições. . . . . . . . . . . . . . 38

Figura 4 - Validação Cruzada por unidade. . . . . . . . . . . . . . . 38

Figura 5 - Veículo do projeto Carina $3 \ldots \ldots \ldots$. . . . . . . 62

Figura 6 - Informações do conjunto de dados DS1. . . . . . . . . . . . . . 66

Figura 7 - Saída estimada do Modelo 4, treinado conjunto de dados DS1. . . . . . 67

Figura 8 - Dados do conjunto de treinamento DS2. . . . . . . . . . 68

Figura 9 - Saída estimada do Modelo 4, treinado com o conjunto de dados DS2. . 69

Figura 10 - Dados do conjunto de treinamento DS3 . . . . . . . . . . . . . . 69

Figura 11 - Saída estimada do Modelo 4, treinado com o conjunto de dados DS3. . 70

Figura 12 - Saída do conjunto de dados DS1 em modelo treinado com o conjunto de dados DS3. . . . . . . . . . . . . . . . . . 71

Figura 13 - Saída do conjunto de dados DS1 em modelo treinado com o conjunto de dados DS2. . . . . . . . . . . . . . . . . . . . 71

Figura 14 - Model-based Predictive Controller. . . . . . . . . . . . . 73

Figura 15 - Saída do sistema e sinal de controle para uma estrada plana. . . . . . . 76

Figura 16 - Saída do sistema e sinal de controle para um trecho de subida. . . . . . 76

Figura 17 - Saída do sistema e sinal de controle para um trecho de descida. . . . . 77

Figura 18 - Exemplos de acquisition functions e suas configurações. . . . . . . . . . 84

Figura 19 - Exemplos de Interpolação de uma curva utilizando splines cúbicas. . 89

Figura 20 - Simulador de corridas Speed Dreams. . . . . . . . . . . . . . . . 91

Figura 21 - Características do circuito utilizado nos testes. . . . . . . . . . . . . . 92

Figura 22 - Dados iniciais e política inicial parametrizada por splines . . . . . . . 93

Figura 23 - Desempenho das técnicas testadas utilizando 50 dimensões . . . . . . . 93

Figura 24 - Desempenho das técnicas testadas utilizando 200 dimensões . . . . . . 94

Figura 25 - Consumo de combustível utilizando CDBO com 200 dimensões . . . . . 95 



\section{Lista de tabelas}

Tabela 1 - Principais kernels aplicados a processos Gaussianos. . . . . . . . . . 55

Tabela 2 - Erro quadrático médio dos modelos propostos utilizando o conjunto de treinamento DS1. . . . . . . . . . . . . . . 6 67

Tabela 3 - Erro quadrático médio dos modelos propostos utilizando o conjunto de treinamento DS2. . . . . . . . . . . . . . . . 68

Tabela 4 - Erro quadrático médio dos modelos propostos utilizando o conjunto de treinamento DS3. . . . . . . . . . . . . . . . 70

Tabela 5 - Performance dos modelos treinados. . . . . . . . . . . . 75

Tabela 6 - Desempenho das políticas otimizadas. . . . . . . . . . . . 94 



\section{Sumário}

INTRODUÇÃO $\ldots \ldots \ldots \ldots \ldots \ldots \ldots$

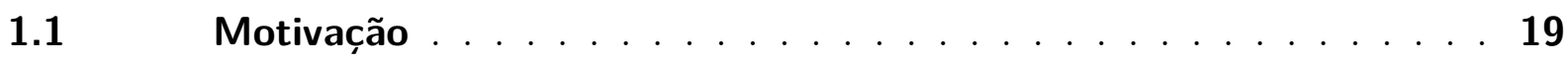

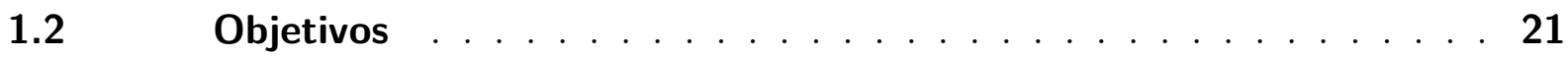

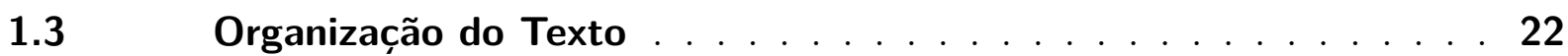

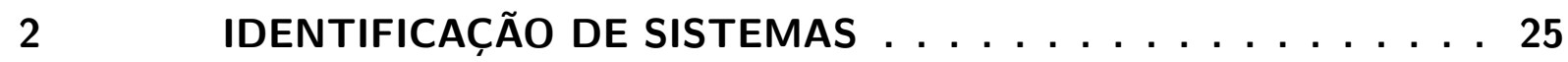

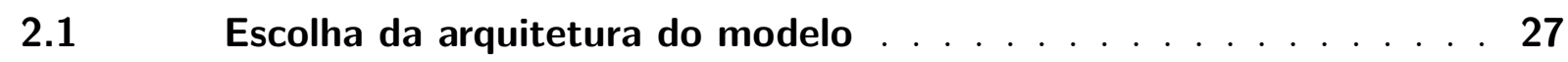

$2.2 \quad$ Planejamento e Execução do Experimento . . . . . . . . . . . 33

2.3 Otimização dos Parâmetros do Modelo . . . . . . . . . . . 35

$2.4 \quad$ Validação do Modelo . . . . . . . . . . . . . . . . . 37

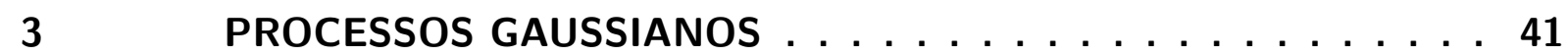

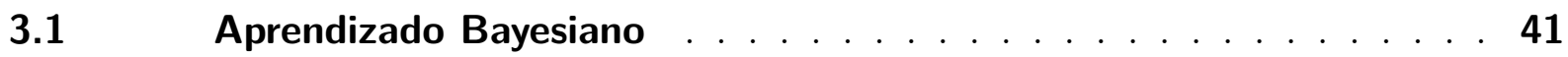

3.2 Aprendizado utilizando Processos Gaussianos . . . . . . . . . . . 44

3.3 Aplicação de Processos Gaussianos em Regressões . . . . . . . . . 50

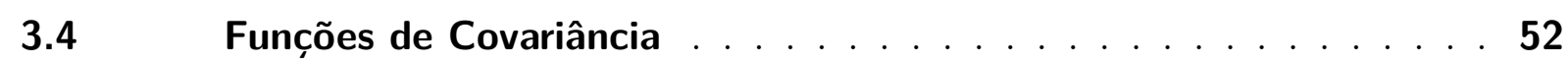

$3.5 \quad$ Otimização dos Hiperparâmetros . . . . . . . . . . . . . 57

4 MODELAGEM E CONTROLE DE VELOCIDADE DE UM VEÍCULO DE GRANDE PORTE UTILIZANDO GPS . . . . . . . . 61

4.1 Modelo Longitudinal de um veículo de grande porte utilizando GPs 61

4.1.1 Implementação do modelo com Processos Gaussianos . . . . . . . . . . 64

4.1.2 Resultados do processo de modelagem . . . . . . . . . . . . . . 65

4.2 Controle Preditivo de Velocidade de um veículo de grande porte utilizando modelos GP . . . . . . . . . . . . . . . . . 72

4.2.1 Controlador Preditivo Baseado em Modelo . . . . . . . . . . . . . 72

4.2.2 Model Predictive Control baseado em modelos GP aplicado a um Veículo de Grande Porte . . . . . . . . . . . . . . . . . . . . . . . . . . . . 74

4.2.3 Resultados do controle de velocidade . . . . . . . . . . . . . . . 75

5 OTIMIZAÇAO BAYESIANA DE POLÍTICAS DE CONTROLE DE

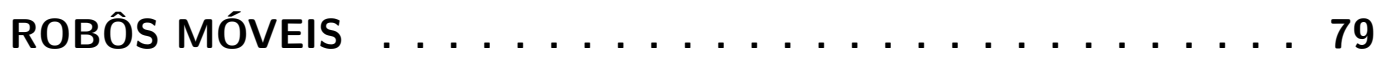

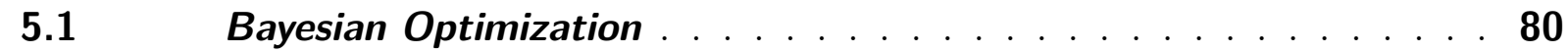

$5.1 .1 \quad$ Acquisition Functions . . . . . . . . . . . . . . . . . 81

5.1.2 Bayesian Optimization em Aplicações Robóticas . . . . . . . . . . . 83

5.1.3 Bayesian Optimization para problemas de alta dimensionalidade . . . . . 84 
5.3 CDBOaplicado na redução do consumo de combustível de um veículo autônomo de grande porte . . . . . . . . . . . . . . . . 87

5.3.1 Experimentos utilizando um simulador de corrida . . . . . . . . . . . . . . 91

Referências . . . . . . . . . . . . . . . . . 999 


\section{Introdução}

Antes de se aventurar a lidar com um objeto, é necessário conhecê-lo. Na engenharia, e também em outras áreas do conhecimento, este objeto é chamado formalmente de sistema, e pode ser conhecido através de modelagem e identificação, e entendido a partir de análises. O campo de estudo em Identificação de Sistemas tem como objetivo o desenvolvimento de modelos matemáticos de sistemas ou processos reais, utilizando conhecimentos prévios sobre o sistema e dados empíricos. Portanto, técnicas de modelagem e identificação ajudam a aprimorar o conhecimento sobre um sistema.

Entretanto, os problemas encontrados na construção de uma representação precisa de um sistema podem ser utilizados em conjunto com outras formas de análises empíricas, em que informações são obtidas a partir dos dados disponíveis. Desta forma, o tópico de modelagem matemática aparece em praticamente todas as disciplinas de pesquisas técnicas, sendo, até mesmo, pré-requisito para algumas práticas em engenharia e tecnologia, com especial importância ao campo de Controle Automático.

Modelagem e identificação de sistemas é uma área vasta e com vários métodos bem estabelecidos baseados em vários princípios. Em destaque, ideias dos campos da estatística e computação são aplicadas no viés de engenharia da área de identificação de sistemas. Em muitos casos, metodologias originadas de diferentes áreas de pesquisa possuem similaridades, mesmo tendo sido desenvolvidas separadamente, como a tarefa de aprendizagem associada com a área de inteligência artificial ou sistemas adaptativos, que tem sido tema de pesquisa tanto para a comunidade de Aprendizado de Máquina (machine learning) como para a de Controle Automático.

As comunidades de estatística, econometria e séries temporais contribuíram significativamente com o desenvolvimento das técnicas de modelagem (GEVERS, 2006). Das áreas de matemática e estatística, a análise de probabilidade e erro forneceram ferramentas para identificar a solução mais provável ou ótima, como algoritmos de regressão, e também os meios para avaliar e validar o desempenho dos modelos identificados. A utilização da teoria e métodos probabilísticos é relevante, pois introduz a análise da incerteza no procedimento de modelagem. Como o objetivo da identificação de sistemas é investigar sistemas os quais se tem pouco conhecimento e com incertezas, a aplicação de métodos probabilísticos é totalmente pertinente.

Vários domínios da engenharia, como o aeroespacial, automobilístico, indústria de máquinas ferramenta, tecnologia de veículos espaciais, engenharia civil e estrutural, apresentam sistemas não-lineares. Algumas ocorrências comuns de não linearidades em engenharia são (GONDHALEKAR, 2009): 
- Não-linearidades induzidas por atritos em juntas aparafusadas;

- Não-linearidades de folgas em superfícies de controle de aeroestruturas;

- Não-linearidades da rigidez polinomial observada na conexão entre motor e asa de um avião;

- Não-linearidades demonstradas por materiais modernos, como compostos, plásticos e materiais viscoelásticos.

Como pode ser visto em (WORDEN; TOMLINSON, 2000), não-linearidades surgindo de várias fontes podem facilmente invalidar os resultados de simulações baseadas em linearidade. Foi mostrado por Goege (2007), tanto experimentalmente como por simulações, que o comportamento dinâmico de sistemas fortemente não-lineares podem ser consideravelmente diferentes de seus relativos sistemas lineares. Portanto, para o correto entendimento deste tipo de sistema, é muito importante prever seu comportamento de maneira precisa.

Enquanto existem vários métodos para a identificação de sistemas dinâmicos lineares a partir de medições, como mostrado em Ljung (1999), Soderstrom e Stoica (1989), a modelagem de sistemas não-lineares requer abordagens mais sofisticadas. As escolhas mais comuns incluem redes neurais artificiais (NARENDRA; PARTHASARATHY, 1990), modelos fuzzy (TAKAGI; SUGENO, 1985) e outros (SJöBERG et al., 1995; KOCIJAN, 2008).

A modelagem utilizando Processos Gaussianos (Gaussian Process, GP), que é abordada neste trabalho, se origina de pesquisas em estatística de dados espaciais, e recentemente tem recebido interesse considerável da comunidade de aprendizado de máquina como uma ferramenta para regressões não-lineares, sendo uma alternativa viável a sistemas de aprendizados bem estabelecidos, como redes neurais (THOMPSON, 2009).

A saída do modelo construído com GPs é uma distribuição normal, expressa em termos de média e variância. A média representa o valor de saída mais provável e a variância pode ser interpretada como a medida de confiança desse valor de saída. Esta medida, que depende da quantidade e qualidade de dados disponíveis para identificação, é a informação que distingue os modelos GP de outros métodos. A determinação da estrutura destes é também simplificada, sendo necessária somente a escolha da função de covariância e dos regressores. Outro atributo interessante de modelos GP é a possibilidade de incluir diversas formas de conhecimentos prévios no modelo (AžMAN, 2005). E também, a quantidade de parâmetros do modelo que precisam ser otimizados é menor do que em outras técnicas de identificação de sistemas.

O modelo dinâmico de um sistema pode ser empregado tanto no projeto de controladores, que visam manter este sistema em um estado desejado (set-point), como 
em técnicas de controle preditivo (CAMACHO; ALBA, 2007), quanto na otimização de políticas de controle que façam com que o sistema atinja um objetivo de longo prazo, como em técnicas de Reinforcement Learning (SUTTON; BARTO, 1998). Em alguns casos, a obtenção de medidas imediatas do estado do sistema não é possível, impossibilitando a construção do modelo e a predição do desempenho do sistema. Porém, alguns problemas apresentam uma medida do desempenho do sistema após a execução de uma sequência de ações, sendo esta sequência chamada de política de controle. Nesta configuração, é possível aprender a política de controle diretamente a partir de experiências, sem a etapa intermediária do aprendizado do modelo do sistema (LIU, 2014). Geralmente, a relação entre a medida de desempenho e os parâmetros da política de controle é desconhecida, tornando a otimização de forma analítica da política de controle inviável. Neste caso, o aprendizado Bayesiano também pode ser aplicado, através da técnica Bayesian Optimization. Ao invés de mapear o resultado de ações de controle para um estado futuro do sistema, um modelo Bayesiano é usado para identificar e predizer o desempenho do sistema quando uma política de controle é aplicada.

\subsection{Motivação}

O principal incentivo para a contínua pesquisa em métodos alternativos de identificação de sistemas é a demanda crescente por novas aplicações e aprimoramentos em aplicações existentes. Modelos matemáticos de sistemas reais são frequentemente necessários no processo de desenvolvimento de um sistema para simulações de desempenho, avaliações de custos e também como base para o projeto de controladores automáticos.

Atualmente, há uma busca incessante pela diminuição do ciclo de projeto de produtos. Para se manterem competitivas no mercado, é essencial para os fabricantes reduzirem custos e o tempo associado à validação de protótipos. Essa necessidade, associada com a disponibilidade de ferramentas numéricas, aumentam o uso de simulações computacionais para prever comportamentos estruturais. Para sistemas lineares, o comportamento dinâmico pode ser simulado de maneira precisa utilizando ferramentas numéricas. Porém, em aplicações reais, não-linearidades são comuns, enquanto que comportamento linear é a exceção. Como as empresas buscam desenvolver produtos mais leves, rápidos e eficientes, os projetos tendem a seguir o regime não-linear. Em contrapartida, existem poucos métodos estabelecidos e validados para a previsão da resposta de sistemas não lineares (GONDHALEKAR, 2009).

Identificação para o controle tem sido a maior aplicação para novos paradigmas de identificação de sistemas como um desafio de projeto. As principais razões para o grande investimento em pesquisas nessa área são (GEVERS, 2006):

- Na área de identificação de sistemas, controle é geralmente a maior motivação para 
a construção de modelos;

- Foi observado que controles de alto desempenho podem ser alcançados com modelos simples, desde que algumas características dinâmicas básicas do sistema sejam capturadas de maneira precisa;

- Embora a teoria de controle robusto baseado em modelos e conjuntos de incertezas tenha sido desenvolvida na década de 1980, os modelos e conjuntos de incerteza não eram baseados nos dados, por não haver uma teoria adequada;

- Pesquisas em identificação para controle forneceram modelos iterativos e ferramentas de ajuste de controladores intuitivas e práticas, de fácil implementação por engenheiros de processos.

Em ambos os casos, a qualidade do modelo identificado representa um grande papel na determinação da qualidade da solução final. Para se projetar um sistema de controle que maximize o desempenho potencial de um sistema, o modelo matemático deve representar o sistema da maneira mais fiel possível. O aumento na precisão da predição, fornecida por um modelo matemático preciso, possibilita o desenvolvimento de sistemas de controle para funcionar com maior confiança em relação a como o sistema se comportará quando submetido aos sinais de entrada do controlador. De maneira geral, sempre haverá demanda por métodos que consigam aumentar a precisão de uma descrição matemática (THOMPSON, 2009).

A modelagem utilizando GPs gera grande interesse na área de identificação de sistemas devido a diversos fatores. A aplicação de métodos Bayesianos pelos modelos baseados em GP permitem superar dificuldades na otimização de sistemas complexos de aprendizado, sendo esta uma característica útil na área de Aprendizado de Máquina. Com o surgimento de sistemas cada vez mais complexos e a necessidade de modelagem matemática destes, essa abordagem probabilística também vem sendo empregada para a identificação destes modelos complexos, atraindo também o interesse da comunidade de Identificação de Sistemas.

Outra característica dos modelos baseados em GP é que, através da análise probabilística, uma distribuição de probabilidades, ao invés de apenas um valor, é a saída do modelo. Dessa forma, os modelos baseados em GP fornecem previsões de comportamento de sistemas não-lineares, bem como uma medida da incerteza sobre cada previsão. Essa incerteza, ou variância, tem grande potencial para ser aproveitada no projeto de controles adaptativos ou preditivos, nos quais o comportamento do sistema de controle pode ser modificado de acordo com a incerteza associada com a previsão. Outra possível aplicação para a variância é no auxílio à identificação de regiões no espaço operacional que não estão muito bem descritas pelos dados empíricos, sendo esta uma informação extremamente útil para os chamados métodos de identificação caixa-preta. 
Outra importante característica da modelagem por GPs é que foi provado que esta supera outros sistemas de aprendizado quando a quantidade de dados empíricos é limitada. Em sistemas reais, a quantidade de medidas que podem ser usadas para o treinamento de um modelo pode ser limitada por uma série de fatores. Em muitos sistemas reais, pode ocorrer de as informações serem escassas em algumas regiões do espaço operacional (geralmente regiões fora do ponto de equilíbrio). Sem dados suficientes, a identificação de um modelo preciso nessas regiões torna-se complicada, e essa deficiência é passada também para qualquer sistema de controle correspondente. Entretanto, como os modelos GP mostraram desempenho satisfatório em problemas nos quais os dados eram limitados, estes tem sido propostos como ferramentas úteis na identificação de sistemas fora da região de equilíbrio, na qual métodos mais convencionais falham (THOMPSON, 2009).

Porém, em uma série de problemas, é impossível mensurar o efeito de uma ação de controle isolada, impossibilitando a aplicação de técnicas de controle tradicionais baseadas em informações do estado instantâneo do sistema. Nesses cenários, técnicas de otimização de políticas de controle devem ser empregadas, seja utilizando um modelo do sistema para simular o funcionamento desse por um longo intervalo de tempo, ou então otimizando diretamente uma politica de controle baseado somente nas experiências anteriores. Entretanto, muitas vezes, o custo de se obter experiências com um sistema é elevado, seja financeiro, de tempo ou computacional. Dessa forma, são necessárias técnicas eficientes de otimização baseadas em amostras ruidosas do desempenho de uma política de controle. Dentre as técnicas de otimização global de funções desconhecidas presentes na literatura, a Otimização Bayesiana (Bayesian Optimization - BO) tem se destacado, inclusive na área de robótica, sendo um bom candidato à solução do problema de otimização de políticas de controle. Um dos problemas enfrentados ao se utilizar BO é o da dimensionalidade, sendo nesserárias adaptações para sua aplicação em problemas de alta dimensionalidade. Este ainda não possui solução definitiva, sendo tema de diversas pesquisas recentes.

\subsection{Objetivos}

Neste trabalho, ambas as estratégias foram analisadas na solução de problemas de controle do sistema de aceleração e frenagem de um veículo autônomo de grande porte. No Capítulo 4 são apresentados os resultados referentes à aplicação de modelos GP no projeto de um controlador preditivo baseado em modelo (Model Predictive Control) ao sistema longitudinal do veículo, e o Capítulo 5 apresenta a aplicação da Otimização Bayesiana para otimizar uma política de controle com o objetivo de reduzir o consumo de combustível do veículo. Como a política empregada possui alta dimensionalidade, foi proposta a técnica Coordinate Descent Bayesian Optimisation, um algoritmo de otimização caixa-preta baseado em Otimização Bayesiana capaz de lidar com problemas de alta 
dimensionalidade de forma eficiente, sendo esta a principal contribuição deste trabalho.

Para atingir tal objetivo, foram executadas as seguintes etapas:

- Estudar as principais características e procedimentos dos métodos de identificação de sistemas;

- Analisar as bases teóricas dos Processos Gaussianos, bem como os detalhes da implementação prática deste, seguindo as teorias de Aprendizado de Máquina.

- Aplicação dos processos gaussianos para a identificação de sistemas em dados reais, para verificar a viabilidade prática da solução.

- Projeto de um controlador preditivo para a velocidade de veículos de grande porte utilizando modelos GP.

- Analisar a aplicação de Bayesian Optimization em problemas de policy search.

- Propor uma técnica de otimização baseada no algoritmo BO, que seja capaz de lidar com problemas de alta dimensionalidade.

- Verificar o desempenho da técnica proposta no problema de otimização de políticas de controle para economia de combustível de veículos de grande porte.

\subsection{Organização do Texto}

Para melhor organização e construção sequencial do tema abordado, este trabalho é organizado da seguinte maneira:

Capítulo 2: Identificação de Sistemas - Neste capítulo é abordada uma visão geral do processo de identificação de sistemas. Detalhes importantes, como a escolha da arquitetura do modelo empregado, o papel dos conhecimentos prévios, o projeto dos experimentos para obtenção dos dados empíricos, o pré-processamento dos dados de treinamento, otimização e validação do modelo são discutidos.

Capítulo 3: Processos Gaussianos - No Capítulo 3, a metodologia dos processos gaussianos é discutida, com a introdução de funções gaussianas aleatórias e distribuição de probabilidades conjuntas. É analisado também o modelo prévio, incluindo as classes de funções de covariância usadas para parametrizá-lo. E ao final, a tarefa de regressão utilizando processos gaussianos é discutida.

Capítulo 4: Modelagem e controle de velocidade de um veículo de grande porte utilizando GPs - Neste capítulo, o desafio específico de implementar um modelo GP para identificação do modelo dinâmico de um sistema real é tratado, utilizando dados de um veículo de grande porte para identificação de seu modelo longitudinal (motorização 
e frenagem). Através deste exemplo, todas as etapas da identificação de sistemas são analisadas de maneira prática, e os problemas que surgem na implementação prática, como dificuldades do experimento, problemas com o GP devido ao tamanho dos conjuntos de dados, são discutidos. É mostrado também nesse capítulo, o processo de desenvolvimento de um controlador preditivo utilizando o modelo GP aprendido. Ao final do capítulo, são apresentados resultados experimentais do controlador proposto para controle de velocidade de um veículo de grande porte.

Capítulo 5: Bayesian Optimization aplicada à otimização de Políticas de Controle Neste capítulo, a teoria de bayesian optimization é apresentada, bem como as soluções presentes na literatura para seus problemas mais comuns. São discutidas também as técnicas utilizadas para problemas de policy search, e também de direção ecológica (ecodriving). Ao final do capítulo, é apresentada a Coordinate Descent Bayesian Optimisation, técnica proposta para solucionar o problema da dimensionalidade do BO, bem como resultados experimentais da aplicação desta técnica à busca de políticas de controle de um veículo de grande porte com o objetivo de reduzir o consumo de combustível. 



\section{Identificação de Sistemas}

Identificação de sistemas pode ser visto como o processo de obtenção de um modelo matemático através de dados empíricos, em conjunto com conhecimentos prévios de uma característica particular de um sistema. Modelagem é uma maneira importante de explorar, estudar e compreender o mundo. Um modelo é uma descrição formal de um sistema, e descreve alguns aspectos essenciais deste.

Em modelagem de sistemas, três princípios devem ser considerados: Separação, Seleção e Parcimônia (HORVATH, 2003).

O mundo é uma coleção de objetos, que estão interagindo entre si: a operação de um objeto pode interferir no comportamento de outros. Em modelagem, é necessário separar uma parte do mundo de todo o resto. Esta parte será o sistema a ser modelado. O princípio da separação determina que as fronteiras que separam um sistema de seu ambiente devem ser definidas.

O segundo princípio é a seleção, que define que somente alguns aspectos essenciais de um sistema devem ser considerados. Há diversas interações entre as partes de um mesmo sistema ou entre o sistema e o ambiente, porém, não é possível considerar todas elas em uma tarefa de modelagem. Algumas interações devem ser levadas em conta, enquanto outras devem ser ignoradas, sendo a seleção dependente do objetivo final da modelagem e dos requerimentos de desempenho do modelo. Desta forma, o modelo é sempre imperfeito, uma simplificação do sistema que somente se aproxima de seu comportamento. Devido a esta simplificação, é sempre mais fácil trabalhar com o modelo do que com o sistema real. Apesar da maior facilidade, a validade dos dados obtidos usando o modelo de um sistema é sempre limitada, em relação ao sistema real.

O terceiro princípio é a parcimônia. Na construção de modelos, é possível obter muitos modelos diferentes a partir do mesmo conjunto de observações, e todos serem consistentes com os dados observados. Então, algum princípio deve ser aplicado para selecionar um modelo dentre as diversas opções. Parcimônia na modelagem define que é sempre desejável se utilizar o modelo mais simples possível.

O procedimento de identificação de sistemas segue uma sequência de tarefas, conforme Figura 1, que podem ser repetidas, até que os requisitos de desempenho sejam atingidos. O processo se inicia com a definição dos objetivos da modelagem, como a exatidão, robustez e nível de complexidade desejado, e também com a avaliação dos conhecimentos prévios disponíveis sobre o sistema. Estes conhecimentos iniciais podem surgir na forma de entendimento detalhado das características do sistema, como modelos físicos ou analíticos derivados de princípios da física clássica, ou também somente conhecimentos sobre a 
disponibilidade e forma dos dados experimentais.

Figura 1 - Etapas e informações necessárias para a modelagem de sistemas.

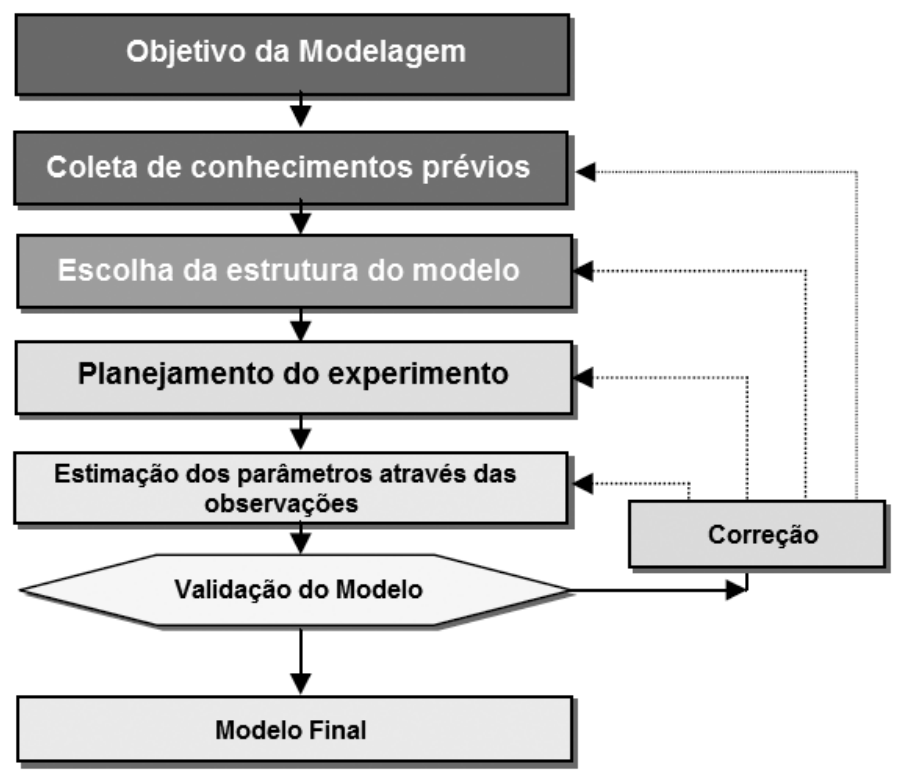

Fonte: (HORVATH, 2003)

A escolha do tipo de modelo, ou arquitetura, em conjunto com o nível dos dados empíricos disponíveis terão influência na maneira com que o modelo será ajustado aos dados por um processo de otimização. Neste processo, os parâmetros e a estrutura são identificados através da aplicação de técnicas de Aprendizado de Máquina, como o método dos mínimos-quadrados. Estes dados empíricos obtidos a partir de experimentos com o sistema, que muitas vezes necessitam de algum tipo de pré-processamento, são chamados dados de treinamento, pois o modelo será treinado a partir deles.

Depois de identificado, todo modelo deve ser validado antes de ser utilizado, através de comparação com a resposta do sistema. Um novo conjunto de dados, conhecido como dados de teste, é utilizado nesse processo. Medidas estatísticas do erro do modelo e das semelhanças podem ser calculadas a partir da comparação com a saída do modelo real. O resultado do processo de validação determina se o modelo identificado atinge aos critérios de desempenho desejados. Caso não os atinja, algumas escolhas que foram adotadas no início do processo devem ser revistas, e todo o processo executado novamente, até que se atinja o desempenho desejado.

Nas próximas seções, as etapas do processo de identificação de sistemas serão discutidas com mais detalhes. 


\subsection{Escolha da arquitetura do modelo}

A seleção da arquitetura do modelo define a formulação matemática que relaciona as entradas com as saídas de um sistema, ou seja, define a estrutura do modelo e também um conjunto de parâmetros, que devem ser determinados pelo processo de identificação.

Baseado na quantidade de informações prévias disponíveis sobre um sistema, é possível construir três tipos de modelos:

Modelos Caixa-Branca (white-box models): Quando a estrutura do modelo e também seus parâmetros são conhecidos totalmente, ou seja, todo o conhecimento físico sobre o sistema está disponível, tem-se um modelo caixa-branca. Estes podem ser construídos somente a partir dos princípios físicos fundamentais, sem a necessidade de medidas do sistema real. São de fácil interpretação, entretanto, em sistemas complexos, são de difícil obtenção.

Modelos Caixa-Preta (black-box models): Quando a construção do modelo é baseada somente nos dados medidos do sistema real, este é chamado modelo entradasaída ou modelo comportamental. Este tipo de modelo também é conhecido com modelo empírico ou caixa-preta, pois o sistema a ser modelado é considerado uma caixa preta, sendo caracterizado somente por seu comportamento, sem informações detalhadas sobre a estrutura do sistema. Neste tipo de modelo, a estrutura do modelo em si não reflete a estrutura do sistema físico, e os elementos da estrutura do modelo não possuem nenhum significado físico. Em vez disso, a estrutura escolhida deve ser flexível o suficiente para atender a uma grande classe de sistemas.

Modelos Caixa-Cinza (grey-box models): Na maioria das aplicações reais, há alguma informação física, mesmo que incompleta, disponível. Desta forma, a estrutura do modelo corresponde à estrutura dos fundamentos físicos, enquanto os parâmetros deverão ser estimados utilizando os dados observados, ou seja, serão ajustados ao modelo empiricamente.

Baseado nas características do sistema, podemos distingui-los principalmente por (HORVATH, 2003):

- Linear ou não-linear;

- Paramétrico ou não-paramétrico;

- Estático ou dinâmico;

- Contínuo ou discreto;

- Determinístico ou estocástico;

- Variante ou invariante no tempo;

- Outros. 
A principal diferenciação feita entre os tipos de modelos são entre modelos lineares e não-lineares. Os sistemas são também caracterizados como lineares e não-lineares, apesar da maioria dos sistemas reais possuírem algum nível de não-linearidade. Parece lógico que um sistema não-linear necessite de um modelo não-linear para representá-lo de maneira plena. Entretanto, é comum se utilizar um sistema linear como primeira escolha de estrutura para a identificação do modelo de um sistema não-linear, e mesmo com essa diferença, atingir um nível de semelhança satisfatório entre o modelo e o sistema.

Uma das principais razões para se adotar uma estratégia linear é que sua metodologia para definir uma estrutura linear e utilizar uma técnica simples de otimização para identificar os parâmetros através dos dados já foi bem compreendida e amplamente adotada (THOMPSON, 2009). A abordagem não-linear geralmente requer um esforço muito maior, devido ao aumento da complexidade e da dificuldade de otimização. Por isso, técnicas de modelagem linear são utilizadas com sucesso em sistemas não-lineares, muitas vezes sendo o início da construção de um modelo não-linear. Outro ponto interessante é que sistemas não-lineares operando próximos a um ponto de equilíbrio, podem ser modelados com métodos lineares.

O procedimento de projeto para um sistema de controle de um sistema se torna mais simples se um modelo linear e invariante no tempo representa o sistema de maneira satisfatória. Existem metodologias diretas e bem estabelecidas para este tipo de projeto, sendo encontrada nos livros introdutórios sobre teoria de controle, como em Nise (2012). Isto não acontece com sistemas que apresentem não-linearidades significativas, na qual a descrição do sistema através de um modelo linear traria uma representação inadequada do comportamento do sistema, ou seja, em sistemas que apresentam não-linearidades consideráveis, um modelo linear não é capaz de descrever de maneira precisa o comportamento do sistema, quando este opera longe da região de equilíbrio em que foi linearizado.

Sistemas não-lineares não apresentam uma resposta padrão, podendo apresentar diversos comportamentos distintos, como comportamentos aleatórios ou não determinísticos, oscilações periódicas e aperiódicas, multi-estabilidade, entre outros. Consequentemente, não há uma metodologia genérica para modelagem e controle de sistemas não-lineares, mantendo esta linha de pesquisa bastante ativa.

Outra característica importante distingue os tipos de modelo em paramétricos e não-paramétricos. Um modelo paramétrico possui uma função construída com um número limitado de parâmetros variáveis. Esta função será otimizada, através desses parâmetros, para se encaixar da maneira mais próxima possível aos dados medidos. Este tipo de modelo pode ser aplicado quando se tem conhecimento prévio das características do sistema, possibilitando ao modelo refletir diretamente as relações entre quantidades físicas. Já a modelagem não-paramétrica não impõe uma estrutura definida à função a ser identificada. Esta abordagem geralmente oferece maior flexibilidade à tarefa de identificação, pois não há 
uma estrutura fixa, e uma quantidade infinita de parâmetros podem ser empregados para descrever corretamente o processo. Sendo assim, métodos não-paramétricos são ferramentas ideais para a identificação de sistemas dos quais não há conhecimento prévio, como em problemas de modelagem caixa-preta (THOMPSON, 2009).

Uma abordagem comum para a descrição de diversos modelos dinâmicos lineares pode ser encontrada na maioria dos livros sobre identificação de sistemas, como Ljung (1999), Soderstrom e Stoica (1989), Nelles (2001). Para simplificar a descrição desse modelo, assumimos que o sistema implemente um mapeamento $f: \mathbb{R}^{N} \rightarrow \mathbb{R}$. Este mapeamento é representado por um conjunto de dados de entrada e saída $\{x(i), y(i)\}_{i=1}^{P}$, com $P$ amostras medidas do sistema.

Dessa forma, a relação entre as entradas e a saída medida pode ser definida na Equação (2.1):

$$
y(i)=f(x(i))+n(i)
$$

onde $n(i)$ representa o ruído nas observações.

Este sistema será modelado por uma estrutura geral. O mapeamento $\hat{f}$ se aproxima do mapeamento realizado pelo sistema.

$$
y_{M}(i)=\hat{f}(x(i), \Theta)
$$

O modelo da Equação (2.2) também realiza o mapeamento $R^{N} \rightarrow R, y_{M}$ é a saída do modelo e $\Theta$ é o vetor de parâmetros da estrutura do modelo. Existem diversos modelos que se baseiam nesse modelo básico, como ARX, ARMAX, ARARX, entre outros (LJUNG, 1999), tendo como diferença uma ponderação maior ou menor dos elementos do sistema, como as entradas e o ruído.

\section{Modelo ARX}

O modelo ARX (Auto Regressive with External input - Autorregressivo com entradas exógenas), é considerado um modelo com erro na equação, pois o ruído branco entra diretamente como erro da equação da diferença:

$$
\left[1-a_{1} q^{-1}-\cdots-a_{n_{a}} q^{n_{a}}\right] y(k)=\left[b_{1} q^{-1}+\cdots+b_{n_{b}} q^{n_{b}}\right] u(k)+e(k)
$$

onde $u(k)$ e $y(k)$ são os dados de entrada e saída do sistema, e $(k)$ é o ruído branco adicionado ao modelo, $b_{i}$ e $a_{i}$ são os coeficientes dos regressores de entrada e saída e $q^{-1}$ se refere ao operador de atraso, sendo que $y(k) q^{-1}=y(k-1)$.

Reescrevendo o modelo, temos:

$$
y(k)=\frac{B(q)}{A(q)} u(k)+\frac{1}{A(q)} e(k)
$$


Neste modelo, o erro adicionado à equação representativo do ruído, é o ruído branco filtrado por um modelo autorregressivo (AGUIRRE, 2007). Este tipo de modelo é muito utilizado na área de processamento de sinais.

\section{Modelo ARMAX}

Uma desvantagem do modelo ARX é que não há liberdade adequada na descrição das propriedades do termo ruído. Essa flexibilidade é adicionada no modelo ARMAX (Auto Regressive Moving Average with Exogenous input - Autorregressivo com Média móvel e entrada exógena), visto na Equação (2.5).

$$
\left[1-a_{1} q^{-1}-\cdots-a_{n_{a}} q^{n_{a}}\right] y(k)=\left[b_{1} q^{-1}+\cdots+b_{n_{b}} q^{n_{b}}\right] u(k)+\left[c_{1} q^{-1}+\cdots+c_{n_{c}} q^{n_{c}}\right] e(k)
$$

Escrevendo na forma compacta:

$$
y(k)=\frac{B(q)}{A(q)} u(k)+\frac{C(k)}{A(q)} e(k)
$$

O modelo ARMAX, visto na Equação (2.6), dá maior flexibilidade à modelagem do erro tornando-o uma média móvel do ruído branco. Este modelo se tornou um padrão nas aplicações de controle e econométrica (LJUNG, 1999).

\section{Modelo NARX}

Os modelos apresentados anteriormente foram estendidos para atender também a sistemas não-lineares. Por exemplo, o modelo NARX (Nonlinear ARX - ARX Não-linear) utiliza a mesma estrutura do modelo ARX, porém, substitui as relações lineares por uma função não-linear $f($.$) , como pode ser visto na Figura 2$.

Esta abordagem é conhecida também como "dinâmica externa", pois a estrutura do modelo é separada em um aproximador não-linear estático, e um banco de filtros dinâmicos externo (NELLES, 2001). Dessa forma, qualquer arquitetura de modelos não-lineares pode ser escolhida para o aproximador, como arquiteturas polinomiais não-lineares ou até mesmo redes neurais. Um dos problemas desse tipo de modelo é que uma grande quantidade de entradas são requeridas pelo aproximador, sendo que este deve ser escolhido de forma que seja capaz de realizar mapeamentos de grandes dimensões para sistemas complexos (THOMPSON, 2009).

Quando não há informação prévia suficiente para construir um modelo físico, a modelagem do tipo caixa-preta pode ser empregada, e o modelo identificado a partir dos dados empíricos. Para isso, a arquitetura do modelo escolhida deve facilitar esse processo de aprendizado, de forma que possa ser aplicada a sistemas com diversas formas de não-linearidades. Uma técnica que um grande número de arquiteturas de modelos 
Figura 2 - Modelo NARX genérico.

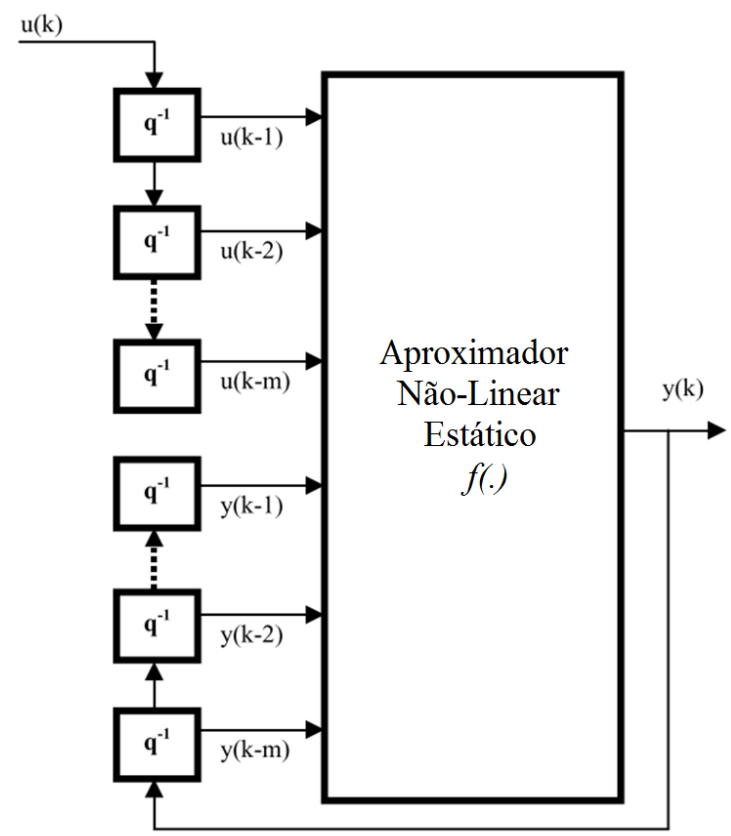

Fonte: (THOMPSON, 2009)

utilizam a formulação da Equação (2.7), na forma de uma rede de funções de base:

$$
y=\sum_{i=1}^{M} \theta_{i}^{l} \phi\left(\theta_{i}^{n l}\right)
$$

Na Equação (2.7), o mapeamento das entradas nas saídas é realizado por uma soma ponderada das funções de base, na qual $\theta^{l}$ são os parâmetros ponderadores lineares e $\theta^{n l}$ são os parâmetros não-lineares da função de base $\phi($.$) . Para sistemas não-lineares,$ as funções de base devem ser não-lineares, porém, essa metodologia pode ser aplicada também a sistemas lineares, utilizando funções de base polinomiais ou outras funções lineares.

Métodos paramétricos clássicos de modelagem de não-linearidades incluem a identificação de representações polinomiais das características do sistema. Estes métodos utilizam modelos de ordens maiores do que para sistemas lineares e geralmente são empregados para interpolação ou ajustes de curvas de dimensões pequenas. Uma discussão sobre as abordagens polinomial de Kolmogorov-Gabor e séries de Volterra para modelagem de sistemas não-lineares com realimentação da saída (semelhante ao NARX), podem ser vistas em (NELLES, 2001). Entretanto, estas abordagens são adequadas somente para problemas de baixa dimensionalidade, pois a quantidade de regressores presentes nesses modelos aumentam rapidamente com o aumento do grau do polinômio. Além disso, abor- 
dagens polinomiais de alta dimensionalidade tendem a um comportamento oscilatório da interpolação (THOMPSON, 2009).

Outros métodos clássicos de modelagem não-linear incluem as abordagens de Hammerstein e Wiener. Estes modelos são amplamente adotados pela indústria e dependem da suposição de que existe uma separação das dinâmicas e da não-linearidade de um sistema. A estrutura do modelo de Hammerstein implementa um modelo não-linear estático em série com um modelo não-linear dinâmico, e no modelo de Wiener a estrutura tem a ordem inversa. Essas implementações dependem de conhecimentos prévios do sistema que facilite essas suposições estruturais, portanto, não podem ser consideradas uma abordagem geral para modelagem caixa-preta. Mais informações sobre esses modelos pode ser vista em (LJUNG, 1999).

Muitas abordagens utilizando funções de base, ou algumas topologias de redes neurais, como a RBF, permitem que uma rede de modelos locais seja construída. Este conceito se mostra interessante, pois a identificação de sistemas complexos pode se tornar tratável se o problema total pode ser dividido em diversos problemas menores. As técnicas que empregam redes de modelos locais são conhecidas como dividir para conquistar, e no campo de identificação de sistemas, podem ser entendidas como a divisão ou particionamento do espaço operacional em regiões menores, e identificar um modelo preciso para cada região. Então, um modelo global pode ser construído a partir da combinação desses modelos locais.

Vários métodos de modelagem múltipla foram propostos para solucionar os problemas de identificação de sistemas não-lineares complexos. Uma proposta interessante foi a aplicação de lógica difusa (Fuzzy) para o particionamento do campo de operação, na qual uma série de regras devem ser definidas (ZADEH, 1965). Dessa forma, qualquer conhecimento do sistema, principalmente qualitativo, pode ser incorporado diretamente no modelo através da definição de funções de pertinência. Um método importante, introduzido por Takagi e Sugeno (1985) permitiu a aplicação das regras fuzzy para problemas de identificação, conhecido com modelo TS. Diferente de modelos fuzzy linguísticos ou singleton, as saídas do modelo TS são funções (geralmente modelos lineares) das entradas do sistema. Dessa forma, modelos locais baseados em conhecimentos qualitativos de especialistas podem ser definidos.

Entretanto, é improvável que o conhecimento qualitativo forneça informações suficientes para a identificação de um modelo bem sucedido, para que se possa alcançar um desempenho satisfatório, a inclusão de dados empíricos e métodos de aprendizagem é necessária. Estes métodos combinados, conhecidos como Neuro-fuzzy, apresentam maior interpretabilidade em relação aos modelos baseados em redes neurais, entretanto, o desenvolvimento de modelos satisfatórios podem requerer modificações específicas nas regras lógicas que definem as funções de pertinência (THOMPSON, 2009). 
O modelo GP é um modelo caixa-preta probabilístico e não-paramétrico. De um ponto de vista de redes neurais, um modelo GP pode ser caracterizado como uma forma de rede neural com funções de base radial (RBFN), na qual a distribuição dos parâmetros definem o desempenho da rede. Esta distribuição é representada por suas funções de média e covariância. De uma perspectiva de aprendizado de máquina, a função de covariância pode ser entendida como uma função kernel, que, de certa maneira, aproxima o GP aos métodos de kernel, como as support vector machines (SVM) (BISHOP; TIPPING, 2000; SHILTON et al., 2005).

\subsection{Planejamento e Execução do Experimento}

O planejamento do experimento em identificação de sistemas é fundamental, principalmente se a técnica de modelagem escolhida depender significativamente de dados empíricos. Além de escolher quais variáveis devem ser medidas, o projeto do experimento deve considerar o tipo de sinal de excitação que deve ser aplicado, de forma a obter a maior quantidade de informações possível sobre o sistema, bem como a taxa de amostragem utilizada para gravar os dados. Vale ressaltar que enquanto outras escolhas podem ser propostas e analisadas mesmo longe do sistema real (por exemplo, a arquitetura do modelo), mudanças no projeto do experimento só serão realizadas ao se conduzir novos experimentos. Os livros básicos de identificação de sistemas geralmente abordam o projeto de experimentos, como (LJUNG, 1999; SODERSTROM; STOICA, 1989).

Através do projeto de um procedimento experimental adequado, um conjunto de dados de treinamento pode ser construído para a execução dos processos de aprendizado ou otimização a partir dos dados empíricos. Para a identificação de sistemas caixa-preta, a precisão do modelo vai depender inteiramente da qualidade e alcance dos dados de treinamento fornecidos ao sistema de aprendizado. Desta forma, os experimentos devem ser ajustados para cobrir todas as áreas relevantes do espaço operacional do sistema. Caso isso não ocorra, a precisão do modelo nas regiões em que os dados não foram gravados provavelmente será insatisfatória.

No processo de modelagem de um sistema, para que o comportamento do sistema possa ser investigado diretamente, deve-se utilizar sua resposta em malha-aberta. Entretanto, em alguns casos isso não é possível devido a restrições operacionais, como um sistema que se mostre instável em malha-aberta e que possa causar danos ao operador ou ao sistema em si, devendo ser utilizada uma técnica de identificação em malha-fechada. Uma variedade de técnicas foram propostas para a identificação de sistemas em malha-fechada, sendo a mais simples delas a modelagem direta, em que o sistema em malha-fechada é tratado como se fosse malha aberta e as mesmas técnicas de modelagem podem ser aplicadas. Porém, este procedimento pode inviabilizar a utilização de alguns métodos de 
identificação, devido à relação entre as entradas e o ruído de saída. Para eliminar esse problema, foram propostos diversos métodos indiretos, em que medidas dos sinais externos entre o controlador e a planta são incorporados ao modelo (LJUNG, 1999).

A escolha do sinal de excitação vai determinar a natureza dos dados de resposta do sistema adicionados ao conjunto de treinamento, tendo um papel essencial na qualidade de representação que pode ser alcançada. Esta seleção é específica de cada aplicação e depende da perícia e conhecimentos do especialista. Como o ruído do sistema e as perturbações intrínsecas não podem ser influenciadas pelo projetista, o sinal de entrada é a única opção disponível para manipulação. Os sinais de excitação mais comuns são vistos à seguir (THOMPSON, 2009).

\section{Constante}

Não é um sinal adequado para identificação, pois nenhuma dinâmica do sistema é excitada, podendo identificar somente o ganho estático.

\section{Impulso}

Sinal não adequado para tarefas de identificação. É possível obter uma resposta transitória global, mas o ganho não pode ser estimado.

\section{Degrau}

Sinal popular e bastante adequado para identificação de sistemas. Respostas transitórias podem ser analisadas completamente, e boas estimativas do ganho estático e de respostas de baixa frequência podem ser conseguidas. É comum a utilização de um degrau positivo, seguido por um degrau negativo.

\section{Retangular}

Essencialmente, esse sinal tem as mesmas qualidades do degrau, mas também introduz um componente em frequência, permitindo que uma análise mais criteriosa da resposta seja feita em uma determinada frequência. Se é conhecido que o sistema opera em frequências particulares, o projeto do sinal de excitação deve levar esse fato em consideração.

\section{Sinais Binários Pseudo-Aleatórios (Pseudo-Random Binnary Signals -} PRBS)

Outra escolha popular para sistemas lineares é a aplicação de sinais binários pseudoaleatórios, que é um sinal periódico determinístico de amplitude constante, que apresenta as mesmas características do ruído branco. Um conjunto de frequências pode ser analisado de maneira precisa. Entretanto, para a identificação de sistemas lineares, é necessário incluir mudanças na amplitude do sinal, senão só existiriam dados acerca dos limites superiores e inferiores do espaço operacional do sistema. Essa alternativa, conhecida por APRBS (Amplitude modulated $P R B S$ ) permite a investigação de um sistema tanto na 
faixa de amplitude como na faixa de frequência do espaço de entradas.

\subsection{Otimização dos Parâmetros do Modelo}

Uma parte extremamente importante do processo de identificação de sistemas é a tarefa de otimização ou aprendizado que deve ser realizada para ajustar a estrutura escolhida aos dados empíricos disponíveis. Como os sistemas estão cada vez mais complexos, levando a modelos cada vez mais sofisticados, essa tarefa de aprendizado, conhecida também como estimação de parâmetros, se tornam mais elaboradas. Portanto, na seleção de uma estrutura de modelo adequada, a escolha da ferramenta e das características da otimização desejada devem ser consideradas.

As técnicas para otimização podem ser divididas em algumas categorias, de acordo com a quantidade de informações ou dados necessários para sua execução (THOMPSON, 2009).

\section{Aprendizado Supervisionado}

Nos métodos de aprendizado supervisionado, é necessário que exista informações tanto das entradas como da saída do processo, tipicamente na forma de pares entrada-saída. O objetivo do aprendizado supervisionado é identificar uma solução ótima através da minimização de uma medida do erro do modelo em relação ao processo observado. Para a medida do erro, é empregada uma chamada função custo. A saída fornecida pode ser interpretada como exemplos de resposta correta, permitindo a comparação e averiguação da qualidade da resposta atual do processo de aprendizado. A maioria dos problemas de identificação utiliza esse tipo de aprendizado, pois a saída da maioria dos sistemas reais está disponível.

\section{Aprendizado por Reforço (Reinforcement Learning)}

No aprendizado por reforço, algum grau de informação sobre a qualidade do modelo está disponível, mas não se conhece o valor desejado de saída para cada entrada. Este tipo de aprendizado é empregado para avaliar a qualidade de estratégias diferentes ou de objetivos de longo-prazo, ao invés de avaliar o erro dos casos de teste individuais. Esta técnica tem grande relevância em várias aplicações, como em robótica, onde é difícil avaliar a qualidade de manobras ou eventos individuais, e quem define o sucesso ou fracasso é somente o resultado final.

\section{Aprendizado Não-Supervisionado}

No aprendizado não-supervisionado, somente os dados de entrada estão disponíveis. Este tipo de técnica é utilizada para extrair qualquer informação sobre a distribuição dos dados de entrada. Como não são utilizados dados de saída, os métodos não-supervisionados devem ser utilizados em conjunto com métodos supervisionados pra obtenção de modelos 
adequados, sendo usados basicamente como ferramentas de pré-processamento dos dados. Existem duas principais categorias de aprendizado não-supervisionado, com uma diversidade de técnicas em cada categoria. Essas categorias são Principal Component Analysis (PCA) e técnicas de agrupamento (Clustering) (NELLES, 2001).

O processo de otimização dos parâmetros começa com a identificação de um critério que defina a medida matemática exata que deve ser otimizada. Esse critério, conhecido como função custo, é tipicamente uma medida do erro entre a saída do sistema $y(i)$ e da saída correspondente do modelo $\hat{y}(i)$ para um determinado conjunto de treinamento, e pode ser vista na Equação (2.8).

$$
C(\Theta)=C(y(i)-\hat{y}(i))
$$

O modelo $\hat{y}(i)$ do sistema, composto por $n$ entradas independentes $x_{n}$ (regressores) e pelos parâmetros $\theta$, pode ser formulado como a Equação (2.9):

$$
\hat{y}(i)=\theta_{1} x_{1}(i)+\theta_{2} x_{2}(i)+\cdots+\theta_{n} x_{n}(i)
$$

Escrevendo (2.9) na forma matricial temos $\hat{y}(i)=X \Theta$. Se adotarmos a somatória dos quadrados do erro como critério de medida do erro, temos:

$$
C(\Theta)=\sum_{i=1}^{P}(y(i)-\hat{y}(i))^{2}=\sum_{i=1}^{P}(\varepsilon(i))^{2}=\varepsilon^{T} \varepsilon
$$

Para se obter então o valor dos parâmetros, basta realizar a minimização dessa função custo em relação aos parâmetros, como visto em (2.11), método conhecido como mínimos quadrados.

$$
\Theta_{M Q}=\underset{\Theta}{\operatorname{argmin}} C(\Theta)
$$

Para realizar essa minimização, deve-se calcular $\frac{\partial C(\Theta)}{\partial \Theta}$. Na forma matricial, este cálculo leva a (2.12):

$$
\Theta_{M Q}=\left(X^{T} X\right)^{-1} X^{T} Y
$$

Esta equação é chamada de estimador por Mínimos Quadrados. Através de softwares numéricos, esta equação pode ser resolvida de maneira simples. Porém, a inversão de matriz requerida pode se apresentar problemática, se a matriz estiver mal condicionada, o que pode acontecer quando os dados empíricos utilizados para construir a matriz de regressores não foram excitados o suficiente. Foram desenvolvidas diversas técnicas para driblar esse problema, que também aparece em problemas de regressão GP. Além disso, a 
inversão direta dessas matrizes não é realizada devido a essa possibilidade de problemas, e também a diversas ferramentas matemáticas, como eliminação Gaussiana, decomposição Cholesky e decomposição de valores singulares (SODERSTROM; STOICA, 1989).

Outra maneira de se realizar a estimação dos parâmetros é a utilização de métodos probabilísticos, pois eles introduzem o conceito de incerteza para o procedimento de modelagem. A principal técnica probabilística é a estimação por máxima verossimilhança (Maximum Likelihood estimation), que pode ser vista em (2.13).

$$
\Theta_{V M}=\underset{\Theta}{\operatorname{argmax}} f\left(y_{p} \mid x_{p}, \Theta\right)
$$

onde $f\left(y_{p} \mid x_{p}, \Theta\right)$ indica a função de densidade de probabilidade condicional das observações. Este método é empregado também para a otimização dos modelos GP.

Se a função do modelo é não-linear nos parâmetros (os parâmetros são funções), uma técnica de otimização não-linear deve ser empregada para a busca dos valores ótimos dos parâmetros. Uma grande quantidade de técnicas para otimização não-linear estão disponíveis na literatura, e uma boa fonte de informações e algoritmos é Nelles (2001).

A otimização não-linear pode se mostrar um grande desafio devido à presença de pontos ótimos locais. Dessa forma, mais de um conjunto ótimo de parâmetros podem ser identificados, e o conjunto de parâmetros para a solução final deve ser escolhido com cautela, já que alguns conjuntos ótimos podem gerar modelos melhores que os outros conjuntos. Além disso, diferente dos problemas lineares, em que só uma solução ótima existe, as técnicas não-lineares são iterativas, e requerem algoritmos que busquem e convirjam para esses ótimos locais. Dessa forma, esses métodos geralmente não são adequados para aplicações online. Além disso, devido à essa característica iterativa, para se identificar um bom ótimo local e agilizar a convergência do algoritmo, a escolha dos parâmetros iniciais é um aspecto importante. Enquanto uma escolha aleatória ou arbitrária pode resultar em convergência para um ponto ótimo adequado, a seleção de parâmetros iniciais adequados, com a ajuda de informações prévias sobre o sistema, pode aumentar a chance de se obter bons resultados e acelerar o processo consideravelmente (THOMPSON, 2009).

\subsection{Validação do Modelo}

Depois que um modelo foi identificado a partir de um conjunto de treinamento, o método mais simples de verificar o desempenho de um modelo, é testá-lo com um conjunto de dados diferente. Este conceito de separar os dados empíricos em conjuntos de treinamento e teste é conhecido como validação cruzada (Cross-Validation). Uma das maneiras de se realizar essa validação é a chamada validação cruzada utilizando n-partições ( $n$-fold cross-validation). O conjunto de dados é dividido em $n$ partições, e o modelo é 
treinado com $(n-1)$, e uma é utilizada para teste. Esse processo é repetido de forma que todas as partições sejam usadas como dados de teste, e o erro do modelo é a média dos erros de cada configuração dos dados de teste. Essa técnica é ilustrada na Equação (3).

Figura 3 - Validação Cruzada utilizando n-partições.

\begin{tabular}{|c|c|}
\hline Conjunto total de dados disponíveis & \\
\hline $4^{\mathrm{a}}$ Partiçăo : $5^{\mathrm{a}}$ Partição & \\
\hline $0000: 0000: 0000: 0000: 0000$ & Ensaio 1 \\
\hline $0000: 0000: 0000: 0000: 0000$ & Ensaio 2 \\
\hline $0000: 0000: 0000: 0000: 0000$ & Ensaio 3 \\
\hline $0000: 0000: 0000: 0000: 0000$ & Ensaio 4 \\
\hline 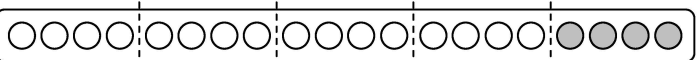 & Ensaio 5 \\
\hline & \\
\hline
\end{tabular}

Fonte: (SILVA; SPATTI; FLAUZINO, 2010)

Quando existem poucos dados empíricos disponíveis, uma alternativa para a validação do modelo é a técnica de validação cruzada por unidade (Leave-One-Out CrossValidation), na qual apenas uma amostra é utilizada como teste, e todas as outras como dados de treinamento. Assim como na técnica anterior, o processo é repetido até que todas as amostras sejam utilizadas, como pode ser visto na Equação (4).

Figura 4 - Validação Cruzada por unidade.

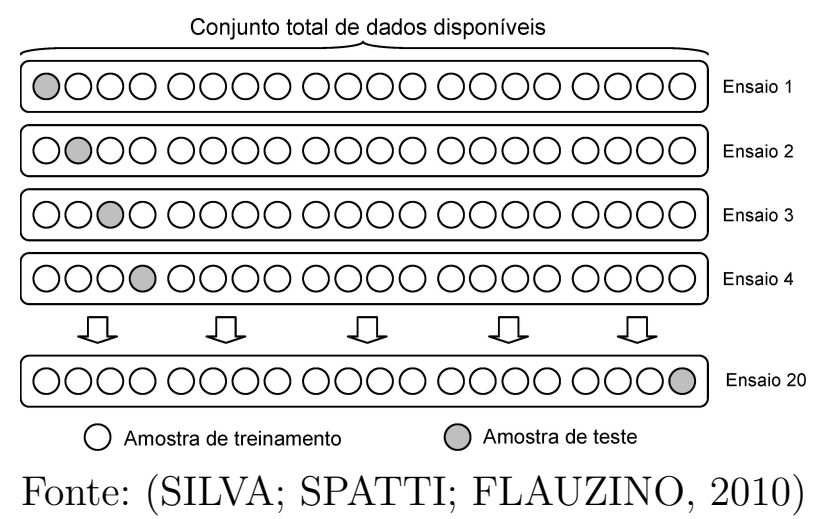

O processo de validação é importante pois avalia a habilidade de generalização do modelo identificado, ou seja, a habilidade de fornecer uma resposta precisa mesmo quando os valores de entrada nunca tenham sido apresentados ao modelo. Esta é uma habilidade importante, já que o modelo deve ser robusto e ter bom desempenho a novos dados, ao invés de "memorizar"os dados de treinamento. Nos casos em que o sistema não consegue estimar corretamente os dados de teste, o que pode ocorrer com um modelo que não seja flexível o suficiente, diz-se que ocorreu o underfitting. Para casos em que um modelo é 
complexo ou flexível, e o erro de treinamento é baixo, mas a generalização não é boa, acontece o overfitting.

A validação do modelo envolve a avaliação do modelo de acordo com um critério de desempenho. Os principais critérios adotados são métodos estatísticos para medir a precisão, como o erro quadrático médio, mas a aplicação de critérios mais subjetivos, como conhecimentos prévios do sistema, podem ser utilizados.

O processo de validação cruzada pode exigir um grande custo computacional, tornando-o um processo extremamente lento para modelos complexos. Dessa forma, uma alternativa é a utilização de vários critérios de informação, como o Critério de Akaike (Akaike's Information Criterion, AIC) e o Erro de Predição Final (Final Prediction Error, FPE) (AKAIKE, 1974). 



\section{Processos Gaussianos}

Os processos Gaussianos (Gaussian Process - GP) podem ser considerados métodos não-paramétricos de identificação de sistemas não-lineares nos quais a predição do comportamento de um sistema é calculada através de técnicas de inferência Bayesiana aplicadas a dados empíricos (THOMPSON, 2009). Este pode ser também considerado como um método de identificação caixa-preta, já que depende fortemente de dados experimentais. Os modelos GP possuem algumas similaridades com alguns tipos de Redes Neurais Artificiais, o que a torna uma ferramenta de interesse do campo de Aprendizado de Máquina, mas é mais comumente encontrada no campo de pesquisa da Estatística (NEO, 2008). Os primeiros trabalhos abordando os GPs podem ser vistos em O'Hagan (1978), porém, o interesse da comunidade científica só aumentou após os trabalhos de Mackay (1998) e Williams (1998).

\subsection{Aprendizado Bayesiano}

Uma abordagem para o problema do overfitting em redes de modelos complexas é a adoção de um método Bayesiano. Esses métodos tentam resolver os problemas de sistemas de aprendizado complexos adotando uma estratégia probabilística. A importância dessa abordagem, em que uma distribuição a priori é definida, e uma distribuição a posteriori é inferida, é que a partir dessas distribuições, informações a respeito do erro geral de aproximação e incerteza associada a esse erro podem ser obtidas. Essa nova informação pode ser utilizada então no aperfeiçoamento da aproximação pretendida.

O termo Bayesiano refere-se ao uso da inferência Bayesiana, uma interpretação da probabilidade que permite que o grau de confiança em uma hipótese ou evento seja a base de uma estimativa de sua probabilidade. Através do uso do Teorema de Bayes, este grau de confiança inicial pode ser atualizado a partir da descoberta de novas informações, dada uma estimativa a posteriori.

O método Bayesiano para a modelagem de dados é baseada na expressão do conhecimento em termos de distribuições de probabilidade. Enquanto métodos paramétricos convencionais de modelagem buscam otimizar os parâmetros de um modelo de forma a minimizar o erro deste, uma abordagem Bayesiana busca maximizar a probabilidade de um modelo a partir dos dados. Desta forma, nos métodos Bayesianos, para se obter uma previsão da resposta $y_{N+1}$, ao invés de calculá-la diretamente, deve-se encontrar primeiramente a probabilidade dessa nova previsão $P\left(y_{N+1}\right)$.

A partir da análise de qualquer conhecimento prévio da função desconhecida, é 
possível especular sobre algumas estruturas de modelo iniciais (ou hipóteses) $H_{i}$ que podem oferecer o nível de flexibilidade ou complexidade necessária para uma representação precisa. Este conjunto de modelos pode ser chamado de espaço de hipóteses, com cada modelo sendo caracterizado por um conjunto de parâmetros $w_{i}$, que serão identificados através dos dados empíricos $D$. No método Bayesiano, essas hipóteses iniciais são expressas através de distribuições a priori sobre todos os modelos possíveis $P\left(H_{i}\right)$. Além disso, é possível definir uma distribuição a priori em relação aos parâmetros $w_{i}$ condicional a estes modelos iniciais $P\left(w_{i} \mid H_{i}\right)$.

No método Bayesiano, a primeira tarefa é ajustar todos os modelos iniciais aos dados observados através da aplicação do Teorema de Bayes, com o objetivo de inferir os parâmetros $w_{i}$ de cada modelo. Esta etapa é bastante semelhante à outras técnicas de modelagem, em que os parâmetros de um modelo são otimizados usando informações dos dados empíricos. Desta forma, o objetivo desta etapa é inferir a distribuição de probabilidade sobre os parâmetros, condicionados aos dados e à hipótese inicial $P\left(w_{i} \mid D, H_{i}\right)$.

Esta etapa é executada através da aplicação do Teorema de Bayes, no qual uma distribuição a posteriori (Posterior) é inferida combinando as informações da distribuição a priori $P\left(w_{i} \mid H_{i}\right)$ (Prior) com as informações obtidas dos dados. A informação obtida dos dados (também chamada Likelihood) é a probabilidade condicional dos dados em relação aos parâmetros e à hipótese inicial $P\left(D \mid w_{i}, H_{i}\right)$ e fornece a probabilidade dos dados observados em função dos parâmetros desconhecidos do modelo.

$$
\begin{gathered}
\text { Teorema de Bayes: } \quad \text { Posterior }=\frac{\text { Likelihood } \times \text { Prior }}{\text { Evidência }} \\
P\left(w_{i} \mid D, H_{i}\right)=\frac{P\left(D \mid w_{i}, H_{i}\right) P\left(w_{i} \mid H_{i}\right)}{P\left(D \mid H_{i}\right)}
\end{gathered}
$$

Nesta equação, a Evidência $P\left(D \mid H_{i}\right)$, conhecida como verossimilhança marginal (Marginal Likelihood), possui o mesmo valor para todas as hipóteses consideradas, funcionando como uma constante normalizadora.

Se o conjunto de dados de treinamento é expresso por $\left\{\left(x^{(1)}, y^{(1)}\right), \cdots,\left(x^{(n)}, y^{(n)}\right)\right\}$, a função de verossimilhança $L\left(w_{i}\right)$, que representa o termo Likelihood, pode ser escrita como:

$$
\begin{array}{r}
L(w)=L\left(w \mid\left(x^{(1)}, y^{(1)}\right), \cdots,\left(x^{(n)}, y^{(n)}\right)\right) \\
L(w) \propto P\left(\left(x^{(1)}, y^{(1)}\right), \cdots,\left(x^{(n)}, y^{(n)}\right) \mid w\right)=\prod_{i=1}^{n} P\left(\left(x^{(1)}, y^{(1)}\right) \mid w\right)
\end{array}
$$

A partir da otimização da Equação (3.2), por exemplo pelo método da máxima verossimilhança (Maximum Likelihood), os parâmetros desconhecidos do modelo podem 
ser identificados. Entretanto, o que se deseja obter é a probabilidade de uma nova saída. Para se obter essa distribuição de probabilidade $P\left(y^{n+1}\right)$, é preciso integrar o modelo em relação à distribuição a posteriori dos parâmetros.

$$
\begin{array}{r}
P\left(y^{n+1} \mid x^{n+1},\left(x^{(1)}, y^{(1)}\right), \cdots,\left(x^{(n)}, y^{(n)}\right)\right) \\
=\int P\left(y^{n+1} \mid x^{n+1}, w\right) P\left(w \mid\left(x^{(1)}, y^{(1)}\right), \cdots,\left(x^{(n)}, y^{(n)}\right)\right) d w
\end{array}
$$

Na Equação (3.3) temos a formulação da distribuição de probabilidade da saída, ou seja, a probabilidade do valor desconhecido $y^{n+1}$. Para a predição de um único valor, deve-se estimar a saída $y$ a partir desta distribuição. A média dessa distribuição de probabilidades é adotada como a estimativa mais provável.

Na primeira etapa da inferência Bayesiana, os parâmetros $w_{i}$ de um modelo $H_{i}$ foram inferidos a partir dos dados observados D, utilizando o Teorema de Bayes. Para a segunda etapa da inferência Bayesiana, o objetivo é comparar um conjunto de modelos diferentes a fim de encontrar o modelo mais provável, de acordo com os dados observados. Esta etapa é semelhante ao processo de validação de modelos, em que vários modelos propostos são analisados e classificados. O objetivo da segunda etapa de inferência não é substituir o processo de validação do modelo. O método Bayesiano fornece informações a respeito da probabilidade de um determinado modelo, o que permite investigar a viabilidade de diversos modelos concorrentes.

Esta etapa também utiliza o Teorema de Bayes para encontrar uma distribuição de probabilidades a posteriori (Posterior) para os modelos, de acordo com os dados, $P\left(H_{i} \mid D\right)$. A probabilidade a priori (Prior) $P\left(H_{i}\right)$, independente dos parâmetros, sobre todas as hipóteses, é utilizada na inferência. A probabilidade $P\left(D \mid H_{i}\right)$ representa a informação que os dados fornecem sobre a verossimilhança de cada modelo $H_{i}$, e corresponde à evidência ou verossimilhança marginal (Marginal Likelihood) do primeiro nível de inferência. Uma constante normalizadora $P(D)$ é utilizada mais uma vez para garantir que a soma das probabilidades seja igual a 1.

$$
P\left(H_{i} \mid D\right)=\frac{P\left(D \mid H_{i}\right) P\left(H_{i}\right)}{P(D)}
$$

Para implementar o método Bayesiano, algumas integrais devem ser avaliadas para calcular a distribuição a posteriori desejada. No primeiro nível de inferência, para se obter o Posterior de qualquer nova saída $y^{n+1}$, deve-se integrar sobre os parâmetros. Além disso, para se calcular os parâmetros mais prováveis, a verossimilhança marginal deve ser calculada, sendo esta uma integral, mostrada em (3.5):

$$
P\left(D \mid H_{i}\right)=\int P\left(D \mid w_{i}, H_{i}\right) P\left(w_{i} \mid H_{i}\right) d w_{i}
$$


A avaliação dessa integral sobre o espaço de parâmetros é importante também para a comparação de diversos modelos, realizada na segunda etapa de inferência. Portanto, o cálculo da verossimilhança marginal é fundamental para a implementação da inferência de Bayes, e é a principal característica que distingue o método de Bayes de outros métodos convencionais de otimização e seleção de modelos (THOMPSON, 2009).

Os componentes dessa integral são a Likelihood e a distribuição a priori, descritas anteriormente. Essas duas distribuições de probabilidade geralmente são funções nãolineares dos parâmetros. O termo Likelihood comumente é expresso por uma soma do quadrado dos erros, e o termo Prior pode ser de qualquer forma necessária para descrever as suposições sobre os parâmetros, antes da observação de qualquer dado. Quando analisadas em conjunto, essas integrais podem se mostrar intratáveis analiticamente, e impossíveis de se calcular diretamente, o que é um problema significativo do método de modelagem Bayesiano, demandando a aplicação de métodos de aproximação.

O método mais geral e eficaz para avaliar essas integrais intratáveis dependem do uso de métodos de Monte Carlo baseado em Cadeias de Markov (Markov Chain Monte Carlo MCMC) (GILKS; RICHARDSON; SPIEGELHALTER, 1996). Outras possibilidades são métodos baseados em aproximações Gaussianas para as modas da distribuição a posteriori (MACKAY, 1991).

Outro ponto que pode apresentar dificuldades na abordagem Bayesiana é a determinação de uma distribuição de probabilidades a priori (Prior) adequada para iniciar o processo de inferência. Para situações em que modelos iniciais complexos são utilizados, expressar os conhecimentos prévios através de distribuições de probabilidade pode ser uma tarefa complicada. Como consequência, devido à dificuldade dessa escolha, bem como das complexidades matemáticas relativas às integrais, a adoção de um Prior por conveniência matemática, ao invés de expressar os conhecimentos verdadeiros sobre a função desconhecida, é uma ideia tentadora. Entretanto, agindo dessa forma, pode-se questionar se o método aplicado é realmente fundamentado na teoria Bayesiana, e até mesmo a validade do método. Desta forma, deve-se balancear entre Priors que sejam interpretáveis e prontamente aplicáveis, e também reflitam o conhecimento sobre o sistema. Na prática, é comum a aplicação de Priors que possuam escopo amplo, de forma a não limitar nem favorecer diferentes modelos (THOMPSON, 2009).

\subsection{Aprendizado utilizando Processos Gaussianos}

Como visto nas seções anteriores, a adoção de uma metodologia Bayesiana para a modelagem de sistemas pode superar as dificuldades relativas ao Overfitting em redes complexas. Porém, esta metodologia apresenta outras dificuldades, como a identificação de Priors adequados, e a possível necessidade de utilização de técnicas de aproximação de 
integrais que demandam grande capacidade computacional.

A principal vantagem da modelagem por Processos Gaussianos (GP) é que é possível remover uma parte da complexidade matemática associada com a implementação do método Bayesiano, enquanto mantém as características apontadas anteriormente. Especificamente, as propriedades matemáticas dos Processos Gaussianos permitem que as integrais problemáticas associadas com a verossimilhança marginal se tornem tratáveis, descartando a necessidade de métodos como o MCMC. Além disso, grande parte da flexibilidade e poder de aproximação de métodos com funções de base adaptativas, como as Redes Neurais, é mantido pelo uso de modelos GP. Ao invés de uma rede neural composta por um número finito de funções de base adaptativas, o modelo GP é correspondente a uma rede de infinitas funções de base fixas (ou a métodos baseados em kernel), permitindo, dessa forma, grandes redução do consumo computacional.

Grande parte do trabalho recente em modelos GP se origina dos trabalhos de MacKay (1991) e Neal (1993). Porém, o uso de processos gaussianos só ganhou força após o trabalho de Mackay (1997), no qual modelos GP foram considerados como potenciais substitutos para Redes Neurais. Este trabalho foi a primeira revisão geral dos métodos envolvidos em aprendizado supervisionado utilizando Processos Gaussianos.

De maneira simplificada, um processo gaussiano pode ser entendido como um processo estocástico. Um processo estocástico matemático pode ser definido como uma coleção de variáveis aleatórias. De maneira geral, um processo estocástico pode ser pensado como uma função aleatória, na qual cada valor dessa função é uma variável aleatória. Considerase que um processo estocástico evolui, e é indexado pelo tempo, tendo especificada uma variável aleatória $X_{t}$ no tempo $t$.

Outra definição importante é o fato de as variáveis aleatórias serem definidas como funções matemáticas, ao invés de uma variável matemática à qual atribui-se um valor. Uma variável aleatória mapeia as possíveis saídas de um experimento, ao invés de descrever uma única saída. Para cada variável aleatória, pode ser definida uma distribuição de probabilidades que descreva suas características. Essa distribuição é muitas vezes caracterizada por uma função de densidade de probabilidade (Probability Density Function - PDF) na qual integrais podem ser definidas sobre um intervalo para determinar a probabilidade exata.

A partir dessas definições, define-se o Processo Gaussiano como uma generalização da distribuição de probabilidade Gaussiana, também chamada de Normal (ou seja, uma variável aleatória $X \sim \operatorname{Normal}\left(\mu, \sigma^{2}\right)$ ), na qual qualquer função amostrada gerada sobre o tempo $X_{t}$ tem a propriedade que qualquer combinação linear será também normalmente distribuída, isto é, o processo é Gaussiano se todas as distribuições conjuntas forem distribuições normais multivariadas. Escrevendo de maneira formal, para um conjunto de entradas $x_{1}, \cdots, x_{n}$, as variáveis aleatórias resultantes $f\left(x_{1}\right), \cdots, f\left(x_{n}\right)$ possuem uma 
distribuição Gaussiana n-dimensional, conforme Equação (3.6):

$$
P\left(f\left(x_{1}\right), \cdots, f\left(x_{n}\right) \mid x_{1}, \cdots, x_{n}\right)=\operatorname{Normal}(\mathbf{m}, \boldsymbol{\Sigma})
$$

onde $\mathbf{m}$ é o vetor $n \times 1$ dos valores esperados (ou médias) e $\boldsymbol{\Sigma}$ é a matriz $n \times n$ das covariâncias entre todos os pares de pontos. A covariância pode ser interpretada como a medida de como duas variáveis variam conjuntamente.

A distribuição Normal é caracterizada pela PDF Gaussiana ("sino"):

$$
f(x ; \mu, \sigma)=\frac{1}{\sigma \sqrt{2 \pi}} \exp \left(-\frac{(x-\mu)^{2}}{2 \sigma^{2}}\right)
$$

com a média $\mu$ sendo o valor esperado da variável aleatória, e a variância $\sigma^{2}$ descrevendo a dispersão estatística em volta do valor esperado, sendo comumente interpretada como a largura da distribuição de probabilidade.

Dadas as propriedades da distribuição normal, pode-se especificar um processo Gaussiano somente através das funções de média e covariância:

$$
f(x) \sim G P\left(m(x), C\left(x_{i}, x_{j}\right)\right)
$$

com a função de média $m(x)=E[f(x)]$ e a função de covariância $C\left(x_{i}, x_{j}\right)=\operatorname{Cov}\left[f\left(x_{i}\right), f\left(x_{j}\right)\right]$ . Escrevendo de acordo com as teorias probabilísticas:

$$
\begin{aligned}
m_{i} & =E\left[f(x) \mid x_{i}\right] \\
\Sigma_{i j} & =\operatorname{Cov}\left[f\left(x_{i}\right), f\left(x_{j}\right) \mid x_{i}, x_{j}\right]=E\left[f\left(x_{i}\right), f\left(x_{j}\right) \mid x_{i}, x_{j}\right]-E\left[f\left(x_{i}\right) \mid x_{j}\right] E\left[f\left(x_{j}\right) \mid x_{i}\right](3.9)
\end{aligned}
$$

Uma matriz de covariância pode ser gerada a partir da avaliação da função de covariância, dados todos os pares de pontos dos dados observados. A matriz de covariância $\Sigma_{i j}$ é definida na Equação $(3.10)$, sendo $C(\cdot, \cdot)$ uma função de covariância qualquer.

$$
\Sigma_{i j}=\left[\begin{array}{ccc}
C\left(x_{1}, x_{1}\right) & \cdots & C\left(x_{1}, x_{n}\right) \\
\vdots & \ddots & \vdots \\
C\left(x_{n}, x_{1}\right) & \cdots & C\left(x_{n}, x_{n}\right)
\end{array}\right]
$$

A partir dessa descrição do processo Gaussiano, percebe-se que a função de covariância desempenha um papel fundamental na especificação do processo Gaussiano. É essa função que gera a matriz de covariância, e direciona como as entradas e saídas serão correlacionadas. O usuário deve selecionar uma função de covariância para ser utilizada no processo Gaussiano, e essa escolha representa um controle significativo sobre o modelo resultante (THOMPSON, 2009). 
Como mencionado anteriormente, grande parte do interesse em processos Gaussianos surgiu a partir da demonstração de que, assumindo Priors apropriados, o processo Gaussiano pode ser comparado à uma rede neural Bayesiana composta de infinitas funções de base fixas. Seguindo essa idéia, o processo de regressão utilizando modelos GP torna-se mais claro, conforme mostra Neal (1996).

Retomando o problema a ser resolvido, a partir de um conjunto dados de treinamento $\left(\mathbf{X}_{N}, \mathbf{t}_{N}\right)$ com $N$ amostras, compostas por um vetor de entradas $\mathbf{x}^{(n)}$ de uma dimensão I fixa, e as saídas correspondentes $t_{N}$, a tarefa é inferir uma função desconhecida $y(x)$ que represente os dados de maneira adequada, e depois calcular previsões de novas saídas $t_{N+1}$, dadas novas entradas $x_{N+1}$.

Adotando uma abordagem paramétrica, o objetivo é modelar uma função desconhecida $y(x)$ através de uma função não-linear $y(\mathbf{x} ; \mathbf{w})$ caracterizada por seus parâmetros w. Adotando uma rede de $H$ funções de base fixas $\phi_{h}(\mathbf{x})_{h=1}^{H}$ como estrutura do modelo, este pode ser especificado por:

$$
y(\mathbf{x} ; \mathbf{w})=\sum_{h=1}^{H} w_{h} \phi_{h}(\mathbf{x})
$$

Adotando essa estrutura, a dependência entre a saída $y$ e os parâmetros $w$ é linear. Como busca-se identificar uma função não-linear $y(x ; w)$, mas especificou-se uma relação linear entre a função e os parâmetros, é possível especificar uma função de base não-linear das entradas $\mathbf{x}$, de forma que o modelo proposto seja não-linear. Se a função de base selecionada for uma função radial centrada nos pontos $c_{h h=1}^{H}$, tem-se:

$$
\phi_{h}(\mathbf{x})=\exp \left[\frac{\left(\mathbf{x}-c_{h}\right)^{2}}{2 r^{2}}\right]
$$

Para seguir a notação adotada em outros trabalhos de processos Gaussianos, definese a matriz $\mathbf{R}(N \times H)$ para representar os valores das funções de base $\phi_{h}(\mathbf{x})_{h=1}^{H}$ nos pontos $x^{(n)}$. Dessa forma, define-se o vetor $\mathbf{y}_{n}$ como o vetor $y(\mathbf{x})$ nos $N$ pontos:

$$
\begin{aligned}
R_{n h} & =\phi_{h}\left(\mathbf{x}^{(n)}\right) \\
\mathbf{y}_{n} & =\sum_{h} R_{n h} w_{h}
\end{aligned}
$$

De acordo com a Equação (3.13), o modelo pode ser entendido como uma rede multicamada na qual somente os pesos w são adaptativos, sendo as conexões entre a camada de entrada e as camadas ocultas fixas.

Seguindo o método Bayesiano, depois de definir o a estrutura inicial do modelo, é necessário definir uma distribuição de probabilidade a priori sobre os parâmetros desse 
modelo. Na ausência de dados, uma possibilidade seria a escolha de uma distribuição Gaussiana com média zero.

$$
P(\mathbf{w})=\operatorname{Normal}\left(\mathbf{0}, \boldsymbol{\sigma}_{w}^{2} \mathbf{I}\right)
$$

Como y foi definida como uma função linear de w, é possível deduzir que $y$ também terá distribuição Gaussiana, com média $E[y]=0$. Dessa forma, a matriz de covariância $\mathbf{Q}$ de $y$ é definida na Equação (3.15):

$$
\begin{aligned}
& \mathbf{Q}=E\left[(\mathbf{y}-E[\mathbf{y}])(\mathbf{y}-E[\mathbf{y}])^{T}\right] \\
& \mathbf{Q}=\left\langle\mathbf{y} \mathbf{y}^{T}\right\rangle=\left\langle\mathbf{R} \mathbf{w} \mathbf{w}^{\mathbf{T}} \mathbf{R}^{\mathbf{T}}\right\rangle=\mathbf{R}\left\langle\mathbf{w} \mathbf{w}^{T}\right\rangle \mathbf{R}^{T} \\
& \mathbf{Q}=\boldsymbol{\sigma}_{w}^{2} \mathbf{R R}^{T}
\end{aligned}
$$

Assim, temos a distribuição a priori de $\mathbf{y}$ :

$$
P(\mathbf{y})=\operatorname{Normal}(\mathbf{0}, \mathbf{Q})=\operatorname{Normal}\left(\mathbf{0}, \boldsymbol{\sigma}_{w}^{2} \mathbf{R R}^{T}\right)
$$

Dessa forma, para qualquer número de pontos $\mathbf{X}_{\mathbf{N}}$, o vetor com os valores da função y sempre terá distribuição Gaussiana. Como consequência da escolha do Prior Gaussiano de média zero, recria-se a propriedade que define os processos Gaussianos, que diz que a distribuição de probabilidade de uma função $y(x)$ é um processo Gaussiano para qualquer conjunto finito de pontos $x^{(n)}$, a PDF $P\left(y\left(x^{(1)}, x^{(2)}, \cdots, x^{(n)}\right)\right.$ também é Gaussiana.

Um elemento $\left(n, n^{\prime}\right)$ individual da matriz de covariância $\mathbf{Q}$ pode ser visto em (3.17).

$$
Q_{n n^{\prime}}=\left[\sigma_{w}^{2} R R^{T}\right]=\sigma_{w}^{2} \sum_{h} \phi_{h}\left(x^{(n)}\right)
$$

A matriz de covariância $\mathbf{Q}$ descreve a covariância dos valores da função nos pontos $\mathbf{X}_{\mathbf{N}}$, mas é necessário também descrever a covariância na saída $t_{n}$. Assumindo que cada saída $t_{n}$ difere-se do valor correspondente da função por um ruído Gaussiano aditivo $\sigma_{v}^{2}$, então as saídas também terão distribuição a priori Gaussiana:

$$
P(\mathbf{t})=\operatorname{Normal}\left(\mathbf{0}, \mathbf{Q}+\boldsymbol{\sigma}_{v}^{2} I\right)
$$

Descrevendo a matriz de covariância $\mathbf{C}$ das saídas, tem-se:

$$
\mathbf{C}=\mathbf{Q}+\boldsymbol{\sigma}_{v}^{2} I=\boldsymbol{\sigma}_{w}^{2} R R^{T}+\boldsymbol{\sigma}_{v}^{2} I
$$


Analisando-se o elemento individual $\left(n, n^{\prime}\right)$ da matriz de covariância $\mathbf{C}$, tem-se:

$$
Q_{n n^{\prime}}=\left[\sigma_{w}^{2} R R^{T}\right]=\sigma_{w}^{2} \sum_{h} \phi_{h}\left(x^{(n)}\right) \phi_{h}\left(x^{\left(n^{\prime}\right)}\right)+\delta_{n n^{\prime}}
$$

Se for adotado um modelo baseado em um número infinito de funções de base $(H \rightarrow \infty)$, o somatório sobre a função de base se torna uma integral. É possível simplificar a forma dos elementos $Q_{n n^{\prime}}$ assumindo que as funções de base são uniformemente espaçadas, e cada função de base $h$ centradas no ponto $x=h$. Além disso, o termo variância $\sigma_{w}^{2}$ pode ser dimensionado para não divergir com o aumento de $H$, redefinindo-o como uma constante $S$ dependente do número de funções de base por unidade de comprimento do eixo $x$.

$$
\begin{aligned}
Q_{n n^{\prime}} & =S \int_{h_{\min }}^{h_{\max }} \phi_{h}\left(x^{(n)}\right) \phi_{h}\left(x^{\left(n^{\prime}\right)}\right) d h \\
Q_{n n^{\prime}} & =S \int_{h_{\min }}^{h_{\max }} \exp \left[\frac{\left(x^{(n)}-h\right)}{2 r^{2}}\right] \exp \left[\frac{\left(x^{\left(n^{\prime}\right)}-h\right)}{2 r^{2}}\right]
\end{aligned}
$$

Colocando os limites de integração em $\pm \infty$, tem-se:

$$
Q_{n n^{\prime}}=\sqrt{\pi r^{2}} S \exp \left[\frac{\left(x^{\left(n^{\prime}\right)}-x^{(n)}\right)}{4 r^{2}}\right]
$$

A partir da descrição de um termo individual da matriz de covariância $\mathbf{Q}$, mostrada em (3.23), é possível generalizar para formar a função de covariância que descreva todos os termos, agrupando as constantes para constituir o hiperparâmetro $\theta_{1}$.

$$
C\left(x^{(n)}, x^{\left(n^{\prime}\right)}\right) \equiv \theta_{1} \exp \left[\frac{\left(x^{\left(n^{\prime}\right)}-x^{(n)}\right)}{4 r^{2}}\right]
$$

Dessa forma, para qualquer função de covariância válida, é possível definir a matriz de covariância $\mathbf{Q}$ para $N$ valores da função nos pontos $\mathbf{X}_{\mathbf{N}}$ :

$$
\left.\mathbf{Q}=C\left(\mathbf{x}_{(n)}\right), \mathbf{x}_{\left(n^{\prime}\right)}\right)
$$

Assumindo a presença de ruído Gaussiano aditivo, a matriz de covariância C para os $N$ valores de saída correspondentes é dada por:

$$
\left.\mathbf{C}=C\left(\mathbf{x}_{(n)}\right), \mathbf{x}_{\left(n^{\prime}\right)}\right)+\sigma_{v}^{2} \delta_{n n^{\prime}}
$$

A consequência do aumento do número de funções de base do modelo para infinitas é que o processo de definição de Priors adequados para um modelo é simplificado, pois 
ao invés de definir Priors individuais sobre o modelo ou a função, parâmetros, e ruído, todas essas informações são combinadas através da definição de um processo Gaussiano $a$ priori, especificado através da escolha da função de covariância C. Além disso, as etapas subsequentes requeridas para a obtenção de previsões de saída também se tornam mais simples, pois as integrais intratáveis que surgem no cálculo de alguns componentes da inferência Bayesiana tornam-se tratáveis com o uso de processos Gaussianos, podendo ser tratadas analiticamente.

\subsection{Aplicação de Processos Gaussianos em Regressões}

A aplicação do aprendizado Bayesiano se torna facilitada utilizando processos Gaussianos. Para sua aplicação, é preciso especificar as características que definem um processo Gaussiano, que é a média do processo, e uma matriz de covariância que representa as correlações encontradas no conjunto de dados de treinamento.

Uma escolha comum para as informações a priori de modelos GP é utilizar média igual a zero, o que pode não representar corretamente os dados, mas não é uma grande limitação, pois a distribuição a posteriori não é limitada a zero. Para a construção da matriz de covariância, uma função de covariância adequada deve ser aplicada aos dados de treinamento. Várias funções de covariância podem ser utilizadas, e a função mais apropriada deve ser escolhida baseando-se em conhecimentos prévios do processo a ser identificado. Essa escolha é de grande importância para a modelagem utilizando processos Gaussianos, já que é ela que define como os dados serão transformados em uma matriz que represente suas correlações (THOMPSON, 2009).

Depois de selecionada uma função de covariância apropriada, os parâmetros dessa função, conhecidos como hiperparâmetros, devem ser otimizados a partir dos dados de treinamento. Essa etapa da utilização de processos Gaussianos será discutida adiante e, para permitir a análise do processo de regressão, ou seja, como fazer previsões da saída do processo utilizando um modelo GP, considera-se que a função de covariância já foi otimizada.

Seguindo o processo de aprendizado Bayesiano, o próximo passo é inferir uma distribuição a posteriori, para então realizar a previsão de saída de acordo com uma nova entrada $\mathbf{x}_{N+1}$. Devido à natureza da distribuição a priori escolhida, é possível pular algumas etapas da abordagem Bayesiana, obtendo-se a distribuição a posteriori aplicando somente uma probabilidade conjunta, ao invés do teorema de Bayes.

Dado um conjunto de $N$ dados de treinamento $\mathbf{D}=\left(\mathbf{X}_{N}, \mathbf{t}_{N}\right)$, composto pelas entradas $\mathbf{X}_{N}=\left[\mathbf{x}_{1}, \mathbf{x}_{2}, \cdots, \mathbf{x}_{N}\right]$, sendo $\mathbf{x}$ vetores de entrada de dimensão fixa, e os valores escalares das saídas $\mathbf{t}$ correspondentes, com $\mathbf{t}_{N}=\left[t\left(\mathbf{x}_{1}\right), t\left(\mathbf{x}_{2}\right), \cdots, t\left(\mathbf{x}_{N}\right)\right]$. O objetivo da regressão é prever uma nova saída $t_{N+1}$ a partir de uma nova entrada $\mathbf{x}_{N+1}$. Devido 
à natureza probabilística da modelagem GP, a regressão se dará pelo cálculo de uma distribuição de probabilidade a posteriori sobre $t_{N+1}$, e depois a determinação de uma estimativa $\hat{t}_{N+1}$ baseada na média dessa distribuição.

Para a modelagem GP, define-se uma distribuição a priori no espaço de funções. Como um processo Gaussiano é um conjunto de variáveis aleatórias que possuem distribuição conjunta multivariada Gaussiana totalmente especificado através de sua média $\boldsymbol{\mu}$ e matriz de covariância $\mathbf{C}$, é possível definir a probabilidade da saída como a seguinte distribuição conjunta:

$$
\begin{aligned}
& P\left(\mathbf{t} \mid \mathbf{C}, \mathbf{X}_{N}\right)=\prod_{i=1}^{n} P\left(t_{i} \mid C\left(\mathbf{x}_{m}, \mathbf{x}_{n} ; \boldsymbol{\theta}\right),\left\{\mathbf{x}_{n}\right\}\right) \\
& P\left(\mathbf{t} \mid \mathbf{C}, \mathbf{X}_{N}\right)=\frac{1}{Z} \exp \left(-\frac{1}{2}(\mathbf{t}-\mu)^{T} \mathbf{C}^{-1}(\mathbf{t}-\mu)\right)
\end{aligned}
$$

na qual $\mathbf{C}$ é a matriz de covariância formada pela função parametrizada $C\left(\mathbf{x}_{m}, \mathbf{x}_{n} ; \boldsymbol{\theta}\right)$ aplicada aos dados de entrada, $\mu$ é a média do processo e $Z$ é uma constante normalizadora. Como o Prior definido para o processo Gaussiano foi que a média é igual a zero, $\mu_{N}=0$, pode-se reescrever:

$$
P\left(\mathbf{t}_{N} \mid \mathbf{C}_{N}, \mathbf{X}_{N}\right)=\frac{1}{Z_{N}} \exp \left(-\frac{1}{2}\left(\mathbf{t}_{N}^{T} \mathbf{C}_{N}^{-1} \mathbf{t}_{N}\right)\right)
$$

Para a efetuar a regressão, é preciso inferir um valor $t_{N+1}$ utilizando este Prior do processo Gaussiano e uma nova entrada $x_{N+1}$. Portanto, a distribuição de probabilidade desejada pode ser interpretada como uma distribuição de probabilidade condicional sobre $t_{N+1}$ :

$$
P\left(t_{N+1} \mid \mathbf{D}, \mathbf{C}_{N}, \mathbf{x}_{N+1}\right)=\frac{P\left(\mathbf{t}_{N+1} \mid \mathbf{C}_{N}, \mathbf{X}_{N}, \mathbf{x}_{N+1}\right)}{P\left(\mathbf{t}_{N} \mid \mathbf{C}_{N}, \mathbf{X}_{N}\right)}
$$

Para encontrar a distribuição condicional sobre a nova saída, é necessário primeiramente definir a distribuição conjunta $P\left(\mathbf{t}_{N+1} \mid \mathbf{C}_{N}, \mathbf{X}_{N}, \mathbf{x}_{N+1}\right)$. Esse passo pode ser realizado considerando essa nova entrada como uma continuação do processo Gaussiano, aplicando a função de covariância a essa nova observação, de forma a atualizar a matriz de covariância $\mathbf{C}_{N}$ para $\mathbf{C}_{N+1}$, que resulta na distribuição conjunta vista em (3.31).

$$
P\left(\mathbf{t}_{N+1} \mid \mathbf{C}_{N}, \mathbf{X}_{N}, \mathbf{x}_{N+1}\right)=\frac{1}{Z_{N+1}} \exp \left(-\frac{1}{2}\left(\mathbf{t}_{N+1}^{T} \mathbf{C}_{N+1}^{-1} \mathbf{t}_{N+1}\right)\right)
$$

A partir dos dados de treinamento, foi construída uma matriz de covariância $\mathbf{C}_{N}$. Para as predições, é necessário incorporar a nova entrada nessa matriz, de forma a obter 
uma matriz $(N+1) \times(N+1)$, com a estrutura mostrada em (3.32):

$$
\mathbf{C}_{N+1}=\left[\begin{array}{ll}
{\left[\mathbf{C}_{N}\right]} & {[\mathbf{k}]} \\
{\left[\mathbf{k}^{T}\right]} & {[\boldsymbol{\kappa}]}
\end{array}\right]
$$

onde a submatriz $\mathbf{k}=\left[C\left(\mathbf{x}_{1}, \mathbf{x}_{N+1} ; \boldsymbol{\theta}\right), \cdots, C\left(\mathbf{x}_{N}, \mathbf{x}_{N+1} ; \boldsymbol{\theta}\right)\right]$ é o vetor de covariâncias entre a nova entrada e os dados de treinamento existentes, e $\boldsymbol{\kappa}=C\left(\mathbf{x}_{N+1}, \mathbf{x}_{N+1} ; \boldsymbol{\theta}\right)$ é a variância da nova entrada.

Dessa forma, substituindo (3.28) e (3.31) em (3.30), tem-se:

$$
P\left(t_{N+1} \mid \mathbf{D}, \mathbf{C}_{N}, \mathbf{x}_{N+1}\right)=\frac{Z_{N}}{Z_{N+1}} \exp \left(-\frac{1}{2}\left(\mathbf{t}_{N+1}^{T} \mathbf{C}_{N+1}^{-1} \mathbf{t}_{N+1}-\mathbf{t}_{N}^{T} \mathbf{C}_{N}^{-1} \mathbf{t}_{N}\right)\right)
$$

A partir da Equação (3.33), para calcular esta distribuição a posteriori e prever a saída $t_{N+1}$, é necessário que essa saída que se deseja estimar já tenha sido observada. Utilizando substituições matemáticas através do uso da regra da inversa particionada (BARTNETT, 1979), é possível calcular essa distribuição. As equações da inversa particionada permitem que se realize o cálculo de $\mathbf{C}_{N+1}^{-1}$ utilizando $\mathbf{C}_{N+1}$ e $\mathbf{C}_{N}^{-1}$, o que também traz a vantagem de economia computacional, já que se realiza a inversão de uma matriz $N \times N$, ao invés de uma $(N+1) \times(N+1)$. Ao aplicar essas equações, obtém-se uma distribuição a posteriori em termos de $\mathbf{C}_{N}$ e $\mathbf{k}$, que pode ser calculada sem dificuldades. Os detalhes dessa manipulação matemática podem ser vistos em Gibbs (1997), e o resultado é a distribuição a posteriori mostrada em (3.34).

$$
P\left(t_{N+1} \mid \mathbf{D}, \mathbf{C}_{N}, \mathbf{x}_{N+1}\right)=\frac{1}{Z} \exp \left(-\frac{\left(t_{N+1}-\hat{t}_{N+1}\right)}{2 \sigma_{\hat{t}_{N+1}}^{2}}\right)
$$

A partir de (3.34), a média e variância são definidas por:

$$
\begin{aligned}
\hat{t}_{N+1} & =\mathbf{k}_{N+1}^{T} \mathbf{C}_{N}^{-1} \mathbf{k}_{N} \\
\sigma_{N+1}^{2} & =\kappa-\mathbf{k}_{N+1}^{T} \mathbf{C}_{N}^{-1} \mathbf{k}_{N+1}
\end{aligned}
$$

Dessa forma, utilizando a Equação (3.35) é possível obter uma estimativa da saída $\hat{t}_{N+1}$, e com (3.36) obtém-se a medida da incerteza sobre o valor de saída estimado.

\subsection{Funções de Covariância}

Como foi mostrado anteriormente, a função de covariância é o componente principal de um modelo GP, pois codifica as suposições sobre a função a ser identificada. Esse 
processo é semelhante à definição da estrutura de um modelo em métodos paramétricos. Em aprendizado supervisionado, a noção de similaridade entre os dados é de grande importância. Uma suposição pertinente é que entradas próximas provavelmente terão saídas similares. Nos processos Gaussianos, é a função de covariância que define essa proximidade ou similaridade. Em problemas de regressão, e principalmente de identificação de sistemas reais, os dados usados para treinamento têm grande chance de terem sido corrompidos por ruído. Dessa forma, um modelo desse ruído é uma característica importante a se incorporar na função de covariância.

O processo de escolha de uma função de covariância viável pode ser entendido também como o processo de construção de um processo Gaussiano válido. Devido a esse fato, não é qualquer função arbitrária que pode ser utilizada como função de covariância, já que a construção de processos estocásticos exigem que essa função tenha características específicas. Para a seleção de uma função adequada, deve-se atender à restrição de que essa função deve gerar uma matriz de covariância positiva semi-definida (RASMUSSEN; WILLIAMS, 2006).

Uma matriz $K$ real, de dimensão $n \times n$ é dita positiva semi-definida (PSD) se satisfaz a condição $Q(\mathbf{v})=\mathbf{v}^{T} \mathbf{K} \mathbf{v} \geq 0$ para todos os vetores $\mathbf{v} \in \mathbb{R}^{n}$, e $Q$ possui forma quadrática. Uma matriz simétrica é PSD se e somente se todos os seus autovalores são não-negativos.

Em geral, as propriedades de processos estocásticos ou campos aleatórios podem ser descritas por um conjunto de distribuições de dimensões finitas. Para um processo Gaussiano, essas distribuições são distribuições Normais multivariadas. Para este sistema de distribuições de dimensões finitas, um processo estocástico válido existe somente se certas condições de compatibilidade de simetria são atendidas. Essas condições são descritas no Teorema da Existência de Kolmogorov (ou Extensão de Kolmogorov). Para atender a essas condições aplicadas a processos Gaussianos, deve-se utilizar uma função de covariância positiva-semidefinida, o que gera uma matriz de covariância também positiva semidefinida, garantindo a validade do processo Gaussiano.

A metodologia envolvida na construção de processos estocásticos e a dedução de funções de covariância a partir dessa metodologia é uma área complexa da estatística, e diversos trabalhos apresentam essa metodologia em detalhes, como por exemplo Adler (1981). Para simplificar essa análise, diversas funções de covariância já foram definidas na literatura e identificadas como apropriadas para utilização em modelagem utilizando processos Gaussianos. Uma revisão dessas diversas funções de covariância pode ser encontrada em Stein (1999), Mackay (1998), Rasmussen e Williams (2006).

Na descrição de funções de covariância, a principal distinção entre os tipos de função são as funções estacionárias e não-estacionárias. Uma função de covariância é dita estacionária se ela for definida em função de $\mathbf{x}-\mathbf{x}^{\prime}$ e são ditas invariantes a translações 
no espaço de entradas, ou seja, funções com essa característica se comportam da mesma maneira em qualquer posição de x. Para funções não-estacionárias, isto não acontece, podendo variar drasticamente em termos de suavidade variável sobre todo o espaço de entradas. Se a função for definida em termos de $\left|\mathbf{x}-\mathbf{x}^{\prime}\right|$, esta é descrita como isotrópica, e é invariante a qualquer movimento rígido.

Outra característica que deve ser levada em conta na seleção da função de covariância é em relação sua propriedade de suavidade. Esta é a principal característica que distingue as diferentes funções de covariância. Para descrever essa suavidade das funções, são empregados termos como continuidade e diferenciabilidade. Portanto, ao selecionar uma função de covariância adequada, busca-se uma função com as características de suavidade apropriadas analisando sua continuidade ou diferenciabilidade. Porém, a determinação dessa característica a partir de uma função de covariância não é matematicamente simples, e algumas outras propriedades, como a diferenciabilidade média quadrática (mean-square MS), são aplicadas. As propriedades MS são obtidas mais facilmente e são diretamente relacionadas às derivadas da função de covariância. Uma discussão mais detalhada das propriedades geométricas de processos estocásticos pode ser encontrada em Adler (1981), Stein (1999).

A forma geral de uma função de covariância pode ser vista na Equação (3.37). Observa-se nessa equação que um termo relativo a um ruído gaussiano aditivo com variância $\boldsymbol{\sigma}_{n}^{2}$ é adicionado, pois supõe-se que os dados empíricos apresentam um certo nível de ruído, que precisa ser modelado.

$$
\mathbf{C}_{m n}=C\left(\mathbf{x}_{m}, \mathbf{x}_{n} ; \boldsymbol{\theta}\right)+\boldsymbol{\sigma}_{n}^{2} \boldsymbol{\delta}_{n m}
$$

onde $\delta_{n m}$ é o delta de Kronecker, o qual tem valor 1 se e somente se $m=n$ e zero caso contrário. Desta forma, considera-se o ruído independente, e uma matriz diagonal é adicionada.

Para a análise das funções de covariância, ao invés da forma geral (função $C$ com adição de ruído) são analisadas as propriedades dos diferentes kernels $k$. A Tabela 1 apresenta os kernels mais comumente aplicados em processo Gaussianos. A variável $r=\left|\mathbf{x}-\mathbf{x}^{\prime}\right|$ é a medida de distância da entrada, e $l$ é o hiperparâmetro referente à escala de comprimento característica (characteristic lenght-scale).

A função mais adotada na literatura de processos Gaussianos é a Squared Exponential. Ela gera uma distribuição com formato Gaussiano, similar às funções de base radial utilizada em outras metodologias de modelagem. Essa função de covariância é infinitamente diferenciável, ou seja, o processo Gaussiano que emprega essa função possui derivadas de todas as ordens, o que a caracteriza como muito suave. A função de covariância Squared Exponential geralmente é implementada em uma forma anisotrópica (Equação 
Tabela 1 - Principais kernels aplicados a processos Gaussianos.

\begin{tabular}{cl}
\hline Kernel & Expressão \\
\hline Squared Exponential & $k_{S E}(r)=\exp \left(-\frac{r^{2}}{2 l^{2}}\right)$ \\
Matérn & $k_{\text {Matern }}(r)=\frac{2^{1-v}}{\Gamma(\mathbf{v})}\left(\frac{\sqrt{2 \mathbf{v} r}}{l}\right)^{v} \mathbf{K}_{v}\left(\frac{\sqrt{2 \mathbf{v}} r}{l}\right)$ \\
Exponencial & $k(r)=\exp \left(-\frac{r}{l}\right)$ \\
$\gamma$-Exponentcal & $k(r)=\exp \left(-\left(\frac{r}{l}\right)^{\gamma}\right)$ \\
Rational Quadratic & $k_{R Q}(r)=\left(1+\frac{r^{2}}{2 \alpha l^{2}}\right)^{-\alpha}$ \\
\hline Fonte: (THOMPSON, 2009)
\end{tabular}

Fonte: (THOMPSON, 2009)

(3.38)), na qual a cada dimensão da entrada $(D)$, pode ser atribuído um hiperparâmetro $l_{D}$ diferente, de forma a controlar a escala de comprimento característica de cada dimensão.

$$
C\left(\mathbf{x}, \mathbf{x}^{\prime} ; \boldsymbol{\theta}\right)=\theta_{1} \exp \left[-\frac{1}{2} \sum_{d=1}^{D} \frac{\left(x_{d}-x_{d}^{\prime}\right)^{2}}{2 l_{d}^{2}}\right]+\theta_{2}
$$

na qual $x_{d}$ é o $d$-ésimo elemento do vetor de dimensão $D \mathbf{x}$, e os hiperparâmetros $\boldsymbol{\theta}=$ $\left(\theta_{1}, \theta_{2}, l_{d}\right)$. Percebe-se que o hiperparâmetro $\theta_{1}$ define a escala vertical das possíveis variações da função, enquanto $\theta_{2}$ permite que toda a função seja deslocada de zero por algum valor. Os hiperparâmetros de cada dimensão de entrada $l_{d}$ e determinam a distância em uma direção particular sobre a qual a saída $y$ varia significativamente. Dessa forma, se uma determinada dimensão da entrada receber um valor de $l_{d}$ muito grande, percebe-se que esta não será relevante, ou não contribuirá, com a saída $y$. Essa característica é aproveitada por uma técnica de otimização da estrutura do modelo chamada Deteç̧ão Automática de Relevância (Automatic Relevance Detection) introduzida por Mackay (1994), Neal (1996), que, através da otimização dos hiperparâmetros, é possível verificar a relevância de cada entrada, e, quando se mostrarem pouco relevantes, a estrutura do modelo pode ser modificada de modo a removê-la, o que, além de fornecer uma informação importante sobre o comportamento do processo, traz também economia computacional.

De maneira geral, o uso da função de covariância squared exponential implica na suposição de que a função identificada possui comportamento suave e contínuo, com alta correlação entre saídas e entradas próximas. Esta é uma suposição forte, que deve ser fundamentada em conhecimentos prévios do processo ou em dados empíricos.

Diferentemente da squared exponential, a classe de funções de covariância Matérn permite um certo controle sobre a diferenciabilidade da probabilidade a priori de processos Gaussianos. A descrição desta classe de funções pode ser vista na Tabela 1, na qual v 
e $l$ são parâmetros positivos, e $\mathbf{K}_{v}$ é uma função de Bessel modificada. O parâmetro $\mathbf{v}$ controla a diferenciabilidade das funções amostradas. Com $\mathbf{v} \rightarrow \infty$, a função Matérn se aproxima da squared exponential. No trabalho de Rasmussen e Williams (2006), o autor indica que os casos mais interessantes para problemas de aprendizado de máquina são quando $\mathbf{v}=3 / 2$ e $\mathbf{v}=5 / 2$, pois valores $\mathbf{v}<1 / 2$ produzem funções muito bruscas, e valores de $\mathbf{v} \geq 3 / 2$ não apresentam mudança perceptível, até mesmo em relação a $\mathbf{v} \rightarrow \infty$.

$$
\begin{aligned}
& k_{v=3 / 2}(r)=\left(1+\frac{\sqrt{3} r}{l}\right) \exp \left(-\frac{\sqrt{3} r}{l}\right) \\
& k_{v=5 / 2}(r)=\left(1+\frac{\sqrt{5} r}{l}+\frac{5 r^{2}}{l^{2}}\right) \exp \left(-\frac{\sqrt{5} r}{l}\right)
\end{aligned}
$$

No caso em que $\mathbf{v}=1 / 2$, a função Matérn pode ser considerada equivalente à função Exponencial, que produz resultados altamente não-suaves. Outra classe de funções listada anteriormente é a $\boldsymbol{\gamma}$-Exponencial. Essa função é equivalente à squared exponential quando $\gamma=2$, mas não é MS diferenciável quando $\gamma<2$, sendo, portanto, menos flexíveis do que a classe Matérn (RASMUSSEN; WILLIAMS, 2006).

A função de covariância Quadrática Racional pode ser entendida como uma soma infinita de funções squared exponential com valores de escala de comprimento característica e também exibe a mesma propriedade de diferenciabilidade infinita.

A função de covariância não-estacionária mais simples, conforme Mackay (1998), é representada por uma tendência linear:

$$
k_{l i n}\left(\mathbf{x}, \mathbf{x}^{\prime} ; \sigma_{w}, \sigma_{c}\right)=\sum_{d=1}^{D} \sigma_{w}^{2} x_{d} x_{d}^{\prime}+\sigma_{c}^{2}
$$

Essa função de covariância linear pode ser generalizada para um produto escalar, conforme mostrado em Rasmussen e Williams (2006):

$$
k_{\text {lin }}\left(\mathbf{x}, \mathbf{x}^{\prime}\right)=\left(\mathbf{x} \cdot \mathbf{x}^{\prime}\right)=\left(\sum_{d=1}^{D} x_{d} x_{d}^{\prime}\right)^{p}
$$

Este tipo de polinômio não é exatamente útil para problemas de regressão, já que a variância a priori cresce rapidamente com o crescimento de $|\mathbf{x}|$, para $|\mathbf{x}|>1$. Entretanto, este se mostrou efetivo em problemas de classificação de muitas dimensões, na qual os dados de entradas são binários ou normalizados para $[-1,1]$ (SCHOLKOPF; SMOLA, 2002).

Uma das suposições das funções de covariância estacionárias discutidas anteriormente é que a escala de comprimento característica é fixa em todas as direções. Isto não acontece para todos os sistemas, e uma função de covariância não-estacionária que 
possibilite a variação da escala de comprimento característica foi proposta em Gibbs (1997). Essa função de covariância com escala de comprimento variável no espaço, vista na Equação (3.43), define uma função $l_{d}(x)$ positiva no espaço:

$$
k\left(\mathbf{x}, \mathbf{x}^{\prime}\right)=\prod_{d=1}^{D}\left(\frac{2 l_{d}(x) l_{d}\left(x^{\prime}\right)}{l_{d}(x)+l_{d}\left(x^{\prime}\right)}\right)^{1 / 2} \exp \left(-\sum_{d=1}^{D} \frac{\left(x_{d}-x_{d}^{\prime}\right)^{2}}{l_{d}(x)^{2}+l_{d}\left(x^{\prime}\right)^{2}}\right)
$$

Uma alternativa para funções de covariância não-estacionárias é a função de covariância baseada em redes neurais apresentada em Williams (1998), baseada na pesquisa de redes neurais Bayesianas de Neal (1996). Para sua aplicação, o vetor de entradas é aumentado, sendo $\tilde{\mathbf{x}}=\left(1, x_{1}, \cdots, x_{d}\right)^{T}$, e a função de transferência das camadas ocultas é a função erro de Gauss $h(z)=\operatorname{erf}(z)$, ao invés de uma função sigmoide mais comum, pois esta não é positiva semi-definida.

$$
k_{N} N\left(\mathbf{x}, \mathbf{x}^{\prime}\right)=\frac{2}{\pi} \sin \left(\frac{2 \tilde{\mathbf{x}}^{T} \boldsymbol{\Sigma} \tilde{\mathbf{x}}^{\prime}}{\left(1+2 \tilde{\mathbf{x}^{T}} \boldsymbol{\Sigma} \tilde{\mathbf{x}}\right)\left(1+2 \tilde{\mathbf{x}}^{T} \boldsymbol{\Sigma} \tilde{\mathbf{x}^{\prime}}\right)}\right)
$$

Essa função de covariância também pode ser aplicada em problemas com escala de comprimento específica variável no espaço de entradas, tendo sido aplicada com sucesso em problemas de dados com degraus estáticos (RASMUSSEN; WILLIAMS, 2006).

\subsection{Otimização dos Hiperparâmetros}

Devido à característica probabilística do modelo GP, a técnica na qual os parâmetros do modelo e possivelmente também sua estrutura são otimizados através da minimização de uma função custo definida em termos do erro do modelo, não podem ser aplicados diretamente. Como o processo Gaussiano foi descrito como um método probabilístico Bayesiano, uma abordagem probabilística para a otimização do modelo é apropriada, ou seja, ao invés de minimizar o erro do modelo, a probabilidade do modelo é maximizada. Após a seleção de uma função de covariância adequada, os hiperparâmetros dessa função devem ser otimizados para que as correlações presentes nos dados de treinamento sejam caracterizadas de maneira precisa.

A etapa de otimização dos parâmetros corresponde à primeira etapa da inferência Bayesiana. Como foi visto anteriormente, para se obter uma distribuição a posteriori, é necessário integrar o modelo sobre os parâmetros. Essa integração pode se mostrar intratável, e são necessários métodos numéricos para realizar uma aproximação. Para uma aproximação precisa, o custo computacional dessas técnicas é elevado. Uma alternativa é a utilização de técnicas baseadas na otimização da Máxima Verossimilhança (Maximum Likelihood), e pode ser aplicada na otimização da verossimilhança marginal (Marginal Likelihood). Ao se buscar os hiperparâmetros que maximizam a probabilidade dos dados 
de treinamento, as propriedades do Prior do processo Gaussiano, que será utilizado para gerar uma nova distribuição preditiva, são otimizadas.

O método de maximização da verossimilhança marginal (Marginal Likelihood Maximisation) é baseado na aplicação da inferência Bayesiana, e é conhecido também como maximização da evidência (Evidence Maximisation), como visto em Mackay (1992), Rasmussen (1996), Gibbs (1997). Essa técnica dispensa o uso de técnicas custosas computacionalmente, realizando a aproximação da integral utilizando os valores mais prováveis para os hiperparâmetros $\boldsymbol{\theta}_{M P}$.

$$
P\left(t_{N+1} \mid \mathbf{t}_{N}, \mathbf{X}_{N}, \mathbf{x}_{N+1}\right) \simeq P\left(t_{N+1} \mid \boldsymbol{\theta}_{M P}, \mathbf{t}_{N}, \mathbf{X}_{N}, \mathbf{x}_{N+1}\right)
$$

A base para essa aproximação é a suposição de que a distribuição a posteriori $P\left(\theta \mid t_{N}, X_{N}\right)$ possui picos acentuados em torno de $\boldsymbol{\theta}_{M P}$ relativos à variações na distribuição $P\left(t_{N+1} \mid t_{N}, X_{N}, x_{N+1}, \theta\right)$. Dessa forma, essa técnica de otimização depende da identificação dos parâmetros mais prováveis a partir dos dados, através da distribuição a posteriori $P\left(\theta \mid t_{N}, X_{N}\right)$, obtida através da aplicação do Teorema de Bayes, conforme Equação (3.46).

$$
P\left(\boldsymbol{\theta} \mid \mathbf{t}_{N}, \mathbf{X}_{N}\right) \propto P\left(\mathbf{t}_{N} \mid \mathbf{X}_{N}, \boldsymbol{\theta}\right) P(\boldsymbol{\theta})
$$

na qual $P\left(\mathbf{t}_{N} \mid \mathbf{X}_{N}, \boldsymbol{\theta}\right)$ é a verossimilhança marginal e $P(\boldsymbol{\theta})$ é uma probabilidade a priori sobre os hiperparâmetros. O sinal de proporcionalidade foi utilizado pois o denominador do teorema de Bayes é independente dos hiperparâmetros.

Esta técnica de determinação dos hiperparâmetros oferece diversas vantagens significativas em relação a outros métodos de seleção e de otimização de modelos adotadas por outras abordagens de modelagem. Ao se realizar a otimização utilizando a análise da verossimilhança marginal, segundo Thompson (2009), automaticamente se aplica a Navalha de Occam (Occam's Razor), que diz que na presença de diversos modelos ou hipóteses, não devem ser feitas mais suposições do que o necessário, o que leva a uma preferência por soluções mais simples, o que regula a complexidade do modelo e ameniza os efeitos do overfitting.

O componente verossimilhança marginal da função anterior já foi mostrado na Equação (3.29). Ignorando a probabilidade a priori sobre os hiperparâmetros $P(\boldsymbol{\theta})$, é possível reescrever a verossimilhança marginal como uma função custo que será maximizada. O log da verossimilhança marginal é utilizado para ajuste de escala numérica.

$$
L(\boldsymbol{\theta})=-\frac{1}{2} \log \left(\left|\mathbf{C}_{N}\right|\right)-\frac{1}{2} \mathbf{t}_{N}^{T} \mathbf{C}_{N}^{-1} \mathbf{t}_{N}-\frac{N}{2} \log (2 \pi)
$$

Os três componentes do log da verossimilhança marginal possuem funções interpretáveis, conforme descreve Rasmussen e Williams (2006). O único componente que inclui os 
dados observados é $-\frac{1}{2} \mathbf{t}_{N}^{T} \mathbf{C}_{N}^{-1} \mathbf{t}_{N}$, e é uma medida de ajuste dos dados ao modelo; o termo $-\frac{1}{2} \log \left(\left|\mathbf{C}_{N}\right|\right)$ só depende da escolha da função de covariância e dos dados de entrada, e pode ser interpretado como uma penalidade por complexidade, enquanto que o termo $-\frac{N}{2} \log (2 \pi)$ é uma constante normalizadora.

A próxima etapa é buscar o máximo ou mínimo dessa função custo, e, dessa forma, encontrar os hiperparâmetros mais prováveis. Como busca-se encontrar o máximo do log da verossimilhança marginal, este processo é semelhante à busca da estimativa do Máximo a posteriori (MAP) dessa distribuição. Sendo assim, busca-se as derivadas parciais da verossimilhança marginal em relação aos hiperparâmetros, como visto na Equação (3.48):

$$
\frac{\partial L}{\partial \theta}=-\frac{1}{2} \operatorname{tr}\left(\mathbf{C}_{N}^{-1} \frac{\partial \mathbf{C}_{N}}{\partial \theta}\right)+\frac{1}{2} \mathbf{t}_{N}^{T} \mathbf{C}_{N}^{-1} \frac{\partial \mathbf{C}_{N}}{\partial \theta} \mathbf{C}_{N}^{-1} \mathbf{t}_{N}^{T}
$$

Para realizar o cálculo desses gradientes, um algoritmo local de otimização deve ser utilizado. Além disso, nota-se que o cálculo dessa derivada depende de um cálculo eficiente da inversa da matriz de covariância, já que a inversão de matrizes grandes é custosa computacionalmente. Dessa forma, o tamanho do conjunto de dados não deve ser grande a ponto de tornar essa inversão inviável. Para essa otimização não-linear, o método do gradiente conjugado pode ser aplicado para encontrar os máximos locais do log da verossimilhança marginal. Comparado com outras técnicas de aproximação de integrais, esses métodos podem encontrar aproximações razoáveis para um máximo local com poucas avaliações da função e do gradiente (THOMPSON, 2009). 



\section{Modelagem e controle de velocidade de um veículo de grande porte utilizando GPs}

Para verificar o potencial dos processos Gaussianos em problemas de identificação de sistemas, foi realizado um estudo de caso, no qual as técnicas de modelagem discutidas anteriormente foram aplicadas em um sistema real.

O interesse em modelagem utilizando processos Gaussianos para a identificação de sistemas não-lineares surgiram das ideias apresentadas nos trabalhos de Murray-Smith, Johansen e Shorten (1999), Leith, Murray-Smith e Leithead (2000), Leithead, Leith e Murray-Smith (2000), nos quais um método de modelagem não paramétrico foi proposto para a identificação de modelos locais em regiões fora do equilíbrio (onde há poucas informações prévias ou dados), como parte de um sistema multi-modelo. Os processos Gaussianos se tornaram uma alternativa viável para esses sistemas pois, devido à sua natureza probabilística Bayesiana, essa escassez de dados é refletida na aproximação através da variância da saída. Outra característica é que os modelos com processos Gaussianos utilizam todos os dados disponíveis para calcular a saída, pois a matriz de covariância é construída a partir da aplicação da função de covariância diretamente sobre os dados de treinamento, ao invés de depender somente de parâmetros definidos através de otimização. Desta forma, mostrou-se que a utilização de modelos de processos Gaussianos possui bom desempenho na identificação de modelos a partir de conjuntos de dados pequenos (KOCIJAN et al., 2003). Outros trabalhos que abordam a modelagem de sistemas dinâmicos utilizando processos Gaussianos podem ser vistos em Gregorčič e Lightbody (2002), Murray-Smith, Shorten e Leith (2002), Kocijan e Ažman (2007).

\subsection{Modelo Longitudinal de um veículo de grande porte utilizando GPs}

Para sistematizar de maneira prática e verificar o potencial do modelo gerado, a técnica de identificação de sistemas utilizando processos Gaussianos foi aplicada para identificar o modelo longitudinal de um veículo terrestre de grande porte. Atualmente, a indústria automotiva tem incentivado o desenvolvimento de conceitos avançados que podem levar a um controle de tráfego mais eficiente (LU; HEDRICK, 2003). Neste sentido, o controle de veículos tem sido estudado por vários anos, e em diversas áreas, como: Autoestradas automatizadas (automated highway system, AHS) (IOANNOU, 1997), controle de estabilidade de veículos (HEBDEN; EDWARDS; SPURGEON, 2004), e também diversas formas de assistência ao motorista. Alguns resultados destas pesquisas tem sido aplicados 
em sistemas reais de assistência ao motorista, como o controle automático de cruzeiro (automatic cruise control, ACC), controle de rolagem e assistente de estacionamento.

Neste cenário, os veículos pesados são grandes candidatos à implantação de sistemas totalmente automatizados, (U. S. Department of Transportation, 1999), (BISHOP, 2000). Dessa forma, os laboratórios de Sistemas Inteligentes (Eng. Elétrica - EESC) e de Robótica Móvel (ICMC), á partir do conhecimento gerado pelo projeto CARINA2 (Carro Robótico Inteligente para Navegação Autônoma) (LRM - ICMC - USP, 2012), estão desenvolvendo o projeto S-Truck, em que diversas dessas aplicações serão desenvolvidas e testadas em um veículo de grande porte, visto na Figura 5.

\section{Figura 5 - Veículo do projeto Carina 3.}

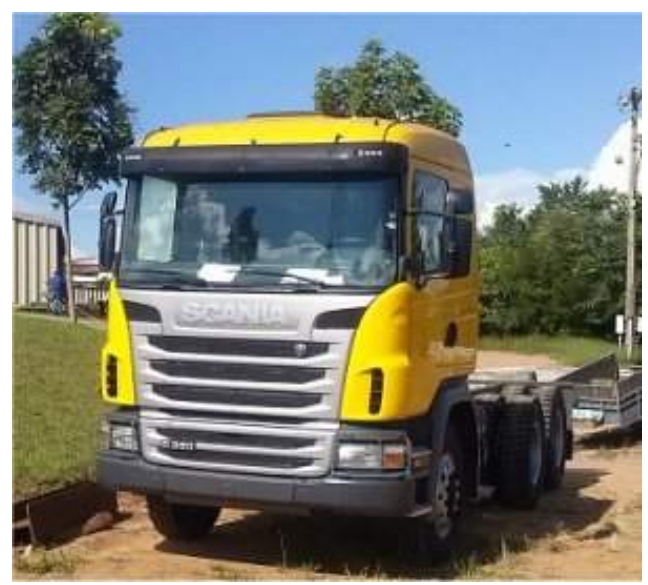

Fonte: (LRM - ICMC - USP, 2012).

A automatização de veículos de grande porte é absolutamente necessária na prática. Ela pode aliviar de maneira significativa a fadiga do condutor, reduzindo a quantidade de acidentes (LU; HEDRICK, 2003). Grande parte das pesquisas envolvendo veículos de grande porte são na área de pelotões em alta velocidade (RAJAMANI et al., 2000; YANAKIEV; KANELLAKOPOULOS, 2001), Controle de cruzeiro adaptativo (adaptive cruise control) (LIANG; PENG, 1999), e estabilidade de fila (string stability) (SWAROOP; HEDRICK, 1996). A utilização de veículos de grande porte em pelotões pode reduzir o arrasto aerodinâmico dos veículos seguidores através da redução da distância entre os veículos, trazendo economia de combustível e segurança. Entretanto, diversos problemas complexos surgem na modelagem e controle dos sistemas dinâmicos do veículo (BU; TAN, 2007).

Os diversos sistemas citados anteriormente realizam o controle da velocidade dos veículos, atuando tanto no controle do motor/fluxo de combustível, quanto no sistema de frenagem, fazendo com que estes mantenham a aceleração desejada. Este controle é chamado de controle longitudinal. 
Em geral, quatro fatores principais afetam o projeto, desempenho e robustez de sistemas de controle: imprecisões no modelo, ruído nas medições, atrasos de tempo e perturbações externas. Pequenos erros no modelo possibilitam uma ampla margem de estabilidade robusta, que pode ser percebida através do tempo de resposta e do erro de seguimento de referência de um sistema de controle, entre outras características desejadas. Porém, para que isso seja possível, o modelo deve ser complexo o suficiente para capturar todos os detalhes da dinâmica do veículo, o que geralmente leva a modelos de ordens elevadas e altamente não-lineares. Entretanto, é necessário que o modelo seja simples o suficiente para o projeto e síntese de sistemas de controle (LU; HEDRICK, 2003).

Já foi comprovado que o problema de controle longitudinal em veículos pesados é bastante diferente de veículos comuns de passageiros (CHO; HEDRICK, 1989; HEDRICK, 1998). As principais diferenças são relacionadas à dinâmica dos veículos, que afetam diretamente a modelagem e o projeto do controle. De fato, o controle longitudinal e de pelotão de veículos pesados é mais complicado, devido a essas características:

- Baixa relação potência/peso: a variável de controle de fluxo de combustível satura facilmente, e a capacidade de aceleração do veículo é bastante limitada. Esta é a principal dificuldade no projeto de controladores.

- Grandes atrasos nos atuadores: Os atrasos aparecem tanto no controle do acelerador quanto no controle do sistema de freios.

- Massa dominante: O termo $m g h \sin \theta$ aparece na dinâmica do veículo. Devido à grande massa do veículo, uma pequena variação na inclinação $\theta$ causa uma variação grande no torque requerido (BU; TAN, 2007).

O veículo a ser modelado, mostrado na Figura 5, possui $7 \mathrm{~m}$ de comprimento e massa de aproximadamente 9 toneladas. O sistema de tração conta com um motor de 12.7 litros, que produz a potência máxima de $360 \mathrm{cv}$, torque máximo de $1850 \mathrm{Nm}$, e caixa de câmbio automatizada com 14 velocidades. O sistema de frenagem é composto por freio motor e também por freios pneumáticos a tambor.

A partir dessas informações, percebe-se que a modelagem precisa das dinâmicas do veículo auxiliam no projeto e desempenho de controladores. A modelagem tradicional torna-se muito complexa, devido à complexidade de construção do veículo em si, que é composto de motor a diesel, compressor, conversor de torque, transmissão, diferenciais, entre outros. O sistema de frenagem também possui diversos componentes como freio pneumático, freio motor, freio de estacionamento, entre outros. Portanto, para a modelagem satisfatória desses sistemas, serão aplicadas técnicas de identificação empírica de sistemas, na qual os dados experimentais coletados do funcionamento do veículo serão utilizados para a construção de um modelo. 


\subsubsection{Implementação do modelo com Processos Gaussianos}

No desenvolvimento de um modelo matemático adequado, uma das etapas fundamentais do processo de identificação de sistemas é a seleção apropriada da ordem do modelo. Como o modelo GP é não-paramétrico, essa etapa não é necessária, pois o modelo é totalmente definido através da seleção de uma função de covariância apropriada associada a um conjunto de dados de treinamento adequado. A escolha da função de covariância impacta significativamente em quais tipos de não-linearidades o modelo resultante será capaz de representar, enquanto que o projeto do conjunto de treinamento tem influência direta sobre a precisão do modelo identificado.

Para a função de covariância, qualquer função que resulte em uma matriz de covariância positiva semi-definida pode ser aplicada. No método de modelagem utilzando processos Gaussianos, a função de covariância Exponencial Quadrática (Squared Exponencial) é amplamente adotada. A utilização dessa função impõe a suposição de que os dados de entrada e saída a serem modelados variem de maneira suave e consistente, qualidades comuns em sistemas reais de engenharia. Desta forma, para a identificação do modelo longitudinal do veículo descrito anteriormente, essa será a função de covariância utilizada.

O projeto de um conjunto de treinamento adequado é essencial para a identificação bem sucedida de qualquer modelo desenvolvido primariamente a partir de dados empíricos, principalmente em relação ao tamanho e condicionamento da matriz de covariância. Como o tamanho do conjunto de treinamento determina o tamanho da matriz de covariância, para garantir que o modelo GP seja viável computacionalmente, a quantidade de pontos do conjunto de treinamento não deve ser muito grande. Dessa forma, a taxa de amostragem e o sinal de excitação devem ser escolhidos com cautela.

Para construção do conjunto de treinamento, foram realizados testes com o veículo em funcionamento no câmpus 2 da USP São Carlos. Os dados de funcionamento do veículo foram obtidos através da rede CAN (Controller Area Network) deste, acessada através de um nó implementado no software ROS, um conjunto de ferramentas para implementação de sistemas robóticos (Open Source Robotics Foundation, 2015). Através dessa interface, foram capturadas a velocidade do veículo, os sinais de comando do acelerador e do freio, velocidade de rotação do motor e marcha atual. Para capturar a inclinação da via, foi utilizada uma unidade de medida inercial modelo MTi-100, da fabricante Xsens. Todos os dados foram capturados com frequência de amostragem de $5 \mathrm{~Hz}$.

Para aplicação dos comandos de aceleração e frenagem, ou seja, dos sinais de excitação do sistema, um nó ROS foi criado que permitiu a aplicação de sinais do tipo degrau. Esse sinal de comando recebe valores no intervalo $[-1,1]$, sendo os valores positivos comandos de aceleração e os valores negativos comandos de frenagem. Para avaliação do efeito de sinais de excitação diferentes, foram capturados três conjuntos de dados: 
1. DS1 - Funcionamento normal do veículo, em que este era controlado pelo motorista como se estivesse em uma situação normal de trânsito;

2. DS2 - Diversos degraus consecutivos, aplicados pelo motorista;

3. DS3 - Um único degrau, aplicado através do nó ROS.

Para verificar o funcionamento adequado do modelo identificado, é necessário realizar a etapa de validação cruzada, utilizando um conjunto de dados de teste diferente dos dados de treinamento. Para essa etapa, foi utilizada a técnica de validação $n$-fold explicado anteriormente, dividindo os conjuntos de dados em 10 partições $(n=0)$. Para quantizar o desempenho do modelo, é possível utilizar diversas medidas diferentes, sendo as mais comuns aquelas relacionadas diretamente ao erro do modelo, como o erro quadrático médio (Mean Square Error) e o erro quadrático médio relativo (Mean Relative Square Error), mas também é possível aplicar medidas mais voltadas à probabilidade, como a Negative Log Predictive Density (NLPD) e Negative Log-Likelihood (LL) (GELMAN et al., 2013). Para esta etapa, foi utilizada a medida da raiz do erro quadrático médio, conforme Equação (4.1):

$$
R M S E=\sqrt{\frac{1}{N} \sum_{i=1}^{N} e_{i}^{2}}
$$

na qual $e_{i}=\hat{y}_{i}-y_{i}$ é o erro de previsão do modelo para o i-ésimo caso do conjunto de treinamento de tamanho $N$.

Em conjunto com essas medidas quantitativas do desempenho do modelo, é necessário também avaliá-lo de maneira qualitativa, de forma a certificar que o modelo atende ao propósito com que foi idealizado. Dessa forma, aspectos como a interpretabilidade do modelo podem ser avaliados. Dessa forma, associada com uma avaliação criteriosa do erro de previsão, a variância pode fornecer informações valiosas a respeito do funcionamento local em regiões específicas do espaço de operação do sistema.

\subsubsection{Resultados do processo de modelagem}

O modelo a ser construído visa prever a velocidade do veículo baseado em um conjunto de entrada com informações do funcionamento atual do veículo. Para analisar os efeitos que as diferentes informações do veículo causam sobre a precisão do modelo, para cada conjunto de dados, foram construídos quatro modelos:

- Modelo 1: Previsão da velocidade $\left(v_{n+1}\right)$ a partir da velocidade anterior $\left(v_{n}\right)$, ou seja, $v_{n+1}=f\left(v_{n}\right)$. Modelo utilizado como parâmetro de comparação para os outros; 
Figura 6 - Informações do conjunto de dados DS1.

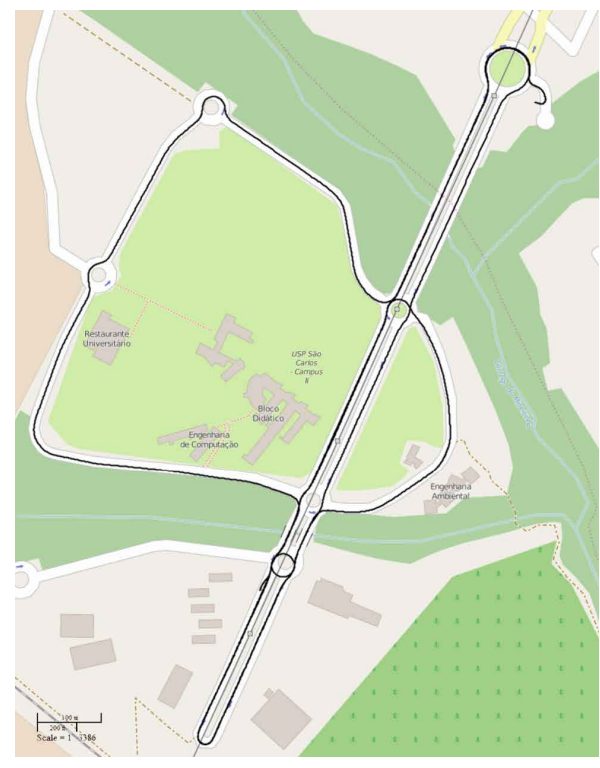

(a) Trajetória do Veículo
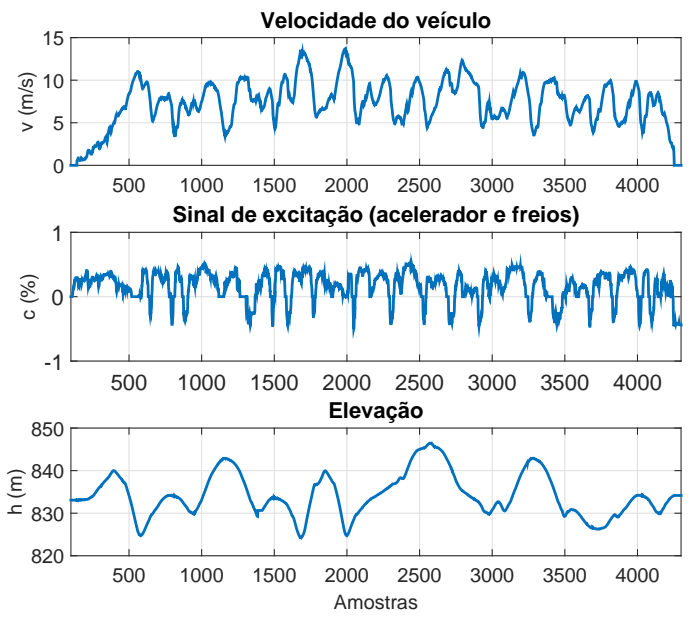

(b) Dados capturados do veículo.

Fonte: O autor.

- Modelo 2: Previsão da velocidade a partir da velocidade anterior e do comando de aceleração e frenagem $(c)$, ou seja, $v_{n+1}=f\left(v_{n}, c\right)$;

- Modelo 3: Previsão da velocidade a partir da velocidade anterior, do comando de aceleração e frenagem e da inclinação da via $(\alpha)$ ou seja, $v_{n+1}=f\left(v_{n}, c, \alpha\right)$;

- Modelo 4: Previsão da velocidade a partir da velocidade anterior, do comando de aceleração e frenagem e da inclinação da via e da marcha atual do veículo $(G)$ ou seja, $v_{n+1}=f\left(v_{n}, c, \alpha, G\right)$;

Na Figura 6 é possível visualizar a trajetória do veículo pelo câmpus 2 da USP São Carlos durante a captura do conjunto de dados DS1, bem como algumas informações a respeito do funcionamento do veículo e também da topografia do trajeto.

O conjunto de treinamento possui $N=4500$ amostras, um número elevado, considerando-se as recomendações de Gibbs (1997) e a complexidade computacional $O\left(N^{3}\right)$ estimada por Rasmussen e Williams (2006), de forma que o treinamento desses modelos levaram um tempo considerável (em torno de 30 segundos para cada iteração da função de otimização), mostrando um dos potenciais problemas que esta técnica apresenta. Os modelos treinados, após a etapa de validação, apresentaram os erros quadráticos médios mostrados na Tabela 2. Percebe-se que de maneira geral, o modelo treinado apresenta uma precisão satisfatória, possuindo erro quadrático médio de aproximadamente 4,8\%. Percebese ainda que a adição dos comandos de aceleração e frenagem e também a inclinação da via como entradas para o modelo proporcionam uma melhora significativa da resposta. 
Tabela 2 - Erro quadrático médio dos modelos propostos utilizando o conjunto de treinamento DS1.

\begin{tabular}{ll}
\hline Modelo & RMSE \\
\hline Modelo 1 & 0,064 \\
Modelo 2 & 0,054 \\
Modelo 3 & 0,050 \\
Modelo 4 & 0,048 \\
\hline
\end{tabular}

Na Figura 7 pode-se observar o desempenho do Modelo 4 através de sua saída. Percebe-se que a saída estimada (linha sólida vermelha) acompanha a saída medida (linha azul tracejada). Como o conjunto de dados DS1 possui muitas amostras, e todas estão dentro do mesmo espaço de operação que o conjunto de treinamento, a variância é pequena e, consequentemente, o desvio padrão da saída estimada, representado pela área sombreada para um intervalo de confiança de 95\%, também é pequeno. Na figura aproximada, percebe-se que a saída medida se encontra dentro da região sombreada, o que significa que, considerando a incerteza do modelo, este representa o comportamento do sistema de maneira fiel.

Figura 7 - Saída estimada do Modelo 4, treinado conjunto de dados DS1.

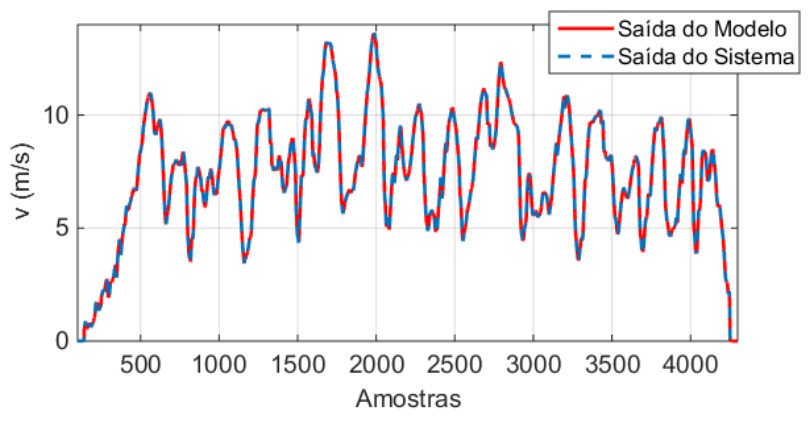

(a) Velocidade estimada.

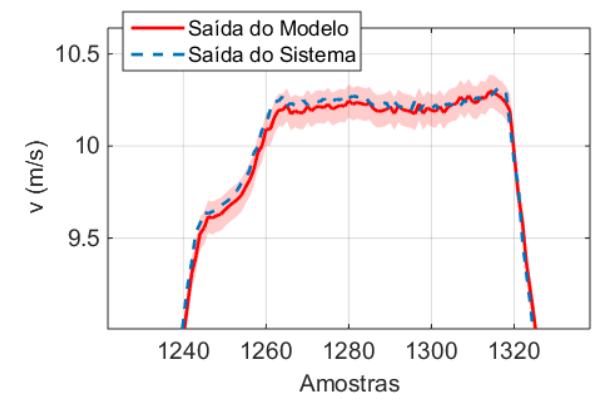

(b) Detalhe da velocidade estimada, mostrando o desvio padrão (área sombreada).

Fonte: $\mathrm{O}$ autor.

Para o conjunto de dados DS2, a velocidade do veículo, bem como os comandos de aceleração e frenagem podem ser vistos na Figura 8. Percebe-se no comando de entrada, aplicado pelo motorista, os diversos degraus, tanto positivos (aceleração forte) seguido de degrau negativo (frenagem forte) até a parada do veículo, o que pode ser visto refletido na velocidade do veículo. Percebe-se também, nos instantes de aceleração, que as trocas de marcha impactam de maneira perceptível a velocidade, principalmente em trechos de 
subida, devido ao peso elevado do veículo.

Figura 8 - Dados do conjunto de treinamento DS2.
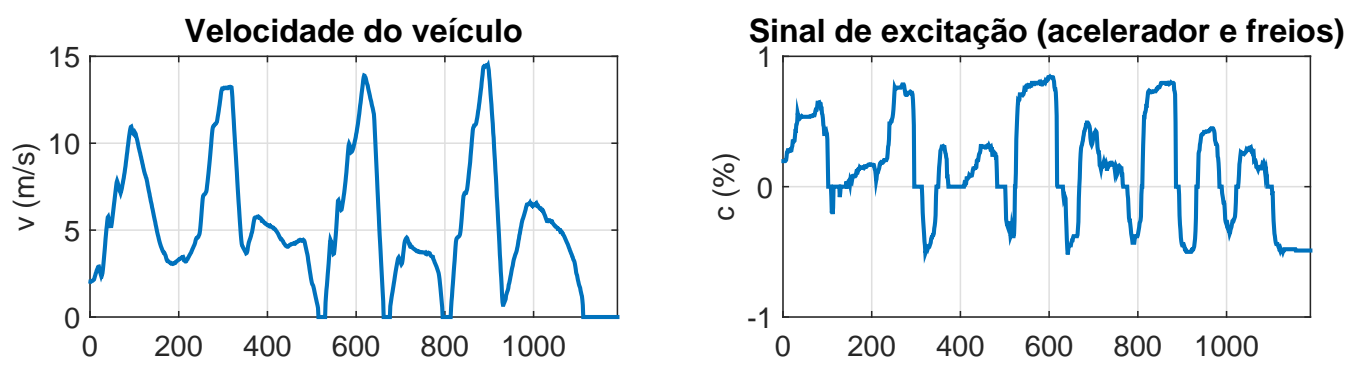

Fonte: O autor.

Os modelos treinados utilizando o conjunto de treinamento DS2 apresentam os erros quadráticos médios mostrados na Tabela 3. Percebe-se, para esse conjunto de treinamento, que o sistema possui desempenho inferior ao conjunto de treinamento 1 , o que pode ser reflexo da quantidade inferior de amostras $(N \approx 1100)$, mas que teve um impacto positivo em relação ao tempo de treinamento, levando cerca de 1 segundo por iteração da função de otimização.

Tabela 3 - Erro quadrático médio dos modelos propostos utilizando o conjunto de treinamento DS2.

\begin{tabular}{cc}
\hline Modelo & RMSE \\
\hline Modelo 1 & 0,088 \\
Modelo 2 & 0,067 \\
Modelo 3 & 0,058 \\
Modelo 4 & 0,060 \\
\hline
\end{tabular}

Na Figura 9 tem-se a saída do Modelo 4 treinado com o conjunto de dados DS2, em comparação à saída medida do sistema. É possível perceber que o modelo segue o comportamento do sistema de forma satisfatória, e que possui variância pequena em praticamente todo o espaço de operação. Na Figura 9b observa-se uma ampliação do desvio padrão em uma curva de aceleração, no momento de uma troca de marchas. Percebe-se que neste instante ocorre uma pequena quebra na rampa de velocidade, que fica mais acentuada em aclives, como se pode observar no gráfico da velocidade (Figura 9a)entre as amostras 500 e 620 .

Para o teste com o conjunto de treinamento DS3, obervam-se a velocidade do veículo e o sinal de comando de aceleração e frenagem na Figura 10. Nesta, é possível 
Figura 9 - Saída estimada do Modelo 4, treinado com o conjunto de dados DS2.

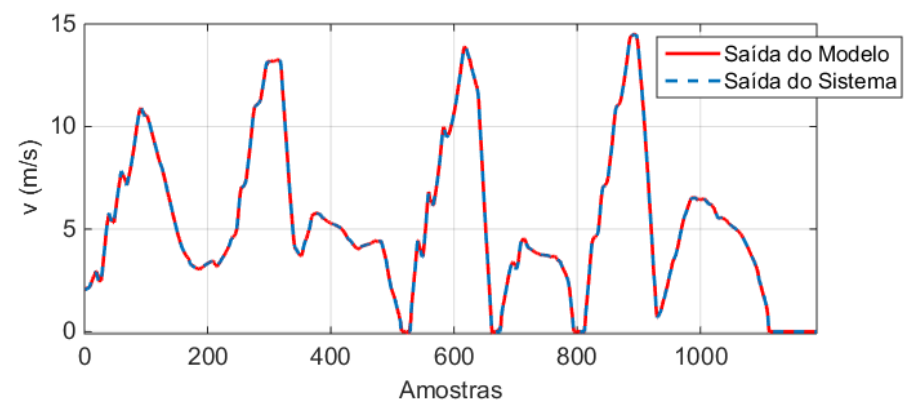

(a) Velocidade estimada.

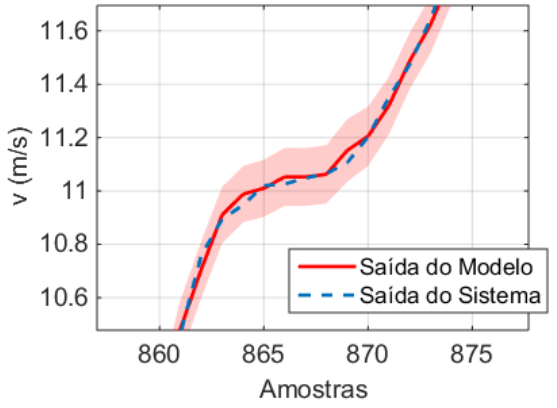

(b) Detalhe da velocidade estimada em uma troca de marcha.

Fonte: O autor.

visualizar de maneira bem definida o comando em degrau aplicado ao acelerador e freios do veículo através do nó ROS, bem como seu comportamento a partir deste sinal de entrada. Percebe-se claramente um dos problemas encontrados na modelagem de veículos de grande porte, que é o atraso dos atuadores. Nota-se que, após a aplicação do sinal de aceleração, a velocidade só começa a subir depois de 2 segundos. Como esse conjunto de treinamento possui poucos dados $(N \approx 200)$, seu treinamento foi rápido, levando em torno de 0,01 segundos para cada iteração da função de otimização.

Figura 10 - Dados do conjunto de treinamento DS3.
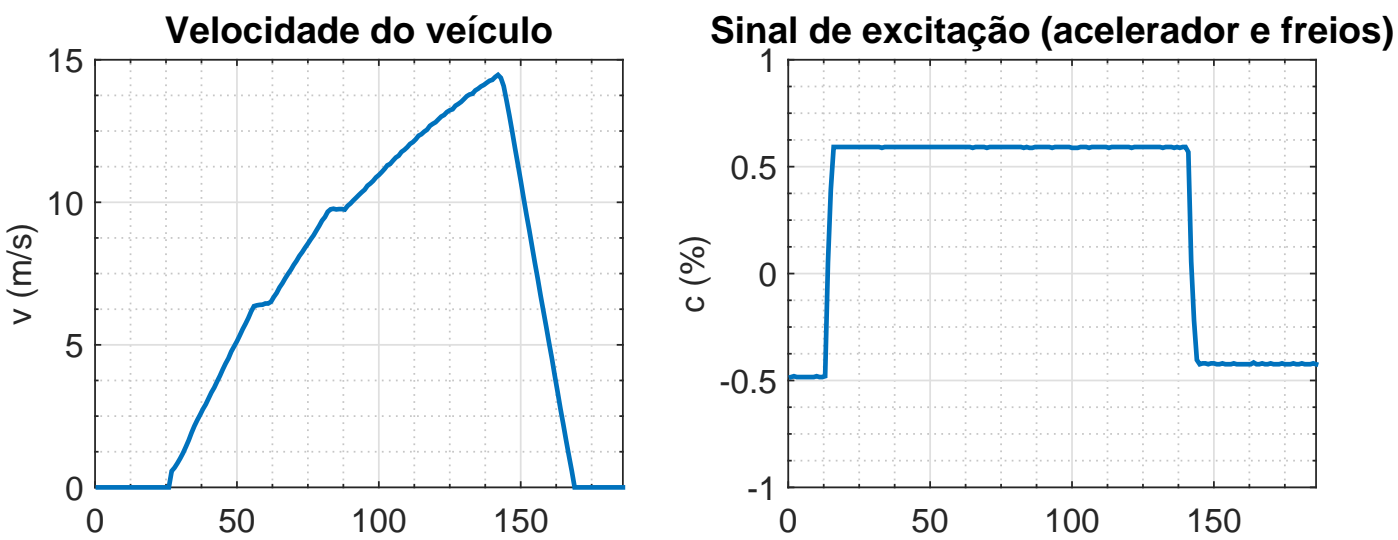

Fonte: $\mathrm{O}$ autor.

Na Tabela 4 é possível visualizar os erros quadráticos médios dos modelos treinados utilizando o conjunto de dados DS3. Verifica-se que a precisão alcançada é alta, pois este apresenta uma resposta ao degrau muito bem comportada (superamortecida), e que a única informação com efeito significativo é o comando de aceleração e frenagem. Diferente dos outros conjuntos de dados, a adição da inclinação da via não proporcionou melhora 
significativa da precisão da saída estimada, pois esse conjunto de dados foi capturado em um trecho relativamente plano do trajeto.

Tabela 4 - Erro quadrático médio dos modelos propostos utilizando o conjunto de treinamento DS3.

\begin{tabular}{cc}
\hline Modelo & RMSE \\
\hline Modelo 1 & 0,119 \\
Modelo 2 & 0,053 \\
Modelo 3 & 0,052 \\
Modelo 4 & 0,051 \\
\hline
\end{tabular}

Na Figura 11 observa-se que o modelo representa de maneira fiel a resposta ao degrau do sistema.

Figura 11 - Saída estimada do Modelo 4, treinado com o conjunto de dados DS3.

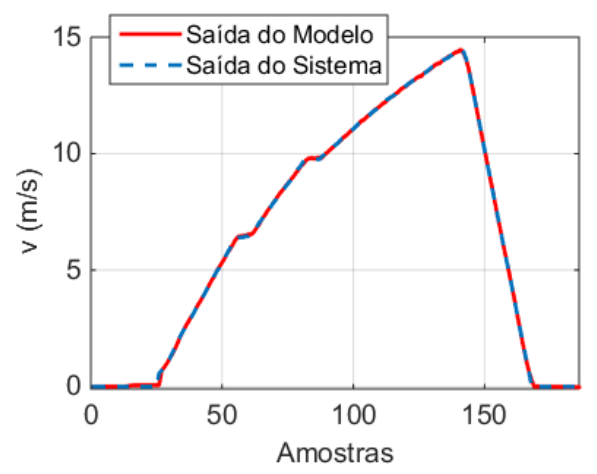

Fonte: O autor.

Para verificar a capacidade de generalização dos modelos treinados, foram realizados testes aplicando-se o conjunto de dados DS1 no modelo treinado utilizando o conjunto de dados DS3, cujo resultado pode ser visto na Figura 12. Percebe-se que o modelo foi capaz de reproduzir razoavelmente o comportamento do sistema, possuindo um erro maior e também uma incerteza maior a respeito da saída em situações de retomadas de velocidade e em desacelerações utilizando somente o freio motor. Ambas as situações não aparecem no conjunto de treinamento, além de não ter observado variações significativas na inclinação da via, o que explica o erro e variância elevada em tais regiões.

Já na Figura 13, que mostra a saída do conjunto de dados DS1 sendo aplicado ao modelo treinado com o conjunto de dados DS2, percebe-se que o modelo reflete o comportamento do sistema de maneira satisfatória, já que foram apresentadas as mesmas situações nos dois conjuntos de dados. 
Figura 12 - Saída do conjunto de dados DS1 em modelo treinado com o conjunto de dados DS3.

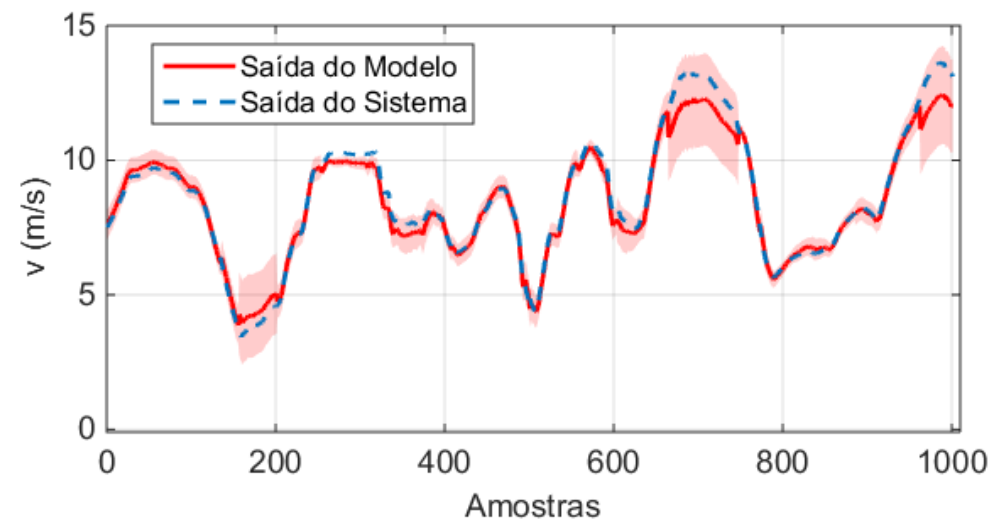

Fonte: $\mathrm{O}$ autor.

Figura 13 - Saída do conjunto de dados DS1 em modelo treinado com o conjunto de dados DS2.

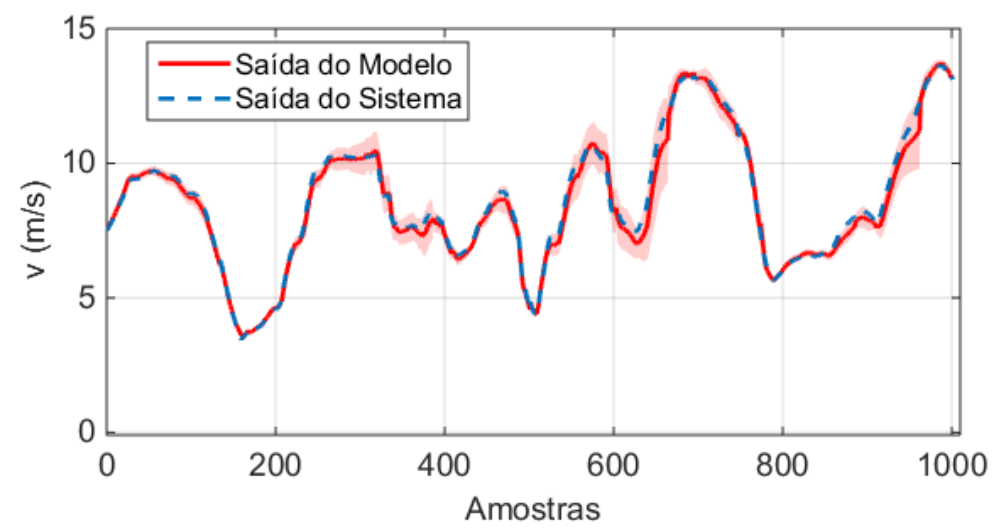

Fonte: $\mathrm{O}$ autor.

Desta forma, percebe-se que modelos construído a partir de dados empíricos empregando-se o método dos processos Gaussianos são uma alternativa viável de técnica não-paramétrica de identificação de sistemas não-lineares, oferecendo ainda diversas simplificações acerca das características de projeto que devem ser escolhidas, se comparada a outras técnicas de identificação de sistemas, além de apresentar informações referentes à incerteza da previsão do modelo, informação esta que pode ser utilizada também para melhorar o próprio modelo. 


\subsection{Controle Preditivo de Velocidade de um veículo de grande porte utilizando modelos GP}

Em controladores projetados a partir do modelo do sistema, o desempenho e robustez do controlador está atrelada diretamente à qualidade do modelo. Para veículos móveis, muitas vezes a modelagem tradicional torna-se muito complexa, devido à complexidade de construção do veículo em si. Portanto, foram aplicadas técnicas de identificação empírica de sistemas, na qual os dados experimentais coletados do funcionamento do veículo foram utilizados para a construção de um modelo. A partir desse modelo, projetou-se um controlador preditivo baseado em modelo (Model Predictive Controller), descrito a seguir.

\subsubsection{Controlador Preditivo Baseado em Modelo}

O termo Model Predictive Control (MPC) é utilizado para se referir a uma ampla gama de controladores que utilizam explicitamente o modelo de um processo para obter o sinal de controle para o sistema através da minimização de uma função objetivo (CAMACHO; ALBA, 2007). As principais características deste tipo de controlador são:

- Uso explícito do modelo para prever a saída do sistema em um horizonte futuro;

- Cálculo de uma sequência de sinais de controle através da otimização de uma função objetivo que mede o desempenho do sistema;

- Estratégia de horizonte deslizante, na qual o horizonte de predição é deslocado para o futuro em cada instante de tempo, e o primeiro elemento da sequência de sinais de controle é aplicado ao sistema.

O apelo desta idéia, a partir da perspectiva de engenharia de controle é óbvio pois fornece uma abordagem sistemática para o projeto de controladores com desempenho ótimo. O MPC é a estratégia de controle moderno mais difundida pois oferece, através da implementação do horizonte deslizante, um compromisso entre a otimalidade e a velocidade de cálculo (KOUVARITAKIS; CANNON, 2016). Um diagrama de blocos desta estratégia de controle pode ser vista na Figura 14.

Os benefícios do controle ótimo são, entretanto, difíceis de se obter no caso de sistemas com modelos não-lineares ou com restrições nas variáveis de entrada ou nos estados do modelo, características presentes na maioria dos sistemas reais. Para ambos os casos, geralmente, não é possível derivar expressões analíticas para a solução do controle ótimo, sendo necessária a utilização de métodos (numéricos) iterativos de otimização.

Para resolver o problema de controle MPC, é necessário definir alguns elementos: 
Figura 14 - Model-based Predictive Controller.

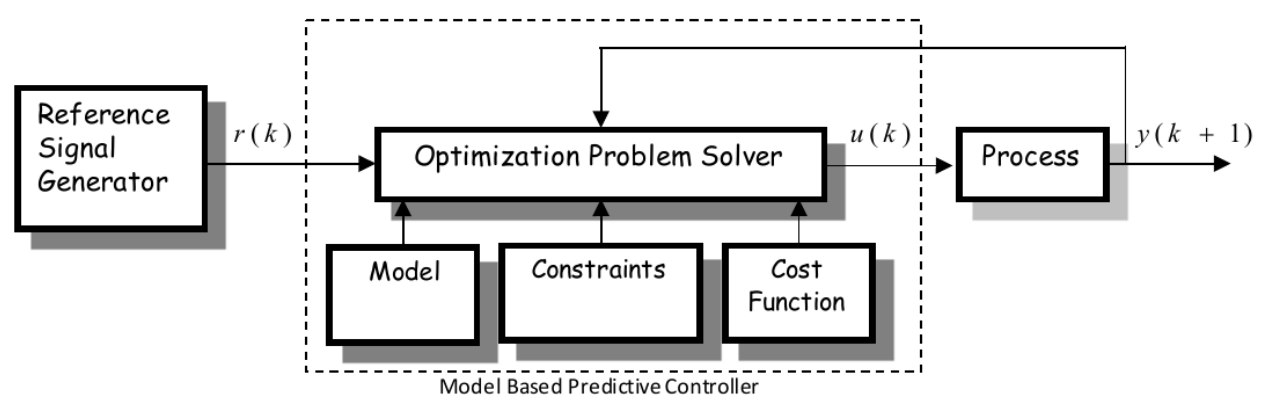

Fonte: (ABBASZADEH; SOLGI, 2014)

Modelo: O modelo do sistema. Praticamente todas as formas de modelar um processo podem ser utilizadas para MPC, como modelo de resposta ao impulso e ao degrau, funções de transferência, espaço de estados, modelos não-lineares, e várias outras abordagens, como Redes Neurais Artificiais, Lógica Fuzzy, Processos Gaussianos (NARENDRA; PARTHASARATHY, 1990; TAKAGI; SUGENO, 1985; SJöBERG et al., 1995; KOCIJAN, 2008).

Função objetivo: Muitas funções objetivo diferentes podem ser utilizadas. O objetivo geral é que a saída futura $y$, no horizonte considerado, siga uma determinada referência $r$ e, ao mesmo tempo, o esforço de controle $(\Delta u)$ necessário seja penalizado(CAMACHO; ALBA, 2007). A função objetivo mais comum em MPC pode ser vista abaixo:

$$
J(P, C, r, y)=\sum_{j=1}^{P} \delta(j)[r(k+j)-y(k+j)]^{2}+\sum_{j=1}^{C} \lambda(j)[\Delta u]^{2}
$$

em que $y(k+j)$ é a saída prevista pelo modelo para todos os instantes de tempo no horizonte de predição $P(j=1, \ldots, P), r(k+j)$ é a trajetória de referência e $C$ é o horizonte de controle, que define que após um intervalo $C<P$ o sinal de controle proposto seja mantido constante $(u(k+j)=u(k+C)$, para qualquer $C \leq j \leq P)$. Os parâmetros $\delta(j)$ e $\lambda(j)$ são sequências que consideram o comportamento futuro e podem ser ajustadas para obter, por exemplo, um controle mais suave com menor esforço, ou um controle mais agressivo.

Restrições: Na prática, todos os processos estão sujeitos a restrições. Os atuadores possuem uma amplitude de atuação e slew rate limitados, e essas limitações devem ser respeitadas para a operação segura e eficiente do sistema.

Para obter a sequência de sinais de controle $u(k+j)$ que levam o sistema ao set-point desejado, é necessário minimizar o funcional $J$ em (4.2), de forma que o erro de predição entre $r(k+j)$ e $y(k+j)$ seja mínimo. Como é utilizada a estratégia de horizonte deslizante, somente o primeiro elemento do vetor $u(k+1)$ é utilizado, descartando o restante do vetor e repetindo os cálculos no próximo instante de amostragem. 
Neste trabalho, o modelo do processo utilizado no MPC é um modelo GP. Um problema que pode ocorrer devido a utilização deste tipo de modelo é a eficiência de uma solução numérica, pois algoritmos de otimização não-lineares são bastante exigentes computacionalmente. Várias técnicas de aproximação e outras abordagens (por exemplo, aproximações de soluções explícitas (GRANCHAROVA; KOCIJAN; JOHANSEN, 2007)) existem, em uma tentativa de diminuir a carga computacional. Outros trabalhos que também investigam a utilização de modelos GP para controle podem ser vistos em (GRANCHAROVA; KOCIJAN; JOHANSEN, 2007; MURRAY-SMITH et al., 2003; KOCIJAN et al., 2004; LIKAR; KOCIJAN, 2007; LOURENçO; LEMOS; MARQUES, 2013).

\subsubsection{Model Predictive Control baseado em modelos GP aplicado a um Veículo de Grande Porte}

Para realizar o controle preditivo de velocidade do caminhão descrito na Seção 4.1, foram utilizados os seguintes conjuntos de dados:

- DS1 - Motorista dirigindo normalmente - 4500 amostras;

- DS3 - Entrada em degrau aplicada através do nó ROS - 160 amostras.

O modelo foi treinado para predizer a velocidade $v$ do caminhão no instante $k+1$, baseada na velocidade do instante anterior, na entrada de controle $u$ e na inclinação da pista $\alpha$, definindo $v(k+1)=f(v(k), u(k), \alpha(k)$. A função de covariância utilizada é a soma das funções linear, squared exponential e Matérn 1/2. Todos os treinamentos e predições dos Processos Gaussianos foram realizados utilizando o toolbox CVPP ${ }^{1}$.

Para analisar o desempenho do modelo foi utilizada a técnica de $n$-fold crossvalidation com 10 folds $(n=10)$. O desempenho foi medido utilizando Erro Quadrático Médio (Root Mean Square Error - RMSE) e também o método mais adequado a modelos probabilísticos Negative Log Probability Density (NLPD) (KOCIJAN et al., 2005; RASMUSSEN; WILLIAMS, 2006). Os resultados estão listados na Tablela 5. Nota-se que ambos os modelos descrevem o comportamento do sistema com erro pequeno, e o modelo treinado com o conjunto de dados maior mostra mais confiança em suas predições, que pode ser visto pelo valor menor da NLPD.

O modelo obtido a partir do conjunto de dados DS3 foi utilizado para executar a arquitetura de controle mostrada na Figura 14. As entradas de controle $u(k+j)$ são obtidas pela minimização da função custo $(4.2)$, com $\delta(j)=1$ e $\lambda(j)=0.3$ para todo $j$, e

$\overline{1}$ https://bitbucket.org/vguizilini/cvpp 
Tabela 5 - Performance dos modelos treinados.

\begin{tabular}{ccc}
\hline Datasets & RMSE & NLPD \\
\hline DS1 & 0.004 & -2.17 \\
DS3 & 0.011 & -1.32 \\
& & \\
DS1-DS3 & 0.012 & -1.14 \\
\hline
\end{tabular}

sob as restrições:

$$
\begin{aligned}
0 \leq y(k+j) & \leq 20 \\
-0.5 \leq u(k+j) & \leq 0.6 \\
\sigma(k+j) & \leq 0.2
\end{aligned}
$$

Além das restrições devido às limitações do sistema, foi definido um limite pra o valor da variância $\sigma \leq 0.2$ para tentar evitar respostas inesperadas devido a incertezas no modelo.

Foi provado em (JADBABAIE; HAUSER, 2005) que um horizonte devidamente longo é adequado para garantir a estabilidade em um esquema de horizonte deslizante, mesmo quando a dinâmica e/ou a função custo são alteradas em tempo-real. Neste trabalho, foi utilizado um horizonte de 2 intervalos de tempo para testar o controlador em situações extremas.

\subsubsection{Resultados do controle de velocidade}

Para verificar o desempenho do controlador, uma simulação do sistema foi conduzida utilizando o modelo treinado com o conjunto de dados DS1 para simular a resposta do veículo. O sinal de referência foi criado artificialmente de forma que apresentasse duas mudanças bruscas no set-point: em $k=4$ segundos, a referência é comandada para ir de 0 para $10 \mathrm{~m} / \mathrm{s}$ e, em $k=40$ segundos, é comandada para ir de 10 para $5 \mathrm{~m} / \mathrm{s}$. No primeiro teste, foi utilizada uma estrada plana. A resposta do controlador para o primeiro teste, bem como a sequência de sinais de controle podem ser vistas na Figura 15. Após o período de acomodação, o controlador foi capaz de seguir a referência com menos de $2.5 \%$ de erro.

Dois outros testes foram executados, com a inclinação da via ajustada para uma condição íngreme (10\%). Nas Figuras 16 e 17 são mostradas a saída do sistema em um trecho de subida e descida, respectivamente. Mesmo nestas condições extremas, o controlador foi capaz de seguir a referência. No caso do trecho de subida, o veículo leva mais tempo para atingir a velocidade, devido a sua grande massa, e à saturação do sinal 
Figura 15 - Saída do sistema e sinal de controle para uma estrada plana.
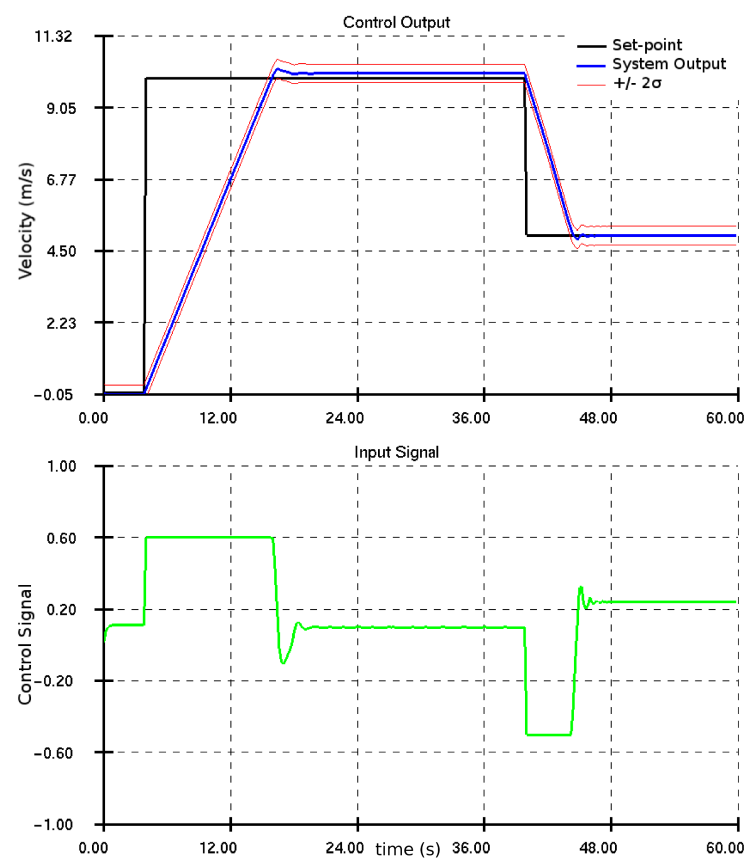

Fonte: o autor.

de controle. Também devido à massa do veículo, no caso do trecho de descida, após o veículo atingir a velocidade de referência, ele passa a maior parte do tempo acionando o freio para manter a velocidade constante.

Figura 16 - Saída do sistema e sinal de controle para um trecho de subida.
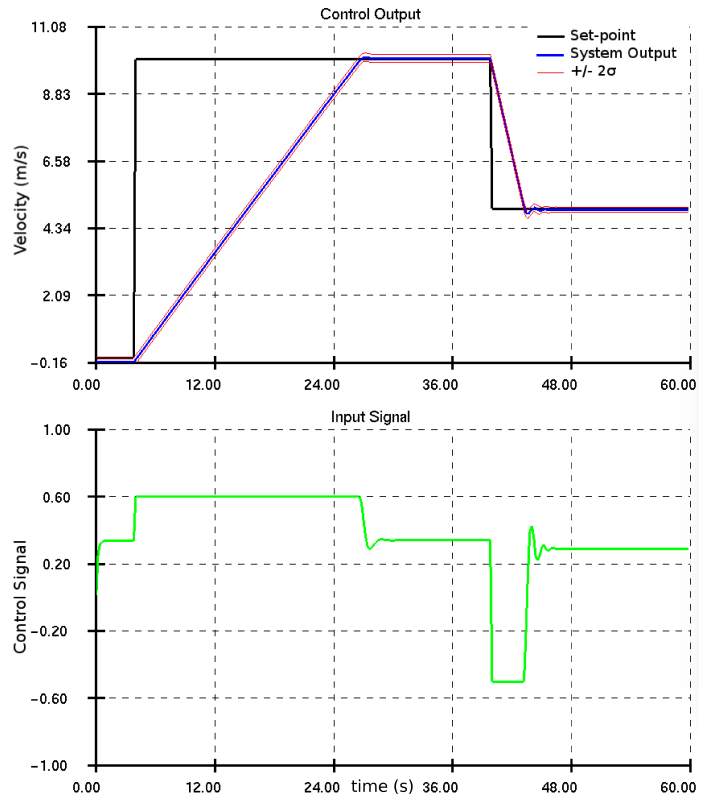

Fonte: o autor.

Os resultados de simulação em malha fechada do sistema apresentaram um desempenho muito bom do controlador proposto, mesmo em condições extremas, como 
Figura 17 - Saída do sistema e sinal de controle para um trecho de descida.
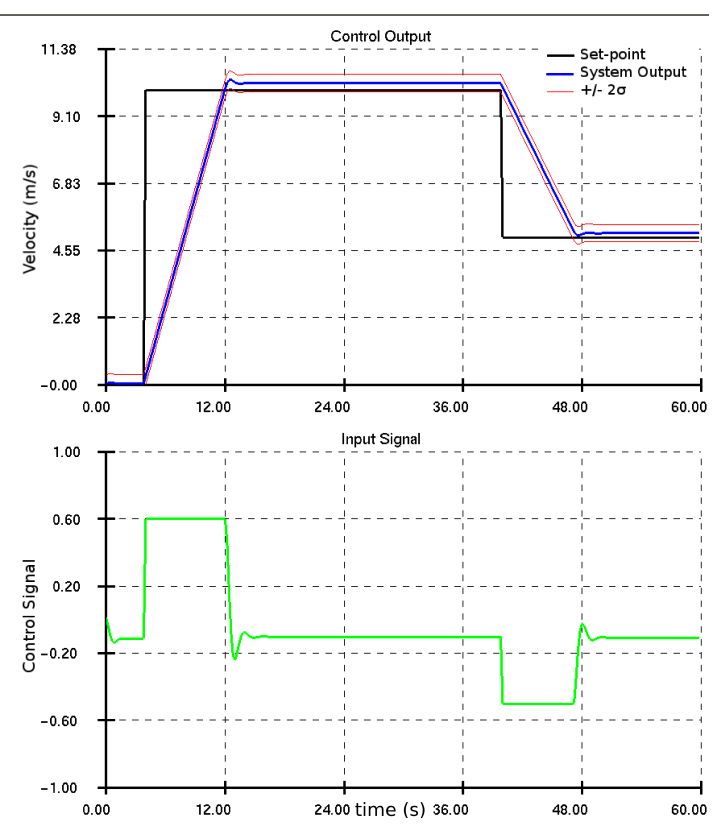

Fonte: o autor.

horizontes de predição pequenos e estradas íngremes, mostrando que modelos utilizando Processos Gaussianos oferecem uma alternativa viável ao projeto de controladores. 



\section{Otimizaçao Bayesiana de Políticas de Con- trole de Robôs Móveis}

No processo de automação de vários tipos de sistemas físicos, muitas vezes é necessária a otimização de um controlador, ou de uma política de controle, baseada somente em uma medida do custo ou recompensa total devido a seu desempenho. Na área da robótica, os processos avaliados geralmente estão relacionados com o movimento ou navegação de um robô. Em alguns casos, é impossível quantificar o efeito que ações de controle individuais tem sobre o resultado final do processo. Exemplos incluem tarefas como o arremesso de bolas (KUPCSIK et al., 2013) ou a tentativa de acertar um alvo na parede com um dardo (KOBER; OZTOP; PETERS, 2010), nos quais a posição final do objeto arremessado vai depender da sequência de ações de controle executadas. Em outros casos, as contribuições instantâneas podem até ser mensuráveis, mas uma abordagem global, considerando todo o episódio de execução, pode trazer mais benefícios, como no caso de veículos autônomos (RIZANO et al., 2013).

A tarefa de aprender uma política de controle que maximize uma recompensa que depende do efeito combinado das ações dessa política também pode ser abordada como um problema de policy-search baseado em episódios (DEISENROTH, 2013). Em (KUPCSIK et al., 2013), por exemplo, o método proposto permite que algoritmos aprendam uma política utilizando um modelo direto do robô, também aprendido, para simular o desenvolvimento das trajetórias. Em (KOBER; OZTOP; PETERS, 2010), um robô aprende como lançar um dardo para atingir um alvo utilizando uma abordagem livre de modelo. O método de atualização da política é chamado de Cost-regularized Kernel Regression (CrKR). Este algoritmo realiza uma busca pela política ótima, sem utilizar modelos, sobre múltiplos contextos, que informam sobre os detalhes da tarefa a ser executada. Isto é feito modelando a distribuição dos parâmetros da política utilizando Processos Gaussianos sobre o espaço de contextos para cada parâmetro da política. Os modelos GP combinados são calculados pelo algoritmo como uma função do contexto atual e dos pares de parâmetros e recompensas observados.

Uma das maneiras mais comuns de se formular problemas de policy-search é a utilização de políticas que sejam eficientes para uma determinada aplicação, e então, buscar no espaço de parâmetros dessa política pelo conjunto de parâmetros que otimize um determinado critério (também chamado de função custo/recompensa ou função objetivo) (ANTONOVA, 2016). Esta formulação é conhecida como direct policy search. Porém, em problemas reais, esse método pode apresentar alguns obstáculos, pois nem sempre a função objetivo possui forma analítica, fornecendo somente observações ruidosas dessa função, 
sendo que em muitos casos (ex: testes de drogas, investimentos financeiros, robótica), a obtenção dessas amostras pode ser difícil ou possuir custo alto. Nesse cenário, uma técnica que se destaca é a Bayesian Optimization, um método de otimização black-box iterativo, que utiliza um modelo Bayesiano para modelar a função objetivo, e assim, decidir de maneira eficiente qual conjunto de parâmetros deve ser avaliado na próxima iteração. Neste trabalho, entretanto, a função objetivo é modelada utilizando um GP como uma função dos parâmetros da política. Mais detalhes desta técnica são apresentados na próxima seção.

\subsection{Bayesian Optimization}

Otimização Bayesiana (Bayesian Optimization, BO) é uma ferramenta para busca global sequencial, adequada para a otimização eficiente de funções desconhecidas e com amostragem dispendiosa. Mesmo que a função seja não-convexa, ou possua múltiplos ótimos, é provável que a BO encontre o ótimo global. Foi introduzida em (JONES; SCHONLAU; WELCH, 1998), e com revisões recentes em (BROCHU; CORA; FREITAS, 2010; SHAHRIARI et al., 2016). O objetivo é encontrar um vetor $\mathbf{x}$ de $D$ dimensões que otimize uma função $f(\mathbf{x}): \mathbb{R}^{D} \rightarrow \mathbb{R}$, enquanto executa o menor numero possível de avaliações de $f$, ou seja, encontrar:

$$
\mathbf{x}^{*}=\underset{\mathbf{x} \in \mathbb{R}^{D}}{\operatorname{argmax}} f(\mathbf{x})
$$

Caso o problema de interesse seja de minimização, é possível maximizar a função transformada $g(\mathbf{x})=-f(\mathbf{x})$. BO é um algoritmo iterativo que utiliza o Teorema de Bayes (Eq. 3.1) a cada iteração para combinar o conhecimento a priori sobre $f$ com os dados observados para produzir uma nova estimativa de $f$. Sendo assim, o objetivo é utilizar evidência e conhecimento a priori para maximizar a função estimada a cada passo, de forma que a cada nova avaliação da função, a distância entre o verdadeiro máximo global e o máximo esperado, dado o modelo, seja reduzida. Neste trabalho, o conhecimento a priori sobre $f$ é representado por um GP. O valor esperado de $f$ possui, portanto, variância associada, que captura o nível de incerteza da predição, conforme Eq. 3.36.

O sucesso do algoritmo BO depende da seleção inteligente de pontos para amostrar a função $f$. A cada iteração, a próxima localização a ser amostrada é a que maximiza um valor utilitário. A função que codifica este valor utilitário a partir de ponto de amostragem $x$ e do modelo de $f$ é chamada função de aquisição (acquisition function), $h$. Sendo assim, a técnica BO utiliza uma medida quantitativa dada pela acquisition function para decidir quais localizações mais prováveis de conter o valor máximo de $f$. Dessa forma, o problema de otimização de $f$ passa a ser a otimização de $h$. Essa otimização secundária é geralmente mais simples, pois a acquisition function é escolhida de forma que sua avaliação seja mais 
fácil e consuma menos recursos. Essa otimização pode ser realizada com qualquer técnica de otimização, sendo as técnicas baseadas em gradientes as mais utilizadas.

O algoritmo da BO pode ser visto no Algoritmo 1. Para a utilização do BO, é necessário informar o conhecimento a priori a respeito da função objetivo, sendo estas codificadas através das funções de média e covariância do modelo GP, e também definir a acquisition function a ser utilizada. Alguns exemplos serão apresentados na Seção 5.1.1. Na Linha 2 do algoritmo, a otimização da acquisition function é realizada. Após a realização da amostragem de $f$, utilizando-se o conjunto de dados observados $X$ e $\mathbf{y}$, atualiza-se o modelo GP que descreve a função objetivo. Nesta etapa, é possível também atualizar os hiperparâmetros do modelo. Como a continuação das iterações, o modelo converge para a função objetivo dentro do espaço de busca definido, e consequentemente, o ótimo global dessa função pode ser encontrado.

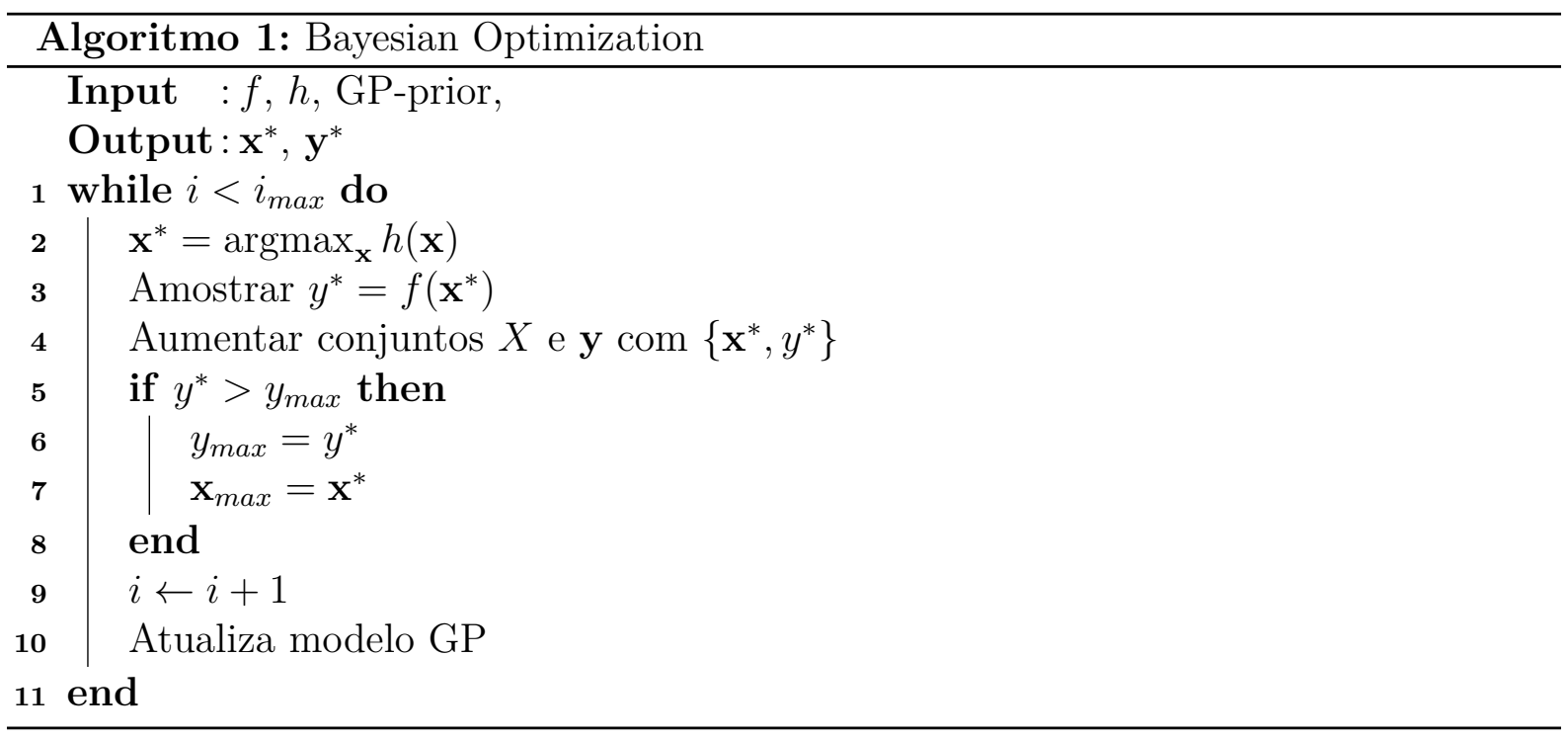

\subsubsection{Acquisition Functions}

O papel da função de aquisição (acquisition function) no BO é direcionar a busca pelo ótimo. A maximização da acquisition function é usada para selecionar o próximo ponto a ser amostrado da função objetivo. Ela é definida de forma que valores utilitários altos correspondam a potenciais valores altos da função objetivo, seja devido ao valor estimado pelo modelo ser alto, ou devido a incerteza alta, ou ambos. Outra característica interessante dessas funções é a capacidade de balancear entre a exploração do espaço de busca ou o melhor aproveitamento de áreas promissoras conhecidas (exploration/exploitation tradeoff) (BROCHU; CORA; FREITAS, 2010). As funções mais populares são: Probability of Improvement, Expected Improvement e Upper Confidence Bound. 


\section{Probability of Improvement}

Apresentada por (KUSHNER, 1964), esta função calcula a probabilidade de melhorar o resultado em relação ao melhor valor da função objetivo, $f\left(\mathbf{x}^{+}\right)$, encontrado no conjunto atual de amostras $X$, em que $\mathbf{x}^{+}=\operatorname{argmax}_{\mathbf{x}_{i} \in X} f\left(\mathbf{x}_{i}\right)$, de acordo com a Eq. 5.2:

$$
\begin{aligned}
P I(\mathbf{x}) & =P\left(f(\mathbf{x}) \geq f\left(\mathbf{x}^{+}\right)\right) \\
& =\Phi\left(\frac{\mu(\mathbf{x})-f\left(\mathbf{x}^{+}\right)}{\sigma(\mathbf{x})}\right)
\end{aligned}
$$

em que $\Phi($.$) é a função de distribuição normal acumulada. Uma desvantagem dessa$ formulação é que ela não permite a exploração do espaço de busca da função, pois pontos que possuem uma probabilidade alta de serem infinitesimalmente maiores do que $f\left(\mathbf{x}^{+}\right)$ são favorecidos em relação a pontos que podem oferecer ganhos maiores, mas com menor probabilidade. Para sanar esse problema, é adicionado um parâmetro $\xi \geq 0$ que regula essa característica, conforme Eq. 5.3.

$$
\begin{aligned}
P I(\mathbf{x}) & =P\left(f(\mathbf{x}) \geq f\left(\mathbf{x}^{+}\right)+\xi\right) \\
& =\Phi\left(\frac{\mu(\mathbf{x})-f\left(\mathbf{x}^{+}\right)-\xi}{\sigma(\mathbf{x})}\right)
\end{aligned}
$$

\section{Expected Improvement}

A Expected Improvement (MOČKUS; TIESIS; ZILINSKAS, 1978) é uma função que mensura, além da probabilidade de melhoria, o quanto de melhoria é esperado ao se amostrar a função em um determinado local. Considere a função que mede a melhoria obtida:

$$
I(\mathbf{x})=\max \left\{0, f(\mathbf{x})-f\left(\mathbf{x}^{+}\right)\right\}
$$

A melhoria esperada é dada por:

$$
\begin{aligned}
E I(\mathbf{x}) & \triangleq \mathbb{E}[I(\mathbf{x})] \\
& =\mathbb{E}\left[\max \left\{0, f(\mathbf{x})-f\left(\mathbf{x}^{+}\right)\right\}\right] \\
& =\int_{f\left(\mathbf{x}^{+}\right)}^{\infty}\left(f(\mathbf{x})-f\left(\mathbf{x}^{+}\right)\right) \phi\left(\frac{\mu(\mathbf{x})-f\left(\mathbf{x}^{+}\right)}{\sigma(\mathbf{x})}\right)
\end{aligned}
$$

em que $\phi$ é a função de densidade de probabilidade. O primeiro termo da integral da Eq. 5.7 é a quantidade de melhoria obtida, enquanto o segundo termo representa a 
probabilidade dessa melhoria. Essa integral pode ser resolvida analíticamente, o que leva à Eq. 5.7:

$$
E I(\mathbf{x})=\sigma(\mathbf{x})[Z \Phi(Z)+\phi(Z)]
$$

em que:

$$
Z=\frac{\mu(\mathbf{x})-f\left(\mathbf{x}^{+}\right)}{\sigma(\mathbf{x})}
$$

Assim como a Probability of Improvement, a EI tende a não explorar o espaço de busca da função. Para ajustar essa característica, utiliza-se:

$$
Z=\frac{\mu(\mathbf{x})-f\left(\mathbf{x}^{+}\right)-\xi}{\sigma(\mathbf{x})}
$$

\section{Upper Confidence Bound}

A função Upper Confidence Bound, apresentada por (COX; JOHN, 1992), utiliza o intervalo de confiança superior do modelo estimado, conforme Eq. 5.11. O parâmetro $\kappa$ controla o quanto o algoritmo vai explorar o espaço.

$$
U C B(\mathbf{x}) \triangleq \mu(\mathbf{x})+\kappa \sigma(\mathbf{x})
$$

Na Figura 18, é mostrada uma comparação das funções apresentadas para um problema unidimensional. Nesta figura, é possível observar também a influência dos parâmetros que controlam a exploração.

\subsubsection{Bayesian Optimization em Aplicações Robóticas}

Bayesian Optimization já foi aplicada com sucesso a uma variada gama de problemas, como: testes A/B para marketing (KOHAVI et al., 2009; AGARWAL, 2010), sistemas de recomendação para provedores de conteúdo/produtos (LI et al., 2010; VANCHINATHAN et al., 2014), monitoramento ambiental (SRINIVAS et al., 2010; GARNETT; OSBORNE; ROBERTS, 2010), entre outras (BROCHU; BROCHU; FREITAS, 2010; SNOEK; LAROCHELLE; ADAMS, 2012; AL-DUJAILI; SURESH, 2016).

Outra área que tem obtido sucesso na utilização de BO em conjunto com GPs é a robótica. Krause, Singh e Guestrin (2008) desenvolveram uma abordagem utilizando GPs e o princípio da otimização da informação mútua para solucionar o posicionamento de sensores. Quando o sensor está montado em uma plataforma móvel, há um custo associado com a medição, relacionado à distância navegada pelo veículo. Este custo pode ser levado em consideração na escolha dos pontos a serem amostrados, como pode ser 
Figura 18 - Exemplos de acquisition functions e suas configurações.
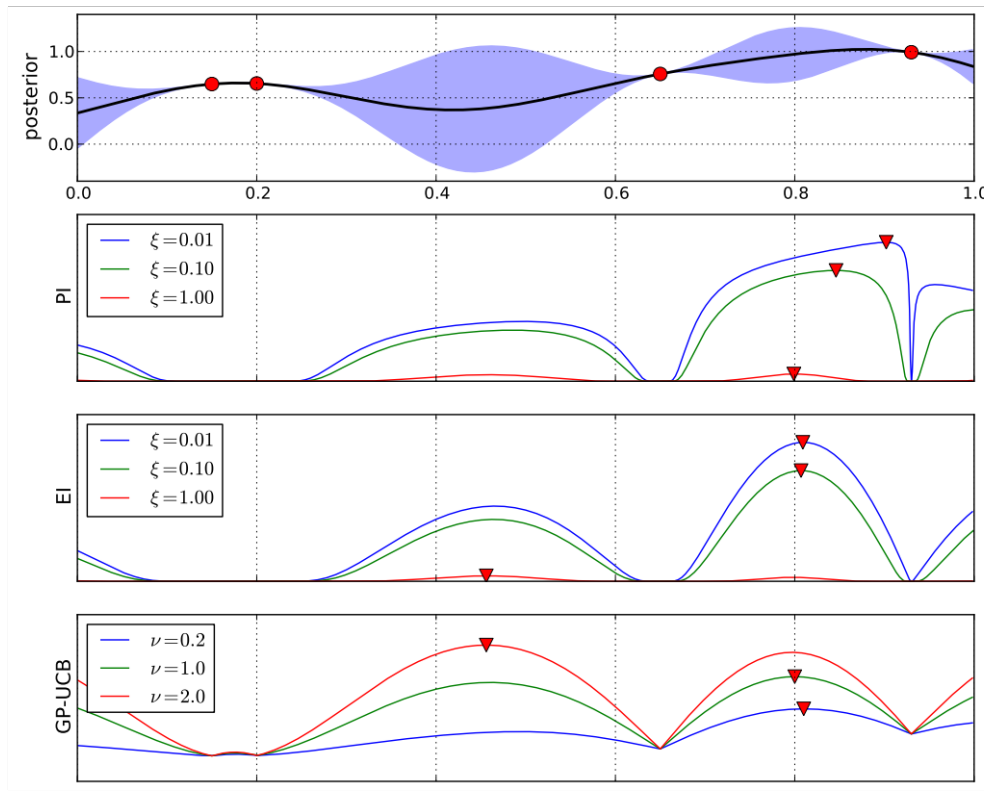

Fonte: (BROCHU; CORA; FREITAS, 2010)

visto em (MARCHANT; RAMOS, 2014). Martinez-Cantin et al. (2009) utiliza BO para o planejamento online de trajetórias de forma a maximizar as informações a respeito da localização do robô. Lizotte et al. (2007) e Calandra et al. (2014) utilizam BO para otimizar a caminhada de robôs que se deslocam utilizando pernas, um quadrúpede no primeiro caso, e um bípede, no segundo.

Apesar do sucesso da aplicação do BO em diversas áreas, elas compartilham uma característica comum: são problemas de baixa ou moderada dimensionalidade. Para poder ser aplicado em mais problemas, e também em diversos cenários reais, BO deve ser adaptado para lidar com espaços de parâmetros de alta dimensionalidade. O problema é que, para garantir que o ótimo global seja encontrado, é necessária uma boa cobertura do espaço de busca dos parâmetros, porém, com o aumento da dimensionalidade desse espaço, o número de avaliações necessárias aumenta exponencialmente, diminuindo a eficiência do algoritmo.

\subsubsection{Bayesian Optimization para problemas de alta dimensionalidade}

Um problema comum das aplicações que utilizam BO é o problema da dimensionalidade. A maioria dos algoritmos de BO utilizam GPs para aprender e modelar a função objetivo. Porém, este não se adapta bem com altas dimensões $\left(\mathcal{O}\left(n^{3}\right)\right)$ e/ou grandes quantidade de dados $\left(\mathcal{O}\left(n^{2}\right)\right)$, degradando o desempenho do BO nestas condições. É difundido na literatura que o BO é efetivo somente em problemas com menos de 10 dimensões. Várias técnicas foram desenvolvidas recentemente para tentar resolver o problema do 
GP/BO não escalar para altas dimensões. Uma das abordagens assume que a função a ser otimizada varia principalmente em um subspaço de pequenas dimensões, com (CHEN; CASTRO; KRAUSE, 2012) apresentando um método de duas etapas, primeiro aprendendo quais dimensões são mais relevantes utilizando uma técnica de Variable Selection, e então otimizando a função nas dimensões selecionadas. (WANG et al., 2013) e (DJOLONGA; KRAUSE; CEVHER, 2013) recorrem à mesma suposição, o primeiro utiliza matrizes aleatórias para projetar linearmente o espaço de entradas em um subespaço menor, e o segundo aplica um algoritmo de low rank recovery para aprender a matriz de projeção. Outra abordagem comum é supor que a função é formada por um conjunto disjunto de funções de baixa dimensão. (KANDASAMY; SCHNEIDER; POCZOS, 2015) assume que a função alvo pode ser decomposta em uma forma aditiva e cada componente da soma pode ser otimizado separadamente. (ULMASOV et al., 2016) descarta a suposição da estrutura aditiva e constrói um modelo GP separado para cada subconjunto de dimensões de entrada. (LI et al., 2016) utiliza uma mistura das duas estratégias, usando diretamente um modelo GP aditivo e projetado em um espaço menor.

Apesar dos trabalhos anteriores terem alcançado êxito, eles dependem de aproximações do modelo GP da função de alta dimensão. Ao limitar a função de grandes dimensões a uma projeção de baixa dimensão, ou ao impor uma estrutura para essa função, perdem-se informações acerca do comportamento dessa função. Além disso, mesmo quando o modelo completo é utilizado, mas a otimização é realizada somente em um subspaço projetado menor, que é o caso de (WANG et al., 2013), pode causar problemas. Como é utilizada uma projeção aleatória, não há garantias de que a porção do espaço sendo otimizada contenha o valor ótimo, então o algoritmo pode nunca chegar perto desse valor. Neste trabalho, foi escolhido atacar o problema a partir do processo de otimização, enquanto utiliza-se todas as informações disponíveis para construir o modelo da função.

\subsection{Coordinate Descent Bayesian Optimisation}

Em aplicações robóticas, e principalmente em estratégias de aprendizado baseada em episódios, um problema comum é a alta dimensionalidade do espaço de busca para a otimização da acquisition function (AF) utilizada pelo BO. Alguns métodos foram propostos na literatura sobre BO para lidar com esse problema, como (WANG et al., 2013; LI et al., 2016). Entretanto, eles requerem algumas suposições possivelmente fortes sobre a função objetivo. Para ser eficiente na otimização de modelos de grandes dimensões, foi desenvolvido o método Coordinate Descent Bayesian Optimisation, uma técnica iterativa, que utiliza a idéia dos algoritmos de Coordinate Descent (WRIGHT, 2015), em que a cada iteração somente uma dimensão é otimizada, enquanto as outras permanecem fixas. Esta técnica se baseia no fato de que cada sub-problema é um problema de otimização de menor ordem, que pode ser resolvido mais facilmente do que o problema completo. 
Nossa estratégia, é a utilização de um método simples, Descida Coordenada Estocástica (Stochastic Coordinate Descent, vista no Algoritmo 2), que utiliza um esquema de seleção aleatória de dimensão para otimizar a AF sobre cada dimensão individualmente, partindo do ótimo atual. Desta forma, mantém-se a busca local, evitando exploração excessiva em um espaço de dimensões muito grandes. Dependendo da escolha da função de aquisição, entretanto, é possível ainda executar a busca com o BO seguindo regiões de incerteza alta em volta do ótimo atual.

Esssa técnica de otimização foi inspirada no método de Descida Coordenada (Coordinate Descent - CD), uma classe de algoritmos que são uma das mais antigas técnicas da literatura de otimização (ROSENBROCK, 1960). Ela é baseada na idéia que um problema $n$-dimensional pode ser decomposto em $n$ subproblemas unidimensionais, o que o torna adequado para ser aplicado a grandes conjuntos de dados ou com muitas dimensões. Nestes métodos, cada dimensão é atualizada sequencialmente pela solução de um problema unidimensional utilizando qualquer algoritmo de otimização adequado, enquanto todas as outras dimensões são mantidas fixas. Os métodos variam na forma como a sequência de dimensões é escolhida, se a otimização é feita em somente uma dimensão ou em um bloco de dimensões, e se utilizam gradientes nas iterações. Muitos trabalhos focam na descrição das características de convergência desses algoritmos (NESTEROV, 1983; TSENG, 2001; BERTSEKAS, 2015). Sob algumas suposições (Continuidade de Lipschitz, convexidade forte) são mostradas provas de taxa de convergência linear para métodos CD sequenciais e aleatórios, e também para CD em blocos. O esquema mais intuitivo para esta técnica seria otimizar as dimensões de maneira cíclica e sequencial. Porém, (POWELL, 1973) mostrou um exemplo de uma função não-convexa que, quando aplicado o esquema sequencial, o processo de otimização não converge. Para evitar este tipo de problema, adotou-se uma sequência aleatória, que é modificada uma vez que todas as dimensões foram otimizadas.

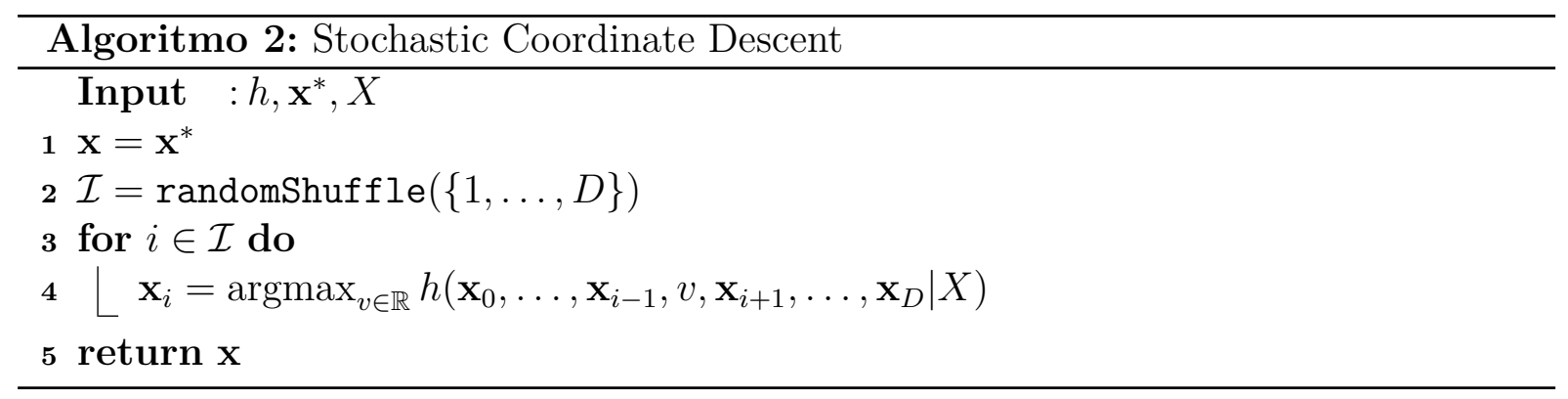

O Algoritmo 2 começa a busca a partir do ótimo atual. A sequência de $D$ índices das dimensões $\{1, \ldots, D\}$ é organizada de maneira aleatória, e segue essa sequência para otimizar uma dimensão após a outra. Após percorrer todas as dimensões, o algoritmo retorna o vetor de pesos otimizado. A utilização dessa técnica de otimização em conjunto com o BO faz com que esse seja adequado a problemas de alta dimensionalidade. 


\subsection{CDBOaplicado na redução do consumo de combustível de um veículo autônomo de grande porte}

Um dos focos da sociedade atual é a redução das emissões de poluentes devido ao uso de combustíveis fósseis. O setor de transportes é responsável por uma quantidade substâncial das emissões de gases do efeito estufa (AGENCY, 2012). Neste cenário, pesquisas em eficiência energética em sistemas de transporte e direção ecológica (ecodriving) tem se intensificado. Principalmente em veículos de grande porte, outro fator que incentiva pesquisas nesse sentido é a economia, já que os custos com combustível podem chegar a 1/3 do custo total de vida útil do veículo (SCHITTLER, 2003).

Vários métodos de controle de veículos para eco-driving podem ser encontrados na literatura. Os mais comuns são: otimização global, look-ahead control e controle instantâneo. O método da otimização global busca obter uma solução ótima para todo o horizonte de controle, utilizando técnicas como programação dinâmica. Devido a seu alto custo computacional e a incapacidade de lidar com situações inesperadas no trajeto, esta técnica é menos adequada à aplicação prática para sistemas reais, e geralmente é utilizada como benchmark (OZATAY et al., 2014) (LIN et al., 2003) (MENSING; TRIGUI; BIDEAUX, 2011).

Já o Model Predictive Control, também chamado de look-ahead control, é amplamente utilizado em sistemas de controle de cruzeiro. Utiliza as informações de inclinação da via e o modelo do veículo em um horizonte deslizante finito para otimizar os perfis de velocidade através da resolução repetitiva de um problema de controle ótimo. Alguns trabalhos que utilizam essa técnica podem ser vistos em (HELLSTRöM et al., 2009; KAMAL et al., 2010; LI et al., 2015; SCHWICKART; VOOS; DAROUACH, 2014). Um problema dessa técnica em aplicações envolvendo veículos de grande porte é que essas necessitam de um horizonte de predição maior, devido ao maior peso e inércia destes veículos, muitas vezes levando décimos de segundo ou até mesmo segundos para o cálculo de um único passo de otimização do MPC.

Por outro lado, o controle instantâneo depende apenas do estado atual do veículo e da informação atual da via para gerar sinais de controle, ao invés de resolver problemas de controle ótimo online, e é uma abordagem bastante aplicada a problemas reais (PISU; RIZZONI, 2007) (XU et al., 2017). Esta abordagem requer pouca capacidade computacional e tem maior confiabilidade, se comparado com o MPC.

Outra forma de resolver esse problema é a utilização de informações externas, através de comunicação entre veículos (V2V), ou de comunicação do veículo com a infraestrutura da via (V2I) (KUNDU; KUNDU, 2015). Porém, todas as técnicas citadas dependem de um modelo do veículo e/ou informações sobre a via em que o veículo vai trafegar (mapa, inclinação, entre outras), as quais nem sempre estão disponíveis e podem ser complicadas 
de se obter, ou então dependem de informações externas ao veículo e modificações na infraestrutura da via.

Neste trabalho, é proposto um algoritmo de otimização global de políticas de controle utilizando CDBO. O algoritmo utiliza uma política inicial válida e busca iterativamente a cada execução de um determinado percurso, políticas que minimizem o consumo de combustível de um veículo autônomo de grande porte. Vale ressaltar que a otimização da política não utiliza informações a respeito do veículo ou do trajeto, como modelo dinâmico, mapa ou topologia do terreno.

Considere políticas de controle mapeando a posição $u \in \mathcal{U}$ do robô ao longo de uma pista às correspondentes ações de controle $a \in \mathcal{A}$. Tanto $\mathcal{U}$ como $\mathcal{A}$ são espaços contínuos. Nosso objetivo é encontrar a política de controle $\pi: \mathcal{U} \rightarrow \mathcal{A}$ que minimize o combustível requerido para o robô completar a pista.

A função de custo $C$ é definida como:

$$
C=w_{0}\left(1-u_{f}\right)+F_{c}+w_{1} \frac{\left(V_{d}-v_{a v g}\right)^{2}}{V_{d}}
$$

em que $u_{f}$ é a posição final do robô ao terminar um episódio, $F_{c}$ é o combustível total consumido durante o trajeto, $V_{d}$ é a velocidade média desejada e $v_{a v g}$ é a velocidade média empregada pelo veículo no percurso. O primeiro termo da Eq. 5.12 atribui um custo caso o veículo não consiga finalizar o trajeto, sendo este proporcional à distância não completada. Utilizando o parâmetro $w_{0}$, atribui-se um custo alto caso o veículo não complete o trajeto, seja por não se movimentar ou por executar ações de controle que afetem a segurança do veículo. O segundo termo atribui um custo proporcional ao combustível consumido, e o terceiro termo adiciona uma penalidade caso o veículo trafegue em velocidade diferente da velocidade desejada. Essa penalidade pode ser ajustada através do parâmetro $w_{1}$, ajustando o comportamento da política, dando ênfase no seguimento da velocidade desejada, ou na economia de combustível.

O espaço de estados do robô é representado por sua posição ao longo de uma dada trajetória normalizada por seu comprimento, $u \in[0,1]$, em que 0 corresponde à linha de largada, aumentando até 1 quando o robô cruza a linha de chegada. Como trajetória, foi definida a linha central da pista, mas poderia ser qualquer outra trajetória válida, permitindo que esse método seja combinado com algoritmos de otimização de trajetória. A política de controle atua na aceleração do veículo otimizando os comandos dados a acelerador e freio, que são combinados em uma única saída escalar $a \in[-1,1]$, com valores positivos para acelerador e negativos para freio. O controle de trajetória foi realizado utilizando um controlador Proporcional-Integral. Não foi abordada a otimização dos comandos de direção do veículo neste trabalho pois, somente a otimização do controle de aceleração já se mostrou um problema extremamente complicado, porém suficiente 
para demonstrar a capacidade do método BO proposto para lidar com altas dimensões. Neste setup, o algoritmo necessita ser cauteloso para não atribuir valores de aceleração muito altos para o carro em partes críticas da pista, como curvas, para não desestabilizar o controle de trajetória e também respeitar os limites de tração dos pneus.

A política de controle $\pi: \mathcal{U} \rightarrow \mathcal{A}$ utilizada foi parametrizada utilizando splines cúbicas, nas quais um conjunto de nós definem uma função polinomial por trechos (piecewise polinomial), enquanto mantém restrições em relação às primeiras e segundas derivadas destas funções nos nós, de forma a se obter uma função contínua e suave que passa por todos os nós (BOOR, 1978). Este tipo de parametrização consegue codificar formas complexas utilizando poucos parâmetros e é bastante utilizada em robótica na parametrização de trajetórias (KOBER; PETERS, 2014). Um exemplo de interpolação de curvas utilizando spline cúbica pode ser visto na Figura 19. A política de controle consiste de $N$ nós $t_{i}=\left(\hat{u}_{i}, q_{i}\right)$, para $i=1, \ldots, N$, regularmente espaçados ao longo da pista, ou seja, $\hat{u}=\left\{\frac{i}{N-1}\right\}_{i=0}^{N-1}$. Neste sentido, nenhuma informação prévia sobre os pontos críticos da pista foram detalhados. Entretanto, uma forma possível de escolher $\hat{U}$ seria a de posicionar os pontos em torno de trechos da pista que requeiram mudanças significativas na aceleração, como curvas, o que necessitaria de informações sobre o mapa da pista. Na formulação proposta, os parâmetros ajustáveis da política são as amplitudes $q_{i}$ dos nós.

Figura 19 - Exemplos de Interpolação de uma curva utilizando splines cúbicas.

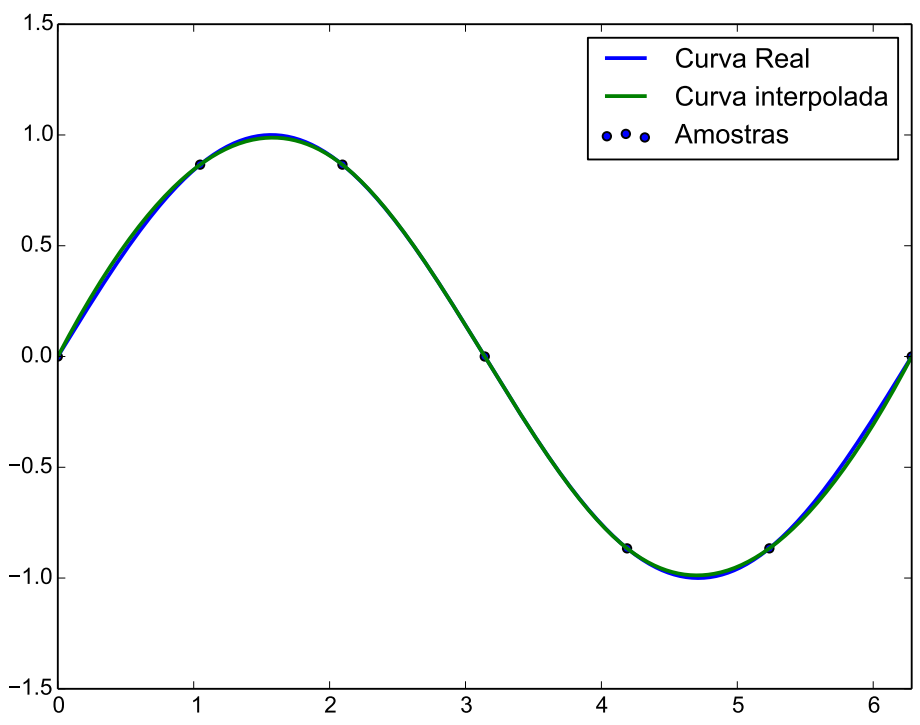

Fonte: O autor.

A política inicial, de onde o algoritmo começa as buscas pelo ótimo, é obtida através da gravação dos dados de um controlador simples ou de um piloto humano, obtendo um conjunto inicial de pontos $U=\left\{u_{i}\right\}_{i=1}^{n}$ e suas ações observadas correspondentes $\mathbf{a}=\left\{a_{i}\right\}_{i=1}^{n}$. 
Os valores iniciais $\mathbf{q}_{0}$ são obtidos a partir das ações de controle executadas nas posições $\hat{u}_{i}$, ou o mais próximo possível dessas.

Antes de começar a busca pela política com o BO, um conjunto de treinamento para o GP é necessário, para se obter uma estimativa de seus hiperparâmetros, que são a variância do ruído e os parâmetros da função de covariância, neste caso. Devido à maioria do espaço ser, em geral, composta por políticas inválidas, que fazem com que o veículo não finalize a trajetória, a utilização de amostras aleatórias por hipercubo latino poderia fornecer muitas políticas com custo elevado. Isto poderia causar um over-fitting na seleção dos hiperparâmetros iniciais do GP. Para evitar esse efeito, foi realizada a amostragem de um conjunto $S$ a partir de uma distribuição normal $\mathcal{N}\left(\mathbf{q}_{0}, I \sigma_{0}\right)$ para formar um conjunto de dados inicial $\left\{\mathbf{q}_{i}, C_{i}\right\}_{i=1}^{S}$ para alimentar o modelo GP, de forma que o BO possa ter alguma informação prévia relevante sobre a função de custo. Além disso, os hiperparâmetros podem ser reestimados durante o funcionamento do sistema, após cada observação do custo.

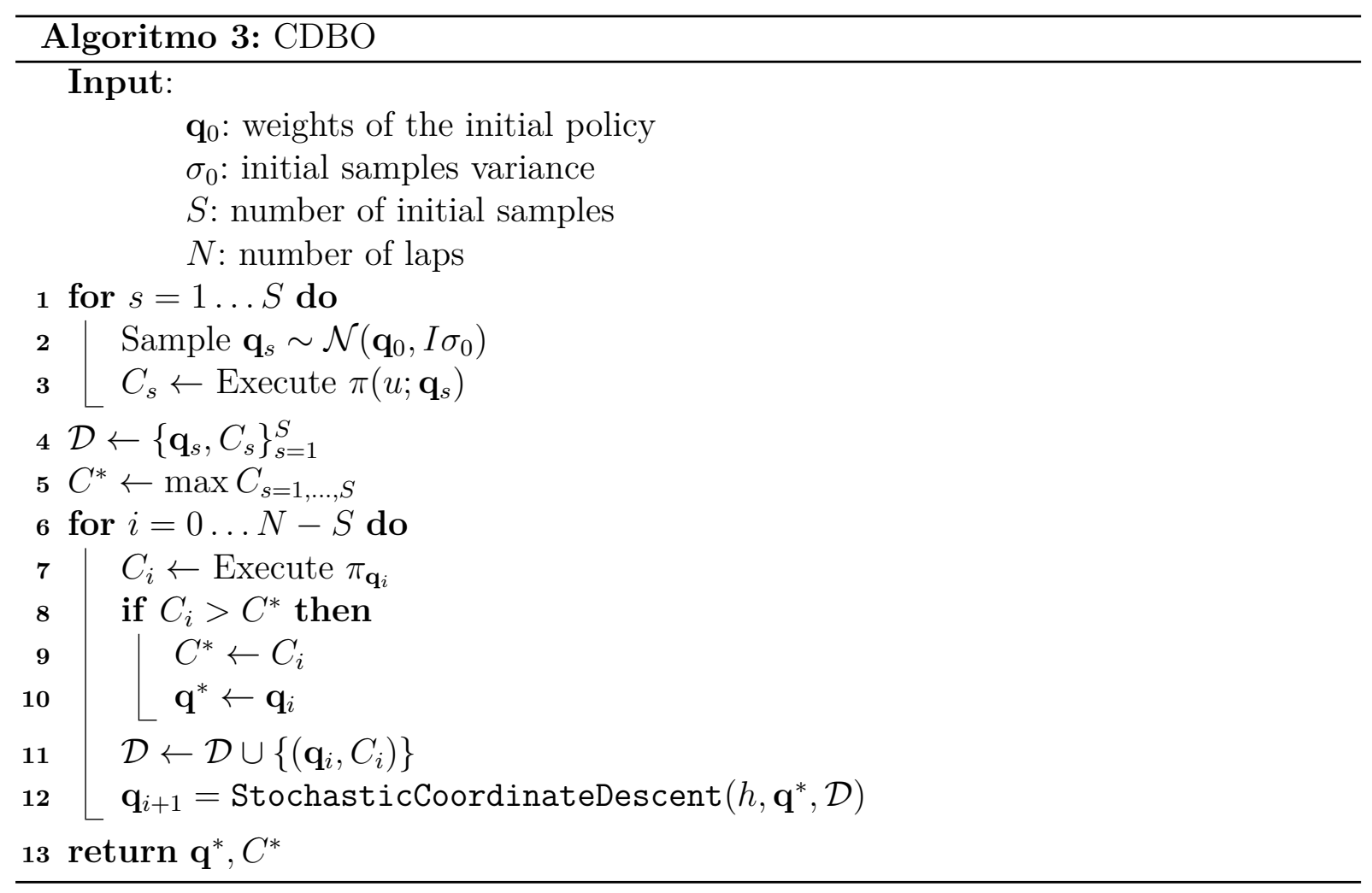

O método proposto é resumido no 3. Nas linhas de 1 a 4, são coletadas as observações iniciais para o GP. Nas linhas de 5 a 12, é realizada a busca pela política ótima. A linha 7 executa a política parametrizada pelos pesos. As linhas de 8 a 10 são utilizadas para manter um registro do ótimo atual. A linha 11 atualiza o conjunto de dados do GP e a linha 12 executa a maximização da acquisition function para selecionar o próximo vetor de pesos a ser avaliado. O algoritmo é executado até que a quantidade máxima de avaliações da função $(N)$ seja atingida. 


\subsubsection{Experimentos utilizando um simulador de corrida}

Foram realizados testes com um carro robótico dirigindo em pistas de corrida e realizando simulações físicas realistas utilizando um simulador de corrida de código aberto, chamado Speed Dreams ${ }^{1}$, que é baseado no TORCS (WYMANN et al., 2014). Uma captura da tela do simulador pode ser vista na Figura 20.

Figura 20 - Simulador de corridas Speed Dreams.

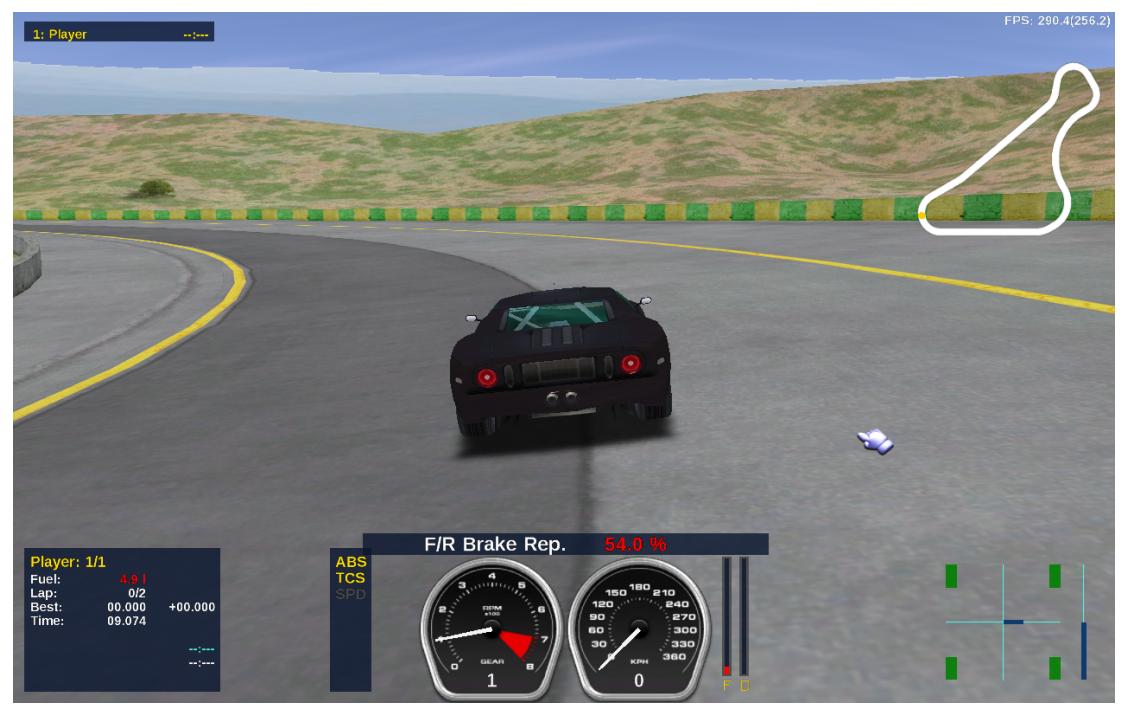

Fonte: $\mathrm{O}$ autor.

Para verificar a capacidade do algoritmo em situações desafiadoras, o circuito escolhido para a execução dos testes foi o Spring, um circuito de estrada montanhoso com 22130 m de comprimento, e vários trechos de subidas e descidas. Seu traçado, bem como a elevação ao longo da pista podem ser vistos na Figura 21.

Em todos os testes, o desempenho foi comparado com os seguintes algoritmos:

- CMA-ES (JONES; PERTTUNEN; STUCKMAN, 1993), que foi aplicado a problemas de Reinforcement Learning (RÜCKSTIESS et al., 2010), em particular, foi utilizado o Active CMA-ES (ARNOLD; HANSEN, 2010), com implementação fornecida por uma biblioteca de código aberto ${ }^{2}$;

- BO padrão, utilizando CMA-ES para otimizar a acquisition function.

A cada teste, ambos algoritmos terão o limite de 200 amostragens da função objetivo, ou seja, 200 voltas no circuito escolhido, para realizar a otimização. Para executar a otimização interna em cada coordenada do método proposto, foi utilizado o COBYLA

$1 \quad$ Speed Dreams: https://sourceforge.net/projects/speed-dreams/

2 <https://github.com/beniz/libcmaes $>$ 
Figura 21 - Características do circuito utilizado nos testes.

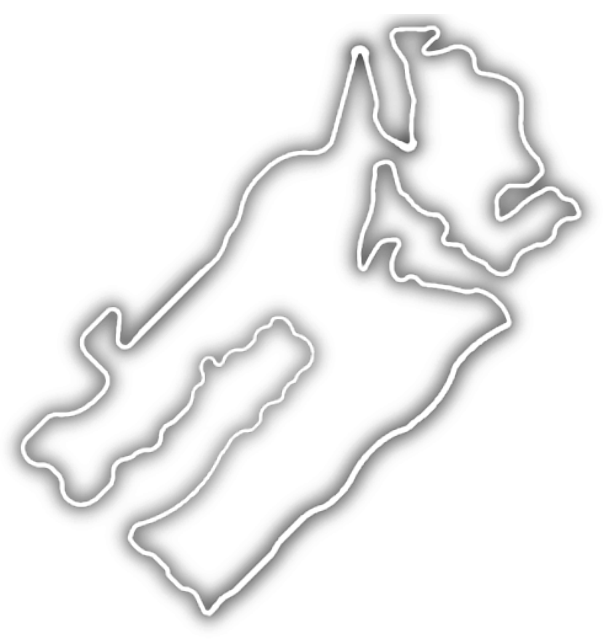

(a) Geometria da pista

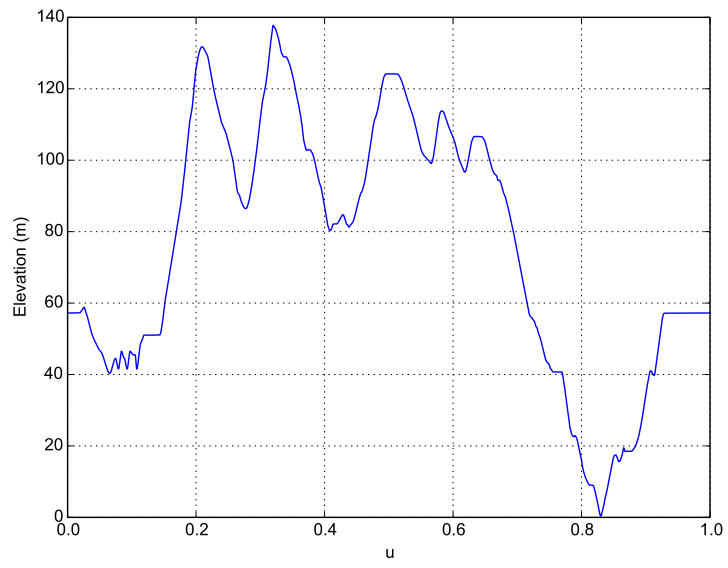

(b) Elevacão ao longo da pista.

Fonte: O autor.

(POWELL, 2007), um algoritmo de otimização local sem derivadas, com implementação fornecida pela popular biblioteca de otimização não-linear NLopt (JOHNSON, 2014).

Para a função de covariância do GP, foi utilizado o Matérn 1 kernel, que fornece flexibilidade suficiente para modelar transições abruptas na função de recompensa. Este kernel Matérn é equivalente à funçao de covariância exponencial:

$$
k_{C}\left(\mathbf{q}, \mathbf{q}^{\prime}\right)=\exp \left(-\sqrt{d^{2}\left(\mathbf{q}, \mathbf{q}^{\prime}\right)}\right)
$$

onde $d^{2}\left(q, q^{\prime}\right)=\left(q-q^{\prime}\right)^{\mathrm{T}} \Lambda^{-1}\left(q-q^{\prime}\right), \operatorname{com} \Lambda=\operatorname{diag}\left(l_{i}^{2}\right), i=1, \ldots, N$, como um comprimento específico da matriz para detecção de relevância automática (Automatic Relevance Detection - ARD), realizada através do mesmo esquema de adaptação dos hiperparâmetros proposto em (WANG et al., 2013).

Como função de aquisição para o BO, foi utilizada a upper confidence bound (UCB):

$$
h(\mathbf{q} \mid \mathcal{D})=\mu(\mathbf{q})+\beta \sigma(\mathbf{q})
$$

onde $\mu(\mathbf{q})$ é a média da predição do GP em $\mathbf{q}, \sigma(\mathbf{q})$ é a raiz quadrada da variância da predição, e $\beta$ é um parâmetro controlando o balanço entre exploração e aproveitamento. Na maioria dos experimentos, foi possível obter bons resultados com $\beta \in[0.5,2]$ utilizando CDBO.

Para todos os testes, foram realizados 5 experimentos completos (200 voltas), e os resultados apresentados são a média aritmética destes experimentos. Na Figura 22, é possível visualizar os comandos gravados a partir de um controlador PID de velocidade, bem como a política obtida a partir destes dados, parametrizada utilizando splines cúbicas. Essa política foi utilizada como política inicial para todos os testes. 
Figura 22 - Dados iniciais e política inicial parametrizada por splines

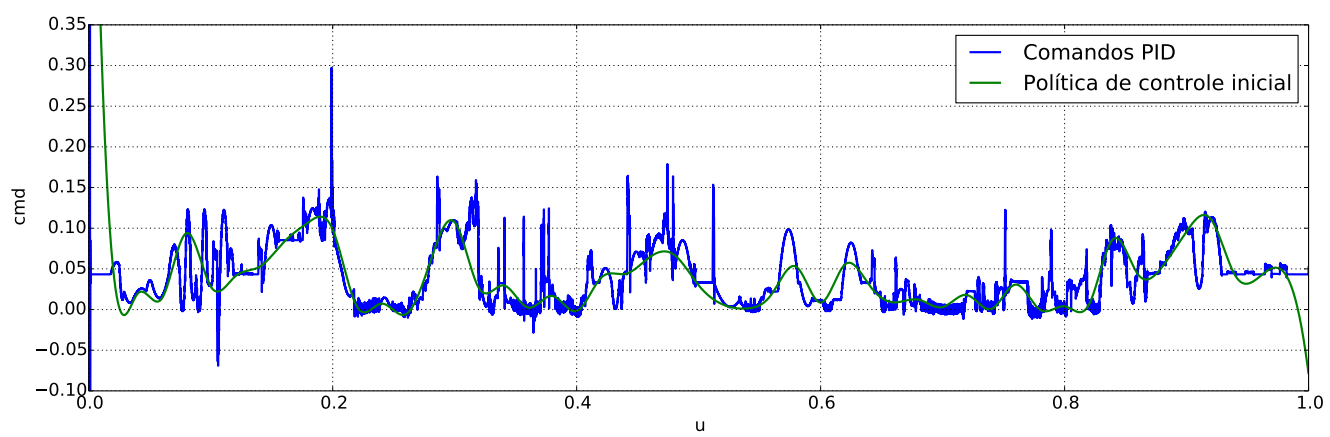

Fonte: O autor.

Para verificar a capacidade da técnica proposta, foram realizados testes em que a política de controle é parametrizada com 50 e 200 dimensões, quantidades bem acima das quais o BO é geralmente aplicado. Na Figura 23 é apresentado o resultado do teste com 50 dimensões.

Figura 23 - Desempenho das técnicas testadas utilizando 50 dimensões

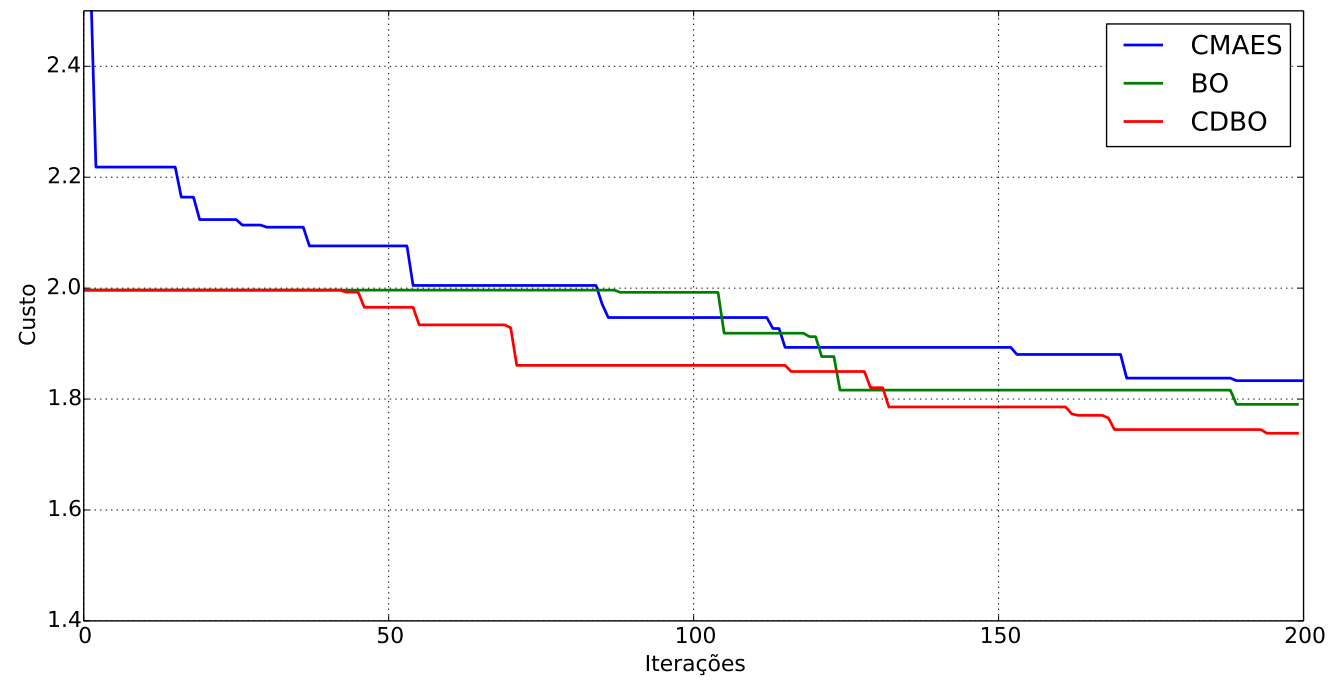

Fonte: $\mathrm{O}$ autor.

No gráfico, verifica-se que todos os métodos apresentam desempenho similar, com destaque para o CDBO, que apresentou o melhor resultado. Apesar de ter sido inicializado com o mesmo conjunto de parâmetros, a CMA-ES apesenta custos superiores aos valores iniciais durante as primeiras 50 iterações, e só encontra um valor menor em relação ao custo inicial após 80 iterações, quantidade similar à necessária pelo BO para encontrar valores melhores. Já a CDBOconsegue encontrar valores inferiores de custo com menos de 
50 iterações.

Figura 24 - Desempenho das técnicas testadas utilizando 200 dimensões

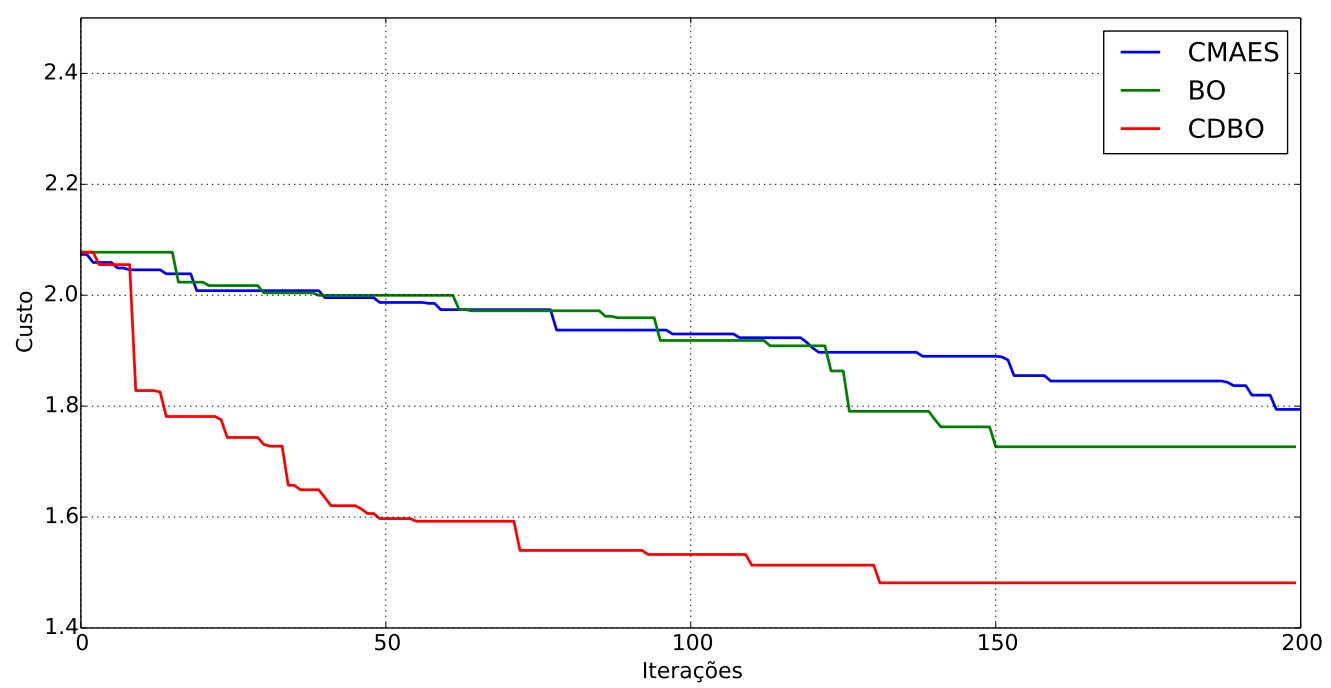

Fonte: O autor.

Na Figura 24, tem-se o resultado para políticas com 200 dimensões. Nesse teste, a técnica CDBOse destaca por possuir desempenho muito superior às outras duas, ressaltando sua capacidade em lidar com problemas de alta dimensionalidade, situação em que as outras técnicas apresentam problemas. O valor de custo obtido pela CDBOé muito menor do que no teste com 50 dimensões, devido à maior flexibilidade que a maior quantidade de parâmetros proporciona para a formulação da política de controle. Na Figura 25 é mostrado o consumo de combustível ao longo dos testes utilizando o CDBO com 200 dimensões.

Tabela 6 - Desempenho das políticas otimizadas.

\begin{tabular}{lcc}
\hline Método & 50 Dimensões & 200 Dimensões \\
\hline CMA-ES & $11.76 \%$ & $13.64 \%$ \\
BO & $13.82 \%$ & $16.88 \%$ \\
CDBO & $16.33 \%$ & $28.69 \%$ \\
\hline
\end{tabular}

A Tabela 6 resume o desempenho das técnicas avaliadas, mostrando o quanto o 
Figura 25 - Consumo de combustível utilizando CDBO com 200 dimensões

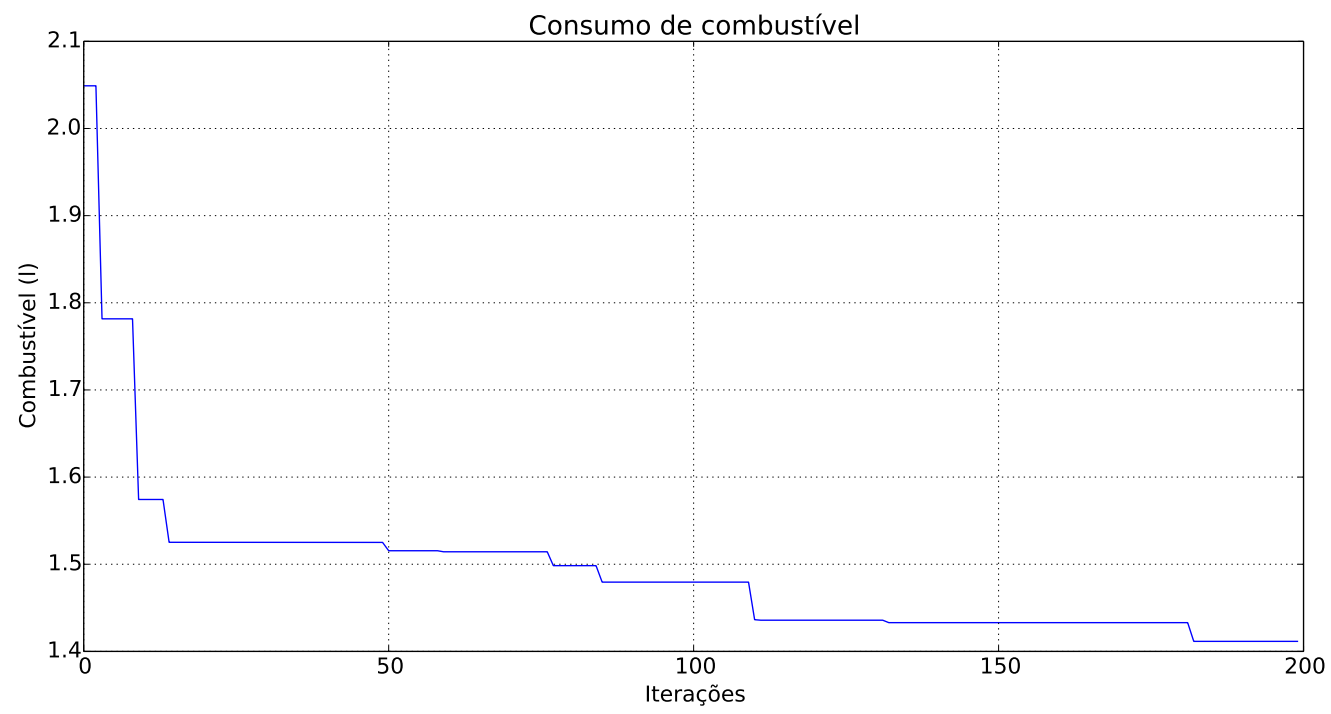

Fonte: $\mathrm{O}$ autor.

custo final foi reduzido em relação ao primeiro experimento. Todas as técnicas obtiveram resultados melhores com o aumento do número de dimensões, porém, destaca-se o resultado da CDBO, que obteve uma diminuição no custo quase duas vezes maior do que as outras técnicas, mostrando que essa técnica é adequada para a solução de problemas de policy search com políticas de alta dimensionalidade. Observa-se também que essa técnica se mostra genérica o suficiente para ser aplicada a uma infinidade de problemas de otimização e também de parametrizações de políticas de controle. 



\section{Conclusão}

O aprendizado Bayesiano engloba um conjunto de técnicas probabilísticas que tem como objetivo realizar inferências. Essas técnicas se baseiam na suposição que as quantidades de interesse são governadas por distribuições de probabilidades, e que, utilizando essas distribuições em conjunto com dados de treinamento observados, podem ser obtidas informações relevantes a respeito da quantidade de interesse, permitindo a tomada de decisões melhor embasada. Algumas características interessantes dessas técnicas são: cada nova amostra pode aumentar ou diminuir incrementalmente a probabilidade estimada de que uma hipótese esteja correta; conhecimentos prévios pode ser combinado com as amostras observadas para determinar a probabilidade final de uma hipótese; utilizando as hipóteses, é possível fazer previsões probabilísticas, entre outras. Na área de robótica, tais métodos podem ser aplicados em diversos problemas, como no projeto de controladores baseados em modelos, como na otimização de políticas de controle sem a utilização de modelos.

Neste trabalho, ambas as estratégias foram aplicadas à solução de problemas envolvendo veículos de grande porte. Um Controlador Preditivo baseado em Modelos com um modelo em Processos Gaussianos, que é uma técnica Bayesiana, foi aplicado na tarefa de controle longitudinal de um veículo de grande porte. Esta categoria de veículos possui algumas características (grande massa, sistema propulsor muito complexo, entre outros) que dificultam a aplicação de técnicas tradicionais de modelagem e controle. Um modelo GP da dinâmica longitudinal do caminhão foi aprendido a partir de dados reais. Por ser um modelo não paramétrico, sua aplicação é muito mais simples, e, apesar de possuir a capacidade de codificar conhecimentos prévios à respeito do sistema, nenhum conhecimento de especialista é necessário em sua utilização. O modelo obtido alcançou alta precisão e também fornece informações a respeito da confiança nas predições, que pode ser usada para obter um controle mais robusto ou até mesmo a coleta de novos dados para melhorar o modelo. Simulações de um sistema de malha fechada apresentaram um desempenho bastante satisfatório do controlador MPC, mesmo em condições extremas, como horizonte de predição pequeno e estradas íngremes, mostrando que o modelo GP oferece uma opção interessante para o projeto de controladores. Algumas modificações podem ser aplicadas ao princípio apresentado neste trabalho para adequá-lo melhor a aplicações práticas, como acelerar os cálculos e a atualização online do modelo. Essas extensões, bem como experimentos com esse controlador em um veículo real, estão planejadas como trabalhos futuros.

Porém, existem problemas em que uma medida instantânea do desempenho de um determinado sistema não é possível, tendo esta medida disponível apenas após uma 
sequência de ações. Este é o caso dos problemas de Eco-Driving, que buscam a utilização mais eficiente de veículos, reduzindo o consumo de combustível. Uma das maneiras de resolver esse problema, é utilizar o modelo do veículo e um mapa do terreno para obter uma sequência de comandos (política de controle) que otimize o consumo de combustível. Quando alguma dessas informações não está disponível, uma das possibilidades de para se solucionar esse problema é a aplicação de técnicas de Reinforcement Learning, entre elas a direct policy-search, que busca diretamente os parâmetros ótimos a partir das experiências anteriores do sistema. Uma técnica que vem se destacando nesse tipo de problema é a Bayesian Optimization, uma técnica de otimização global de funções desconhecidas bastante eficiente. Portanto, para a solução do prolema de otimização de políticas de controle que permita que um robô termine uma dada pista economizando combustível sem penalizar o tempo de viagem, foi proposto o Coordinate Descent Bayesian Optimization, um método de otimização caixa-preta que guia de maneira eficiente a exploração do espaço de parâmetros na direção da política ótima. Ao se utilizar idéias de algoritmos de descidas coordenas aleatórias, otimizando a função uma dimensão por vez, o método proposto é capaz de superar o maior problema do Bayesian Optimization, que é a escalabilidade, conseguindo resolver problemas de otimização de muitas dimensões com bom desempenho. Experimentos em um simulador de carros de corrida demonstraram que essa abordagem relativamente simples é capaz de superar métodos de otimização caixa-preta que são o estado-da-arte, mesmo em cenários complexos, e algumas vezes, em uma fração do tempo levado por esses algoritmos. Como trabalhos futuros, o modelo pode ser melhorado para lidar melhor com espaços de ações não-estacionários e com muitas dimensões, e também a integração deste controle com alguma técnica de planejamento de trajetórias.

A partir dos experimentos realizados nesse trabalho, mostrou-se que as técnicas de aprendizado bayesiano podem ser aplicadas de maneira eficiente na solução de diversos problemas envolvendo veículos autônomos, tornando simplificado o projeto de controladores e também a obtenção de políticas de controle otimizadas, podendo obter desempenho superior à tecnicas que são o estado-da-arte na literatura. Como continuidade desse trabalho, pretende-se investigar outras políticas de controle que possam se mostrar mais eficientes no problema de economia de combustível em veículos autônomos. Já para o desenvolvimento teórico da técnica proposta, pretende-se investigar meios de se limitar o espaço de busca na otimização da função de aquisição, de forma que a buscas se torne ainda mais eficiente. 


\section{Referências}

ABBASZADEH, M.; SOLGI, R. Constrained nonlinear model predictive control of a polymerization process via evolutionary optimization. Journal of Intelligent Learning Systems and Applications, v. 06, n. 01, p. 10, February 2014. Disponível em: <http://www.scirp.org/journal/PaperInformation.aspx?PaperID=42868>.

ADLER, R. J. The Geometry of Random Fields. [S.l.]: Wiley, 1981.

AGARWAL, D. K. 'a modern bayesian look at the multi-armed bandit' by steven 1. scott: Discussion. Applied Stochastic Models in Business and Industry, John Wiley \& Sons, Ltd., v. 26, n. 6, p. 659-664, 2010. ISSN 1526-4025. Disponível em: $<$ http://dx.doi.org/10.1002/asmb.872>.

AGENCY, I. E. CO2 emissions from fuel combustion highlights. [S.l.], 2012.

AGUIRRE, L. A. Introdução À Identificação de Sistemas:Técnicas Lineares e Não-Lineares Aplicadas a Sistemas Reais. 2. ed. [S.l.]: Editora UFMG, 2007.

AKAIKE, H. A new look at the statistical model identification. IEEE Transactions on Automatic Control, v. 19, n. 6, p. 716-723, 1974.

AL-DUJAILI, A.; SURESH, S. Analysis of the bayesian multi-scale optimistic optimization on the CEC2016 and BBOB testbeds. In: IEEE Congress on Evolutionary Computation (CEC). [S.l.: s.n.], 2016.

ANTONOVA, R. Sample Efficient Bayesian Optimization for Policy Search: Case Studies in Robotics and Education. Tese (Doutorado) — The Robotics Institute, Carnegie Mellon University, Pittsburgh, Pennsylvania 15213, July 2016.

ARNOLD, D. V.; HANSEN, N. Active covariance matrix adaptation for the

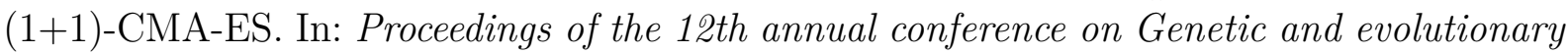
computation - GECCO '10. Portland, OR: [s.n.], 2010. p. 385.

AžMAN, K. Incorporating prior knowledge into gaussian process model. In: In Proceedings of 6th International PhD Workshop on Systems and Control - A Young Generation Viewpoint. [S.l.: s.n.], 2005.

BARTNETT, S. Matrix Methods for Engineers and Scientists. [S.l.]: McGraw-Hill, 1979.

BERTSEKAS, D. P. Parallel and Distributed Computation: Numerical Methods. [S.l.]: Athenas Scientific, 2015.

BISHOP, C.; TIPPING, M. Variational relevance vector machines. In: BOUTILIER, C.; GOLDSZMIDT, M. (Ed.). Proceedings of the 16th Conference on Uncertainty in Artificial Intelligence. [S.l.: s.n.], 2000. p. 46-53.

BISHOP, R. Intelligent vehicle applications worldwide. Intelligent Systems, v. 15, n. 1, p. 78-83, 2000.

BOOR, C. de. A Practical Guide to Splines. New York: Springer-Verlag, 1978. 
BROCHU, E.; BROCHU, T.; FREITAS, N. de. A bayesian interactive optimization approach to procedural animation design. In: Proceedings of the 2010 ACM SIGGRAPH/Eurographics Symposium on Computer Animation. Aire-la-Ville, Switzerland, Switzerland: Eurographics Association, 2010. (SCA '10), p. 103-112. Disponível em: <http://dl.acm.org/citation.cfm?id=1921427.1921443>.

BROCHU, E.; CORA, V. M.; FREITAS, N. de. A tutorial on bayesian optimization of expensive cost functions, with application to active user modeling and hierarchical reinforcement learning. CoRR, abs/1012.2599, 2010. Disponível em: $<$ http://arxiv.org/abs/1012.2599>.

BU, F.; TAN, H. S. Pneumatic brake control for precision stopping of heavy-duty vehicles. IEEE Transactions on Control Systems Technology, v. 15, n. 1, p. 53-64, 2007. ISSN 10636536 .

CALANDRA, R. et al. Bayesian gait optimization for bipedal locomotion. In: . Learning and Intelligent Optimization: 8th International Conference, Lion 8, Gainesville, FL, USA, February 16-21, 2014. Revised Selected Papers. Cham: Springer International Publishing, 2014. p. 274-290. ISBN 978-3-319-09584-4. Disponível em: $<$ https://doi.org/10.1007/978-3-319-09584-4_25>.

CAMACHO, E. F.; ALBA, C. B. Model Predictive Control. 2. ed. [S.l.]: Springer-Verlag London, 2007. (Advanced Textbooks in Control and Signal Processing).

CHEN, B.; CASTRO, R. M.; KRAUSE, A. Joint Optimization and Variable Selection of High-dimensional Gaussian Processes. In: Proceedings of the 29th International Conference on Machine Learning (ICML-12). [S.1.: s.n.], 2012. p. 1423-1430. ISBN 978-1-4503-1285-1.

CHO, D.; HEDRICK, J. K. Automotive power train modelling for control. Transactions of ASME, Journal of Dynamic Systems, Measurement and Control, v. 111, p. 568-576, 1989.

COX, D. D.; JOHN, S. A statistical method for global optimization. In: [Proceedings] 1992 IEEE International Conference on Systems, Man, and Cybernetics. [S.l.: s.n.], 1992. p. 1241-1246 vol.2.

DEISENROTH, M. P. A Survey on Policy Search for Robotics. Foundations and Trends in Robotics, v. 2, n. 1, p. 1-142, 2013.

DJOLONGA, J.; KRAUSE, A.; CEVHER, V. High-Dimensional Gaussian Process Bandits. Advances in Neural Information Processing Systems 26, p. 1025-1033, 2013. ISSN 10495258.

GARNETT, R.; OSBORNE, M. A.; ROBERTS, S. J. Bayesian optimization for sensor set selection. In: Proceedings of the 9th ACM/IEEE International Conference on Information Processing in Sensor Networks. New York, NY, USA: ACM, 2010. (IPSN '10), p. 209-219. ISBN 978-1-60558-988-6. Disponível em: <http://doi.acm.org/10.1145/1791212.1791238>.

GELMAN, A. et al. Bayesian Data Analysis. 3. ed. [S.1.]: CRC Press, 2013.

GEVERS, M. A Personal View of the Development of System Identification. IEEE Controll Systems, v. 26, n. 6, p. 93-105, 2006.

GIBBS, M. N. Bayesian Gaussian Processes for Regression and Classification. Tese (Doutorado) - Department of Physics, University of Cambridge, 1997. 
GILKS, W. R.; RICHARDSON, S.; SPIEGELHALTER, D. Markov Chain Monte Carlo in Practice. [S.l.]: Chapman and Hall, 1996.

GOEGE, D. Fast identification and characterization of nonlinearities in experimental modal analysis of large aircraft. Journal of Aircraft, v. 44, n. 2, p. 399-409, 2007.

GONDHALEKAR, A. C. Strategies for Nonlinear System Identification. Tese (Doutorado) - Imperial College London/ University of London, 2009.

GRANCHAROVA, A.; KOCIJAN, J.; JOHANSEN, T. A. Explicit stochastic nonlinear predictive control based on gaussian process models. In: Control Conference (ECC), 2007 European. [S.l.: s.n.], 2007. p. 2340-2347.

GREGORčIč, G.; LIGHTBODY, G. Gaussian processes for modelling of dynamic non-linear systems. In: In Proceedings of Irish Signals and Systems Conference. [S.l.: s.n.], 2002. p. $141-147$.

HEBDEN, R. G.; EDWARDS, C.; SPURGEON, S. K. Automotive steering control in a split- manoeuvre using an observer-based sliding mode controller. Vehicle System Dynamics, v. 41, n. 3, p. 181-202, 2004.

HEDRICK, J. K. Nonlinear controller design for automated vehicle applications. In: Proc. UKACC Int. Conj on Contr.'98. Swansea, U. K.: [s.n.], 1998. p. 23-31.

HELLSTRöM, E. et al. Look-ahead control for heavy trucks to minimize trip time and fuel consumption. Control Engineering Practice, v. 17, n. 2, p. 245 - 254, 2009. ISSN 0967-0661. Disponível em: <http://www.sciencedirect.com/science/article/pii/S0967066108001251>.

HORVATH, G. Neural networks in system identification. In: ABLAMEYKO, S. et al. (Ed.). Neural Networks for Instrumentation, Measurement and Industrial Applications. [S.1.]: IOS, 2003. p. 36.

IOANNOU, P. Automated Highway Systems. [S.1.]: Plenum, 1997.

JADBABAIE, A.; HAUSER, J. On the stability of receding horizon control with a general terminal cost. IEEE Transactions on Automatic Control, v. 50, n. 5, p. 674-678, 2005.

JOHNSON, S. G. The NLopt nonlinear-optimization package. 2014. < http: //ab-initio.mit.edu/nlopt>. Accessed: 2016-08-16.

JONES, D. R.; PERTTUNEN, C. D.; STUCKMAN, B. E. Lipschitzian optimization without the lipschitz constant. Journal of Optimization Theory and Applications, v. 79, n. 1, p. 157-181, 1993.

JONES, D. R.; SCHONLAU, M.; WELCH, W. J. Efficient global optimization of expensive black-box functions. Journal of Global Optimization, v. 13, n. 4, p. 455-492, Dec 1998. ISSN 1573-2916. Disponível em: <https://doi.org/10.1023/A:1008306431147>.

KAMAL, M. A. S. et al. On board eco-driving system for varying road-traffic environments using model predictive control. In: 2010 IEEE International Conference on Control Applications. [S.l.: s.n.], 2010. p. 1636-1641. ISSN 1085-1992.

KANDASAMY, K.; SCHNEIDER, J.; POCZOS, B. High Dimensional Bayesian Optimisation and Bandits via Additive Models. In: International Conference on Machine Learning (ICML). [S.l.: s.n.], 2015. ISBN 9781510810587. 
KOBER, J.; OZTOP, E.; PETERS, J. Reinforcement learning to adjust robot movements to new situations. In: Proceedings of Robotics: Science and Systems. Zaragoza, Spain: [s.n.], 2010.

KOBER, J.; PETERS, J. Learning Motor Skills: From Algorithms to Robot Experiments. [S.l.]: Springer International Publishing, 2014. (Springer Tracts in Advanced Robotics, v. 97$)$.

KOCIJAN, J. Gaussian Process Models for Systems Identification. In: 9th International PhD Workshop on Systems and Control: Young Generation Viewpoint. [S.l.: s.n.], 2008.

KOCIJAN, J.; AžMAN, K. Gaussian process model identification: A process engineering case study. In: In Proceedings of the 16th International Conference on Systems Science. [S.l.: s.n.], 2007. v. 1, p. 418-427.

KOCIJAN, J. et al. A case based comparison of identification with neural networks and gaussian process models. In: In Proceedings of IFAC ICONS conference. [S.l.: s.n.], 2003. v. 1, p. $137-142$.

KOCIJAN, J. et al. Dynamic systems identification with Gaussian processes. Mathematical and Computer Modelling of Dynamical Systems, v. 11, n. 4, p. 411-424, 2005.

ISSN 1387-3954. Disponível em: <http://www.tandfonline.com/doi/abs/10.1080/ $13873950500068567>$.

KOCIJAN, J. et al. Gaussian process model based predictive control. In: In Proceedings of 4th American Control Conference. Boston, MA: [s.n.], 2004. p. 2214-2218.

KOHAVI, R. et al. Controlled experiments on the web: Survey and practical guide. Data Min. Knowl. Discov., Kluwer Academic Publishers, Hingham, MA, USA, v. 18, n. 1, p. 140-181, fev. 2009. ISSN 1384-5810. Disponível em: <http://dx.doi.org/10.1007/s10618-008-0114-1>.

KOUVARITAKIS, B.; CANNON, M. Model Predictive Control: Classical, Robust and Stochastic. 1. ed. [S.l.]: Springer International Publishing, 2016. (Advanced Textbooks in Control and Signal Processing).

KRAUSE, A.; SINGH, A.; GUESTRIN, C. Near-optimal sensor placements in gaussian processes: Theory, efficient algorithms and empirical studies. J. Mach. Learn. Res., JMLR.org, v. 9, p. 235-284, jun. 2008. ISSN 1532-4435. Disponível em: $<$ http://dl.acm.org/citation.cfm?id=1390681.1390689>.

KUNDU, S.; KUNDU, S. Flexible vehicle speed control algorithms for eco-driving. In: 2015 IEEE 82nd Vehicular Technology Conference (VTC2015-Fall). [S.l.: s.n.], 2015. p. $1-5$.

KUPCSIK, A. G. et al. Data-Efficient Generalization of Robot Skills with Contextual Policy Search. In: AAAI Conference on Artificial Intelligence. [S.l.: s.n.], 2013.

KUSHNER, H. J. A New Method of Locating the Maximum Point of an Arbitrary Multipeak Curve in the Presence of Noise. Journal of Basic Engineering, v. 86, n. 1, p. 97+, 1964. ISSN 00219223. Disponível em: <http://dx.doi.org/10.1115/1.3653121>. 
LEITH, D. J.; MURRAY-SMITH, R.; LEITHEAD, W. E. Nonlinear structure identification: A gaussian process/velocity-based approach. In: In Proceedings of the UKACC Control Conference. [S.l.: s.n.], 2000.

LEITHEAD, W. E.; LEITH, D. J.; MURRAY-SMITH, R. A. Gaussian process prior/velocity-based framework for nonlinear modelling and control. In: In Irish Signals and Systems Conference. [S.l.: s.n.], 2000.

LI, C.-L. et al. High Dimensional Bayesian Optimization via Restricted Projection Pursuit Models. In: Proceedings of the 19th International Conference on Artificial Intelligence and Statistics. [S.l.: s.n.], 2016. p. 884-892.

LI, L. et al. A contextual-bandit approach to personalized news article recommendation. In: Proceedings of the 19th International Conference on World Wide Web. New York, NY, USA: ACM, 2010. (WWW '10), p. 661-670. ISBN 978-1-60558-799-8. Disponível em: <http://doi.acm.org/10.1145/1772690.1772758>.

LI, S. E. et al. Fast online computation of a model predictive controller and its application to fuel economy oriented adaptive cruise control. IEEE Transactions on Intelligent Transportation Systems, v. 16, n. 3, p. 1199-1209, June 2015. ISSN 1524-9050.

LIANG, C.; PENG, H. Optimal adaptive cruise control with guaranteed string stability. Vehicle System Dynamics, v. 32, n. 4, p. 313-330, 1999.

LIKAR, B.; KOCIJAN, J. Predictive control of a gas-liquid separation plant based on a gaussian process model. Computers and Chemical Engineering, v. 31, n. 3, p. 142-152, 2007.

LIN, C.-C. et al. Power management strategy for a parallel hybrid electric truck. IEEE Transactions on Control Systems Technology, v. 11, n. 6, p. 839-849, Nov 2003. ISSN 1063-6536.

LIU, M. Efficient Bayesian Nonparametric Methods for Model-Free Reinforcement Learning in Centralized and Decentralized Sequential Environments. Tese (Doutorado) Department of Electrical and Computer Engineering, Duke University, 2014.

LIZOTTE, D. et al. Automatic gait optimization with gaussian process regression. In: Proceedings of the 20th International Joint Conference on Artifical Intelligence. San Francisco, CA, USA: Morgan Kaufmann Publishers Inc., 2007. (IJCAI'07), p. 944-949. Disponível em: <http://dl.acm.org/citation.cfm?id=1625275.1625428>.

LJUNG, L. System identification: Theory for the user. 2. ed. Prentice Hall, 1999. 238 p. ISSN 00051098. ISBN 0136566952. Disponível em: <http://linkinghub.elsevier.com/ retrieve/pii/0005109889900198>.

LOURENçO, J.; LEMOS, J.; MARQUES, J. Control of neuromuscular blockade with gaussian process models. Biomedical Signal Processing and Control, v. 8, n. 3, p. 244-254, 2013.

LRM - ICMC - USP. CaRINA 2 - Carro Robótico Inteligente para Navegação Autônoma. 2012. Http://www.lrm.icmc.usp.br/web/index.php?n=Site.ProjCarina2Info. 
LU, X.-Y.; HEDRICK, J. Longitudinal control design and experiment for heavy-duty trucks. In: American Control Conference, 2003. Proceedings of the 2003. [S.1.: s.n.], 2003. v. 1, p. 36-41. ISSN 0743-1619.

MACKAY, D. J. C. Bayesian Methods for Adaptive Models. Tese (Doutorado) California Institute of Technology, 1991.

MACKAY, D. J. C. The evidence framework applied to classification networks. Neural Computation, v. 4, n. 5, p. 698-714, 1992.

MACKAY, D. J. C. Bayesian non-linear modelling for the energy prediction competition. ASHRAE Transactions, v. 100, n. 2, p. 1053-1062, 1994.

MACKAY, D. J. C. Gaussian processes - a replacement for supervised neural networks? In: Lecture notes for a tutorial at NIPS 1997. [S.l.: s.n.], 1997.

MACKAY, D. J. C. Neural networks and machine learning. In: . [S.l.]: Springer, 1998. cap. Introduction to Gaussian processes, p. 133-165.

MARCHANT, R.; RAMOS, F. Bayesian optimisation for informative continuous path planning. In: 2014 IEEE International Conference on Robotics and Automation (ICRA). [S.1.: s.n.], 2014. p. 6136-6143. ISSN 1050-4729.

MARTINEZ-CANTIN, R. et al. A bayesian exploration-exploitation approach for optimal online sensing and planning with a visually guided mobile robot. Autonomous Robots, v. 27, n. 2, p. 93-103, Aug 2009. ISSN 1573-7527. Disponível em: $<$ https://doi.org/10.1007/s10514-009-9130-2>.

MENSING, F.; TRIGUI, R.; BIDEAUX, E. Vehicle trajectory optimization for application in eco-driving. In: 2011 IEEE Vehicle Power and Propulsion Conference. [S.l.: s.n.], 2011. p. 1-6. ISSN 1938-8756.

MOČKUS, J.; TIESIS, V.; ZILINSKAS, A. The application of bayesian methods for seeking the extremum. Towards Global Optimization, Springer Berlin Heidelberg, Berlin, Heidelberg, v. 2, p. 117-129, 1978. Disponível em: <https://doi.org/10.1007/3-540-07165-2_55>.

MURRAY-SMITH, R.; JOHANSEN, T. A.; SHORTEN, R. On transient dynamics, off-equilibrium behaviour and identification in blended multiple model structures. In: In Proceedings of European Control Conference. [S.l.: s.n.], 1999.

MURRAY-SMITH, R. et al. Adaptive, cautious, predictive control with gaussian process priors. In: In Proceedings of 13th IFAC Symposium on System Identification. Rotterdam: [s.n.], 2003. p. 1195-1200.

MURRAY-SMITH, R.; SHORTEN, R.; LEITH, D. Nonparametric models of dynamic systems. In: COWANS, C. (Ed.). Proceedings of IEE Workshop on Nonlinear and Non-Gaussian signal processing - N2SP. [S.l.: s.n.], 2002.

NARENDRA, K.; PARTHASARATHY, K. Identification and control of dynamical systems using neural networks. Neural Networks, IEEE Transactions on, v. 1, n. 1, p. 4-27, Mar 1990. ISSN 1045-9227.

NEAL, R. M. Probabilistic inference using Markov Chain Monte Carlo methods. [S.l.], 1993. 
NEAL, R. M. Bayesian Learning for Neural Networks. [S.l.]: Springer, 1996.

NELLES, O. Nonlinear System Identification. [S.1.]: Springer, 2001. ISBN 978-3-642-086748.

NEO, K. Non-linear dynamics identification using Gaussian process prior models within a Bayesian context. 294 p. Tese (Doutorado) — National University of Ireland, 2008.

NESTEROV, Y. A method of solving a convex programming problem with convergence rate o (1/k2). In: Soviet Mathematics Doklady. [S.l.: s.n.], 1983. v. 27, n. 2, p. 372-376.

NISE, N. C. Engenharia de Sistemas de Controle. 6. ed. [S.l.]: LTC, 2012.

Open Source Robotics Foundation. The Robot Operating System (ROS). 2015.

Http://www.ros.org/.

OZATAY, E. et al. Analytical solution to the minimum energy consumption based velocity profile optimization problem with variable road grade. IFAC Proceedings Volumes, v. 47, n. 3, p. 7541 - 7546, 2014. ISSN 1474-6670. 19th IFAC World Congress. Disponível em: <http://www.sciencedirect.com/science/article/pii/S1474667016428016>.

O'HAGAN, A. On curve fitting and optimal design for regression. Journal of the Royal Statistical Society B, v. 40, p. 1-42, 1978.

PISU, P.; RIZZONI, G. A comparative study of supervisory control strategies for hybrid electric vehicles. IEEE Transactions on Control Systems Technology, v. 15, n. 3, p. 506-518, May 2007. ISSN 1063-6536.

POWELL, M. A view of algorithms for optimization without derivatives. Cambridge, United Kingdom, 2007. NA03, 1-12 p.

POWELL, M. J. D. On search directions for minimizaiton algorithms. Mathematical Programming, v. 4, p. 193-201, 1973.

RAJAMANI, R. et al. Design and experimental implementation of longitudinal control for a platoon of automated vehicles. Journal of Dynamic Systems, Measurement, and Control - ASME, v. 122, p. 470-476, September 2000.

RASMUSSEN, C. E. Evaluation of Gaussian Processes and Other Methods for Non-linear Regression. Tese (Doutorado) - Dept. of Computer Science, University of Toronto., 1996.

RASMUSSEN, C. E.; WILLIAMS, C. K. I. Gaussian processes for machine learning. [S.l.]: MIT Press, 2006.

RIZANO, T. et al. Global path planning for competitive robotic cars. In: IEEE Conference on Decision and Control. Florence, Italy: [s.n.], 2013. p. 4510-4516.

ROSENBROCK, H. An automatic method for finding the greatest or least value of a function. Comput. J., v. 3, n. x, p. 175-184, 1960.

RÜCKSTIESS, T. et al. Exploring parameter space in reinforcement learning. Paladyn, v. 1, n. 1, p. 14-24, 2010.

SCHITTLER, M. State-of-the-art and emerging truck engine technologies for optimized performance emissions and life cycle costs. [S.1.], 2003. 
SCHOLKOPF, B.; SMOLA, A. J. Learning with Kernels. [S.1.]: MIT Press, 2002. ISBN 0262194759 .

SCHWICKART, T.; VOOS, H.; DAROUACH, M. A real-time implementable model-predictive cruise controller for electric vehicles and energy-efficient driving. In: 2014 IEEE Conference on Control Applications (CCA). [S.l.: s.n.], 2014. p. 617-622. ISSN 1085-1992.

SHAHRIARI, B. et al. Taking the human out of the loop: A review of bayesian optimization. Proceedings of the IEEE, v. 104, n. 1, p. 148-175, Jan 2016. ISSN 0018-9219.

SHILTON, A. et al. Incremental training of support vector machines. IEEE Transactions on Neural Networks, v. 16, n. 1, p. 114-131, 2005.

SILVA, I. N. da; SPATTI, D. H.; FLAUZINO, R. A. Redes Neurais Artificiais para Engenharia e ciências aplicadas. [S.l.]: ArtLiber, 2010.

SJöBERG, J. et al. Nonlinear black-box modeling in system identification: a unified overview. Automatica, v. 31, n. 12, p. 1691-1724, 1995. ISSN 00051098.

SNOEK, J.; LAROCHELLE, H.; ADAMS, R. P. Practical bayesian optimization of machine learning algorithms. In: Proceedings of the 25th International Conference on Neural Information Processing Systems - Volume 2. USA: Curran Associates Inc., 2012. (NIPS'12), p. 2951-2959. Disponível em: <http://dl.acm.org/citation.cfm?id=2999325.2999464>.

SODERSTROM, T.; STOICA, P. System Identification. [S.l.]: Prentice Hall, 1989. ISBN 0-13-881236-5.

SRINIVAS, N. et al. Gaussian process optimization in the bandit setting:

No regret and experimental design. In: Proceedings of the 27th International Conference on International Conference on Machine Learning. USA: Omnipress, 2010. (ICML'10), p. 1015-1022. ISBN 978-1-60558-907-7. Disponível em: <http: //dl.acm.org/citation.cfm?id=3104322.3104451>.

STEIN, M. L. Interpolation of Spatial Data. [S.l.]: Springer-Verlag, 1999.

SUTTON, R. S.; BARTO, A. G. Reinforcement Learning: An Introduction. [S.l.]: MIT Press, 1998.

SWAROOP, D.; HEDRICK, J. K. String stability of interconnected systems. IEEE Transactions on Automatic Control, v. 41, n. 3, p. 349-357, March 1996.

TAKAGI, T.; SUGENO, M. Fuzzy identification of systems and its application to modelling and control. IEEE Transactions on Systems, Man, and Cybernetics, v. 15, n. 1, p. $116-132,1985$.

THOMPSON, K. R. Implementation of Gaussian Process models for Nonlinear System Identification. Tese (Doutorado) — University of Glasgow, 2009.

TSENG, P. Convergence of a block coordinate descent method for nondifferentiable minimization. Journal of Optimization Theory and Applications, v. 109, n. 3, p. 475-494, 2001. 
U. S. Department of Transportation. Intelligent Vehicle Initiative Needs Assessment. [S.1.], 1999.

ULMASOV, D. et al. Bayesian Optimization with Dimension Scheduling: Application to Biological Systems. In: Computer Aided Chemical Engineering. [S.l.]: Elsevier Masson SAS, 2016. v. 38, p. 1051-1056. ISBN 9780444634283.

VANCHINATHAN, H. P. et al. Explore-exploit in top-n recommender systems via gaussian processes. In: Proceedings of the 8th ACM Conference on Recommender Systems. New York, NY, USA: ACM, 2014. (RecSys '14), p. 225-232. ISBN 978-1-4503-2668-1. Disponível em: <http://doi.acm.org/10.1145/2645710.2645733>.

WANG, Z. et al. Bayesian Optimization in a Billion Dimensions via Random Embeddings. In: Proceedings of the Twenty-Third international joint conference on Artificial Intelligence. [S.l.: s.n.], 2013. p. 1778-1784.

WILlIAMS, C. K. I. Computation with infinite neural networks. Neural Computation, v. 10, n. 5, p. 1203-1216, 1998.

WORDEN, K.; TOMLINSON, G. R. Nonlinearity in Structural Dynamics: Detection, Identification and Modelling. [S.l.]: CRC Press, 2000.

WRIGHT, S. J. Coordinate descent algorithms. Mathematical Programming, Springer Berlin Heidelberg, v. 151, n. 1, p. 3-34, jun 2015. ISSN 0025-5610.

WYMANN, B. et al. TORCS, The Open Racing Car Simulator. 2014.

Http://www.torcs.org.

$\mathrm{XU}$, S. et al. Instantaneous feedback control for a fuel-prioritized vehicle cruising system on highways with a varying slope. IEEE Transactions on Intelligent Transportation Systems, v. 18, n. 5, p. 1210-1220, May 2017. ISSN 1524-9050.

YANAKIEV, D.; KANELLAKOPOULOS, I. Longitudinal control of automated chvs with significant acutator delays. IEEE Transactions on Vehicle Technologies, v. 50, n. 5, p. 1289-1297, September 2001.

ZADEH, L. A. Fuzzy sets. Information and Control, v. 8, p. 338-353, 1965. 